\title{
Orexin action on the dopaminergic system modulates theta during REM sleep and wakefulness
}

\author{
Mojtaba Bandarabadi ${ }^{¥}$, Sha Li ${ }^{1 *}$, Mehdi Tafti ${ }^{1}$, Giulia Colombo ${ }^{2}$, Andrea Becchetti ${ }^{2}$, \\ and Anne Vassalli ${ }^{1} \square$ \\ ¥These authors contributed equally: Mojtaba Bandarabadi, Sha Li. \\ (1) Department of Biomedical Sciences, University of Lausanne, Lausanne, Switzerland; \\ (2) Department of Biotechnology and Biosciences, University of Milano-Bicocca, Milano, Italy \\ Corresponding author: Dr. Anne Vassalli, Department of Biomedical Sciences, Université de Lausanne, CH-1005 \\ Lausanne, Switzerland. \\ Tel: +41-21-692-5540 \\ 曰anne.vassalli@unil.ch
}

\section{Abstract}

Both dopaminergic (DA) and orexinergic (OX) systems establish brain-wide neuromodulatory circuits that profoundly influence brain states and behavioral outputs. To unravel their interactions, we inactivated OX-to-DA neurotransmission by selective disruption of $H c r t R 1 / O x R 1$, or $H c r t R 2 / O x R 2$, or both receptors, in DA neurons. Chronic loss of OXR2 in DA neurons (OxR2Dat-CKO mice) dramatically increased electrocorticographic (EcoG) theta rhythms in wakefulness and REM sleep. Episode duration and total times spent in 'active' wakefulness and REMS were prolonged, and theta/fast-gamma wave coupling was enhanced in both states. Increased theta in OxR2DatCKO mice baseline wake was accompanied by diminished infra-theta and increased fast-gamma activities, i.e. the mice exhibited signs of constitutive electrocortical hyperarousal, albeit uncoupled with locomotor activity. These effects were not seen in OxR1-ablated dopaminergic mutants, which tended to show opposite phenotypes, resembling those caused by the loss of both receptors. Our data establish a clear, genetically-defined link between monosynaptic orexin-to-dopaminergic connectivity and the power of theta oscillations, with a differential role of OXR2 in cross-frequency wave coupling and attentional processes. 


\section{Introduction}

Orexin/Hypocretin (OX) neurons act as brain hub for arousal, behavioral motivation, stress and reward (Harris and AstonJones 2006); (Thompson and Borgland 2011)). OX neurons project to all wake-promoting monoaminergic and cholinergic nuclei of the arousal system. In addition, OX cells directly innervate extensively the arousal system's target regions, such as the neocortex, hippocampus, amygdala, and spinal cord. The OX system is thus part of an intricated regulatory arousal network, in which the main 'executive' structures are regulated by OX neurons directly as well as by the mediation of ascending modulatory inputs. Owing to their ability to compute and integrate a wide variety of incoming information, together with their extensive axonal arborization, OX neurons' activity modulates neurocircuits throughout the brain, and across different physiological and behavioral domains, emotional valence, and timescales (Gonzalez et al. 2016); (Giardino et al. 2018);(Peleg-Raibstein and Burdakov 2021).

OX cells are glutamatergic hypothalamic neurons that express the Hcrt gene, encoding a polypeptide processed into the peptides orexin-A (OXA) and OXB. The action of OX peptides is mediated by two G protein-coupled receptors, orexin receptor type 1 and 2, OXR1 and OXR2, encoded by distinct genes, Hcrtr1 and Hcrtr2, which are differentially expressed throughout the brain. The differential functions and signaling mechanisms of OXR1 and 2 remain poorly delineated ((Kukkonen and Leonard 2014)). While OXR2 binds both OXA and B with high affinity, OXR1 binds with high affinity only to OX-A, thus OXB signals mostly through OXR2. While OXR1 is coupled with Gq, OXR2 was reported to couple with Gq and Gi/o depending on cell types or circumstances. How the 2 receptors interact to control sleep/wake architecture and the complex interplay between brain states and motivated behavior is virtually unknown.

OX neurons mainly fire during wakefulness (W), with highest spiking activity during active W (Lee et al. 2005), but they also regulate, and their firing precedes, transitions from slow-wave-sleep (SWS), or rapid-eye-movement sleep (REMS) to W (Lee et al. 2005); (Adamantidis et al. 2007). In agreement with these functions, impairing the OX system can lead to neurological disease narcolepsy with cataplexy, characterized by excessive daytime sleepiness, cataplexy, a sudden loss of muscle tone triggered by emotionally arousing events, and the occurrence of other types of dissociated states (Liblau et al. 2015).

Although narcolepsy with cataplexy is associated with the loss of OX immunoreactive cells in the hypothalami of postmortem brains, it is the loss of OX peptides rather than OX cells that underlie the neurological disease, as mere inactivation of the OX-encoding gene, or combined disruption of the 2 receptor genes, faithfully recapitulate all narcolepsy pathophysiological symptoms in mice (Liblau et al. 2015). Therefore the loss of orexin signaling underlies the profound disorganization of sleep/wake states characterizing narcolepsy. Which are the specific branches of the OX circuitry whose dysfunction causes the distinct symptoms and underlying mechanisms remains however unfully solved.

Excessive daytime sleepiness and cataplexy triggered by emotional arousal are two symptoms of OX insufficiency that seem a priori diametrically different and that are expected to engage distinct circuits, yet both respond remarkably well to dopamine-enhancing drugs. Injection of D2/3 receptor agonists into the midbrain ventral tegmental area (VTA, housing the A10 DA cell group) of narcoleptic dogs acutely aggravated cataplexy, while D2/3 antagonists had the opposite effect (Reid 
et al. 1996). In mice cataplexy is similarly modulated by D2/D3 receptors, while sleep attacks are contained by drugs activating D1 receptors (Burgess et al., 2010), These neuropharmacological findings suggest that DA may be an important effector of the OX system. OX neurons indeed send dense projections to the DA system, and in particular the VTA (Fadel and Deutch 2002). Electron microscopy showed that OX terminals form close appositions onto VTA DA neurons, however few synapses, indicating that OX-to-DA connection is mostly mediated by en-passant axons and axonal varicosities (BalcitaPedicino and Sesack 2007), suggesting paracrine extrasynaptic neurotransmission. In accordance with these neuroanatomical data, application of OXA on acutely dissociated VTA ${ }^{\text {DA }}$ cells increased intracellular Calcium (OX increase intracellular calcium in acutely isolated VTA ${ }^{\text {DA }}$ neurons (Nakamura et al., 2000) and both OXA and B peptides were shown to increase the firing rate and induce TTX-resistant depolarization in DA cells of VTA slices (Korotkova et al. 2003). Korotkova et al moreover identified different firing responses elicited in different DA groups and showed that both OxR1 and OxR2 genes can be expressed by these cells (Korotkova et al. 2003). It is unclear if different firing patterns correspond to the 2 distinct receptors, or to other DA cell heterogeneity. Importantly, OXA and OXB were furthermore demonstrated to potentiate glutamatergic synaptic inputs onto VTA ${ }^{\text {DA }}$ neurons via NMDAR neurotransmission (Borgland et al. 2006), (Borgland et al. 2008). Altogether these findings revealed that OX modulates VTA ${ }^{D A}$ firing both by directly activating OX receptors on DA neurons, and by potentiating glutamatergic afferents onto them

VTA ${ }^{\text {DA }}$ cell glutamatergic potentiation is a mechanism thought to contribute to heightened arousal and value-driven attentional learning of salient stimuli (Borgland et al. 2006); (Borgland et al. 2008). Borgland et al showed that action of OXA within the VTA is essential for cocaine to induce a locomotor sensitization response in mice, while the hyperlocomotion and stereotypy induced by intracerebroventricular application of OXA itself can be blocked blocked by DA receptor antagonists (Nakamura et al. 2000).

Muschamp et al.(Muschamp et al. 2007) performed extracellular recording of VTA ${ }^{\text {DA }}$ in vivo and showed that local OXA infusion produces dose-dependent increases in firing rate and VTA ${ }^{\mathrm{DA}}$ population activity, and moreover showed that OX and OX fiber-apposed VTA ${ }^{D A}$ cells show FOS protein activation in association with male copulatory behavior, which is repressed by OXR1 antagonism, suggesting that OX-mediated activation of the mesolimbic DA system is involved in sexual approach. OX neurons respond to reward-predicting cues and they are thought to drive reward-seeking behavior at least in part by directly stimulating VTA ${ }^{\mathrm{DA}}$ neurons (Calipari and Espana 2012). OX peptides appear to activate the subgroup of VTA ${ }^{\mathrm{DA}}$ neurons that project to the nucleus accumbens shell and the medial prefrontal cortex (Vittoz and Berridge 2006), suggesting a coordinated arousal system. VTA neurons were shown to be heterogeneous in projection areas, activity patterns, and response to OX. OXA was shown to increase firing of NAc-projecting, but not basolateral amygdala-projecting DA neurons (Baimel et al. 2017).

While OX-induced increase in VTA ${ }^{\mathrm{DA}}$ activity has been linked with reward-seeking behaviors, it also has been associated with stress-induced states of heightened arousal. In rat models of stress-induced psychosis associated with marked increase in VTA $^{\text {DA }}$ activity, OXR1-2 dual antagonism was shown to reverse aberrant VTA ${ }^{\text {DA }}$ neuron activity as well as deficits in behavioral 
corelates of psychosis, suggesting the involvement of OX-to-DA circuit in stress-induced chronic arousal disorders such as PTSD.

Moreover innate risk-avoidance behavior was shown to rely on an OX->NAC ${ }^{\mathrm{D} 2}$ circuit, whereby OX signals activate NAc D2 receptor-expressing medium spiny neurons. Orexin receptor antagonism led to increased risk-taking behaviors, while riskavoidance driven by natural OX signals was abolished when NAc D2 MSNs were silenced. Because D2 MSNs receive excitatory OX input but also inhibitory DA input from the VTA, D2NAc cells may represent a node to compute reward vs stress inputs (Blomeley et al. 2017).

During wakefulness, VTA ${ }^{\mathrm{DA}}$ are strongly activated by various salient stimuli, including sensory cues, social cues, and rewards, however state-specific alterations in DA cell activity have manifested themselves mainly as changes in spiking dynamics rather than mean firing rate (Dahan et al. 2007; Gomperts et al. 2015), as VTA ${ }^{\text {DA }}$ neurons were found to display burst-like firing during active wakefulness and REMS, but single spike mode during SWS (Dahan et al. 2007). The causal role of the VTA ${ }^{\text {DA }}$ system in inducing salience-induced arousal and sleep to wake transitions has only recently been demonstrated (Eban-Rothschild et al. 2016), (Oishi et al. 2017); for Review, (Eban-Rothschild et al. 2018)., and the VTA ${ }^{\text {DA }}$-> NAc circuit is increasingly recognized to exert a coordinating role between its functions in motivation and the regulation of arousal and vigilance states

The NAc was recently shown to play major roles in the tuning of wake/sleep behaviors by cognitive and emotional factors with D2 expressing cells endowed with powerful sleep-promoting properties (Oishi et al. 2017), while D1-expressing cell activity is essential for the induction and maintenance of wakefulness (Luo et al. 2018). The NAc shell is a prominent target of OX neurons with a predominant OxR2 expression (Marcus et al. 2001).

OXA and B have been shown to depolarize NAc shell neurons partly by OXR2-dependent postsynaptic activation (Mukai et al. 2009), but OX released in the NAc may also potentiate DA release presynaptically by acting on VTA ${ }^{\text {DA }}$ terminals (Patyal et al. 2012).

We previously designed floxed alleles of the genes coding for OxR1 and OxR2 to dissect the roles of selective brain targets of OX circuits in narcolepsy, vigilance state regulation, narcolepsy, and motivated behavior (Vassalli et al. 2015), (Li et al. 2018). To functionally address the role of the OX-to-DA circuits in mice, we generate mice whose dopaminergic system could not respond to OX input via OXR1, OXR2, or via either one. We used a combination of genetic and electrophysiological approaches to dissect the mechanisms of orexinergic modulation of DA neurons. Observation of OX axons closely juxtaposed onto VTA DA neurons by electron microscopy reveals that many contacts consist of en-passant varicosities (Balcita-Pedicino and Sesack 2007). Thus encoding by OX neuronal stimulation of appetitive or aversive stimuli, or of an homeostatic imbalance, may be mediated by either synaptic or paracrine transmission. Our mouse models should address the functional relevance of the OX-DA connection endowed by postsynaptic, presynaptic, and extrasynaptic effects of OX on DA cells at the level of somatodendritic or axonal compartments in dopaminergic nuclei and their targets. Our findings place DA signaling under prominent neuromodulatory control by the OX peptidergic system and show that orexinergic modulation of 
dopaminergic pathways is differentially driven by OX peptides acting on OXR1 and OXR2. We reveal a prominent role of OXto-DA circuits mediated by OXR2 in the regulation of theta oscillations across vigilance states.

\section{Results}

\section{Generation of conditional knockout (CKO) lines for Hcrtr1 (OXR1) and Hcrtr2 (OXR2).}

To selectively ablate an OX-to-target monosynaptic connection from the brain-wide OX neuron connectome, and differentiate the role of OXR1 and OXR2, we engineered the Hcrtr1 (OxR1) and Hcrtr2 (OxR2) genes in embryonic stem cells and created a Cre-dependent 'KO-ready' allele of each gene. We previously reported generation of OxR1 $1^{\text {flox }}$ mice (Vassalli et al. 2015) (Li et al. 2018). For OxR2, we targeted a loxP site in OxR2 5'untranslated region (5'UTR) in Exon 1 and a second loxP site followed by a promoter-less GFP coding sequence in Intron 1 (Fig. 1a). CRE-mediated loxP site recombination results in excision of the coding region for the signal peptide, the $\mathrm{N}$-terminal extracellular domain and almost the entire first transmembrane (TM1) region (74 aa in total) of OXR2.

Both OxR1 and 2 floxed alleles were designed such that CRE/lox recombination replaces the coding region of the OX receptor by the one of GFP and terminates downstream transcription, precluding generation of any membrane-bound truncated protein (Fig. 1a). Cells having successfully underwent genomic deletion now express GFP under the endogenous OxR2 promoter (Fig. 1a, d). We further validated the $O x R 1^{\text {flox }}$ and $O x R 2^{\text {flox }}$ lines by crossing the mice with a transgenic line

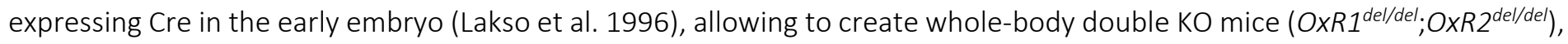
and demonstrating these mice exhibit narcolepsy with cataplexies of similar characteristics and frequency as the $\mathrm{Hcrt}^{\mathrm{ko} / \mathrm{ko}}$ mouse model of narcolepsy.

\section{DA-cell-selective OXR1 and OXR2 gene recombination and GFP labeling of VTA ${ }^{\text {DA }}$ neurons}

To determine the impact of inactivating either receptor singly or both receptors selectively in DA neurons on sleep/wake state architecture and brain oscillations, $O X R 1^{f l o x}$ and $O X R 2^{f l o x}$ mice were mated to dopamine transporter (Dat)-ires-Cre mice (Backman et al. 2006). The Dat-ires-Cre allele was shown to faithfully reproduce endogenous Dat expression without

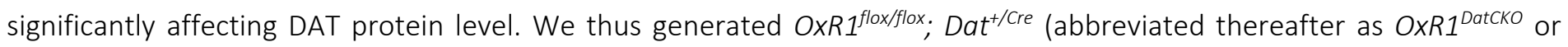

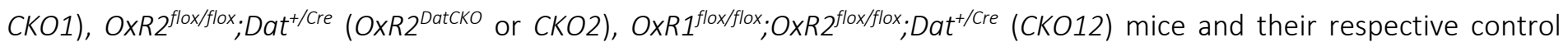

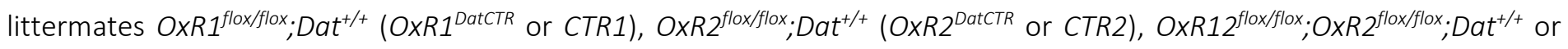
CTR12). Dat-ires-Cre mediates reporter expression at E17, suggesting that $O x R 1$ and $R 2$ gene inactivation occurs in late gestation in CKO1, CKO2 and CKO12 mice. To demonstrate DA-specific gene disruption in vivo, we prepared genomic DNA from various tissues of OxR2 $2^{\text {DatCKO }}$ mice and controls. As seen in Fig. 1b, only VTA shows the diagnostic 865 bp recombination DNA band, absent from extracts from the tuberomammillary nucleus (TMN), neocortex, or ear. Next, because not all midbrain DA cells express Dat (Blanchard 1994, Lammel 2013), we estimated the fraction of DA neurons that express Dat ${ }^{\text {ires- }}$

Cre by counting the cells immunoreactive for both tyrosine hydroxylase (TH) and CRE in the ventral midbrain area (VTA+SN) 
of OXR2 DatCKO mice. Among $2640 \mathrm{TH}+$ cells, 2340 were immunoreactive for CRE $(88.4 \%, \mathrm{n}=4$ mice, 2CKO12 + 2CKO2), suggesting that, globally, approximately $88 \%$ of DA neurons express Dat (SFig. 2).

We previously showed that our Ox1Rflox allele gets efficiently inactivated in presence of a cell-specific Cre recombinase in Noradrenergic cells (Li2018). To quantify the efficiency of Dat-Cre driven OxR1 and OxR2 gene disruption in midbrain DA neurons by of CKO1 and CKO2 mice resp., we first used the GFP reporter of gene inactivation. We found that $83 \%$ and $87 \%$ of TH+ neurons co-expressed GFP in CKO1 $(n=2)$, and CKO2 $(n=2)$ mice, respectively $(83.0 \pm 2.8$ and $87.2 \pm 1.5]$ and therefore had undergone genomic deletion (Fig. 1d and SFig. 1 and 3). As this represents the fraction of TH+ cells that have successively recombined and have an active endogenous $O x R 1$ or 2 promoter (as they express the promoterless GFP reporter), this also indicates that a majority ( $>87 \%$ and $>83 \%$, respectively) of ventral midbrain DA neurons express OxR1 and 2, respectively, and have inactivated OXR expression in CKO1 and 2 mice (SFig. 3). Immunocytochemistry using an anti-OXR1 antibody confirmed that a majority of VTA TH+ cells expressing Dat have lost OxR1 immunoreactivity in OxR1 DatCKO mice (SFig. 1d).

\section{Electrophysiological demonstration that OxR2 Cre/lox recombination inactivates OxR2s.}

To demonstrate that $\mathrm{CRE} /$ lox recombination creates a null in our new line, we performed patch clamp recordings of the most extensively studied neuronal type with selective OxR2 expression, histamine (HA) neurons from the ventral tubero-mamillary nucleus (TMN) in the posterior hypothalamus (Eriksson et al. 2001; Marcus et al. 2001; Yamanaka et al. 2002; Schone et al. 2014; Ikeno and Yan 2018). Putative HA neurons were identified based on their typical electrophysiological properties (Supplementary Fig. 4 and STable 1), i.e. $\sim 2 \mathrm{~Hz}$ spontaneous firing, late-spiking profile, $\mathrm{l}_{\mathrm{h}}$-related sag upon hyperpolarizing pulses, resting membrane potential $\left(V_{m}\right)$ around $-50 \mathrm{mV}$ and cell capacitance $\sim 20 \mathrm{pF}$ (Haas 1988(Michael et al. 2020). The passive membrane properties were overall coherent among genotypes. A fraction of cells was loaded with biocytin for postrecording morphological reconstruction (SFig. 4g), which confirmed the large diameter (20-30 $\mu \mathrm{m}$ ) and multipolar shape of HA TMN neurons (Eriksson 2001). Fig. 1e (top panels) shows the firing response of TMN neurons from C57BL6/J, OxR2 flox/flox and OxR2 del/del mice, after application of the specific OxR2 agonist [Ala11,D-Leu15]-Orexin B (OXB-AL). Spontaneous Vm oscillations were recorded from neurons held at approximately $-50 \mathrm{mV}$, in current-clamp mode. Applying $200 \mathrm{nM}$ OXB-AL in the bath for 2 min triggered an AP train at $2 \mathrm{~Hz}$ in $88 \%$ of C57BL6/J neurons and 100\% of OxR $2^{\text {floxflox }}$ neuron, whereas no response was observed in 91\% of OxR2 del/del mice. Similar results were obtained with $100 \mathrm{nM} O \mathrm{OX}-\mathrm{B}$. The percentage of cells responding or not to treatment is given in Fig. 1e (bottom panels), for the indicated genotypes. Moreover, the specific OxR2 antagonist TCS-OX2-029 (10 $\mu \mathrm{M})$ fully blocked the effects of either OX-B (100 nM) or OXB-AL (200 nM), in 80 to $100 \%$ of the C57BL6/J controls and OxR2 flox/flox cells. We conclude that OX stimulates TMN neurons' firing essentially by activating OXR2s, and that OXR2 is functionally inactive in OXR2 $2^{\text {del/del }}$ mice.

\section{Inactivating OXR2, but not OXR1, in DA cells dramatically alters baseline wakefulness spectral profile.}

To assess the distribution and spectral quality of vigilance states in baseline conditions and after a 6-hour sleep deprivation (SD) homeostatic challenge, we used our standard sleep/wake phenotyping protocol (Vassalli et al. 2013). Because introducing loxp sites and the other genetic components necessary to create floxed alleles of a gene can impact genetic 
expression, all our ECoG analyses are based on pairwise comparison between conditional knockout (CKO) and control (CTR) animal groups bearing the same homozygous floxed gene constitution. Analysis of time spent in wakefulness and SWS did not reveal major genotype differences, albeit CKO mice tended to show higher waking than their respective control littermates during the dark phase, with a significant increase in double OxR1\&2 ${ }^{\text {Dat-CKO }}$ mutant mice (SFig. 5). Time spent awake in single receptor CKO mutants being unchanged, we next analyzed wakefulness quality. Spectral profiles of $O x R 1^{\text {Dat-CKO }}$ mice did not differ from controls in any vigilance state (Fig. 2a Top for wake). ECoG spectra of OxR2 ${ }^{\text {Dat-CKO }}$ mice, however, were profoundly altered. Major differences were found in OxR2 $2^{\text {Dat-CKO }}$ mice wakefulness in the theta range (Fig. 2a). Baseline wakefulness displayed lower power density across the 3.25-4.75 Hz range, but higher density in the 6.75-9.75 $\mathrm{Hz}$ theta range as compared to littermate controls (Bonferroni post-hoc test between genotypes, $p<0.05$ ). Wakefulness of $O x R 1+R 2$ Dat-CKO double mutant mice displayed a similar pattern of changes in lower frequencies (decreased power in 2-7.25 Hz), but a much narrower increase in theta limited to the $8.5-9.75 \mathrm{~Hz}$ band.)

\section{OXR2 Dat-CKO mice show a profound increase in ECOG theta power and time spent in an 'active' type of} wakefulness, albeit uncoupled to locomotion

While total wakefulness did not differ in OxR2DatCKO mice and CTR mice, time spent in the theta-dominated-wakefulness sub-state (TDW, (Vassalli and Franken 2017)was strongly affected by manipulating the OXR2-DA circuit. OxR2 Dat-CKO mice displayed a striking increase in time spent in TDW during the first half of the baseline dark phase, during SD and in the recovery dark phase (Fig. 3a Middle and 3b). To test whether increased TDW results from enhanced state initiation or state stability, mean bout number and duration were determined. Waking bouts were normally distributed in $O \times R 2^{\text {Dat-CKO }}$ mice relative to controls, however TDW bouts were markedly longer. Short TDW bouts $(4 \mathrm{~s}, 8 \mathrm{~s}, 16 \mathrm{~s})$ and medium duration (32s and 64s) were much rarer in OxR2 $2^{\text {Dat-CKO }}$ mice than in controls, and very long TDW episodes (1024 s or 17 min) were enhanced (Fig. 3d). While CTRs did not display any episodes of TDW lasting 1024s (17 min), OxR2 Dat-CKO mice spent $9.81 \pm 4.35 \%$ of their TDW total time in this bout category ( $p=0.014$, Mann-Whitney $U$ statistics). Mean TDW bout duration increased in both baseline dark and light phase (BL dark, CKO2: $12.8 \pm 0.7$ s vs CTR2: $8.7 \pm 0.9$ s; BL light, CKO2: $9.2 \pm 0.4$ s vs CTR2: $7.6 \pm 0.4$ s). Strikingly, mean TDW bout duration more than doubled during SD in OxR2CKO relative to CTRs (CKO2: $18.6 \pm 1.7 \mathrm{~s}$ vs CTR2: $9.6 \pm 1 \mathrm{~s}, \mathrm{p}<0.05$, unpaired t-test, Fig.3 c Bottom). TDW bout number, however, did not differ (Fig. 3c Top), indicating that increased time in TDW was fully due to increased state stability, but W-to-TDW transitions did not seem affected by OXR2 loss in DA cells.

The spectral quality of TDW was next analyzed during the $48 \mathrm{~h}$ baseline recording. OxR1 ${ }^{\text {Dat-CKO }}$ mice showed lower power densities in delta $1-2.75 \mathrm{~Hz}$, as well as lower theta power across $6.75-8 \mathrm{~Hz}$, but higher densities in 8.5-10.75 Hz as compared to controls (Bonferroni post-hoc test, $p<0.05$; Fig. 3e Top). A similar pattern but with a more pronounced decrease in the theta range was found in $O x R 1+R 2^{\text {Dat-CKO }}$ mice (Fig. 3e Bottom). In contrast, $O x R 2^{\text {Dat-CKO }}$ mice showed increase in theta power density across $7.75-10.25 \mathrm{~Hz}$ (Fig. 3e Middle). Because some of these changes could be due to shifts in theta peak frequency 
(i.e., the frequency with highest power within the theta spectral window), we calculated theta peak frequencies in the 6 genotypes. Values did not differ in TDW of the 3 types of CKOs relative to their respective CTRs, indicating that these alterations in theta activity are due to real power density changes.

To rule out a possible effect of the Dat-ires-Cre allele independent of OxR2 in the increase in waking theta and the other phenotypes of $\mathrm{CKO} 2$ mice, we recorded in parallel mice segregating only the Dat-ires-Cre allele in absence of OxR alleles, and compared ECoG characteristics of Dat ${ }^{+/ C r e}$ mice with those of their Dat ${ }^{+/+}$littermates. None of the phenotypes described were observed in $\mathrm{Dat}^{+/ C r e}$ mice. In contrast these animals tended to show a decrease in power density relative to WT littermates across the 2.25-7.5 Hz delta-theta frequency range both during wakefulness and REM sleep (Suppl. Fig. 6).

These data indicate that mice lacking OXR2 in DA cells express constitutive electrocortical activation. Increased TDW state stability and TDW total time were not observed in mice deficient for Ox1R or both receptors in DA cells. Dopaminergic OxR2 inactivation thus causes the mice to spend more time of their active dark phase in a brain state electrocortically akin to the one of exploratory behavior, even in absence of obvious external stimulation. Prominent ECoG theta activity is associated with locomotor activity and exploratory behavior in rodents. Prominent hippocampal theta was however also reported during immobile alertness in rats (McFarland et al., 1975). Thus, we assessed whether the increased TDW matched the levels of the mice locomotor activity. Only $O x R 1+R 2^{\text {Dat-CKO }}$ mice displayed a significant increase in locomotor activity in early baseline dark phase (Suppl. Fig. 7). The however did not in enforced wakefulness during SD, or in recovery after SD (Suppl. Fig. 7). OXR2 ${ }^{\text {Dat-CKO }}$ mice, however, did not show alteration in locomotor activity relative to controls. Thus the dramatic increase in TDW was not coupled to a matching increase in locomotor activity.

To determine the spectral dynamics of other frequency bands in wakefulness of OxR2 Dat-CKO mice, we next analyzed the time course of ECoG activity in specific spectral components during the 3-day recordings.

In all genotypes, when mice are most active, i.e. in the first half of the night, waking delta (1-4 $\mathrm{Hz})$ activity was reduced compared to its reference value in the last $4 \mathrm{~h}$ of the baseline light phase. However this reduction was significantly more pronounced in OXR2 $2^{\text {Dat-CKO }}$ mice relative to littermate controls than in the other lines (Fig. 3f Top). Intringuingly, during SD, as homeostatic sleep pressure augments, $O x R 1+R 2^{\text {Dat-CKO }}$ mice showed a more pronounced increase in waking delta activity than do their controls, suggesting higher degree of 'sleepiness', or sleep propensity. Similar to delta, activity in the 4-7 $\mathrm{Hz}$ range decreased markedly in baseline dark, reaching values below the reference value in all genotypes, but, again, OxR2 DatCKO mice showed a more pronounced decrease in this band activity than did controls, and the same was true in wakefulness during SD. In contrast, again, OxR1+R2 Dat-CKO mice showed the opposite effect during SD, with increased 4-7 Hz activity compared to controls (Bonferroni post-hoc test, $p<0.05$; Fig. 3f). Therefore OxR2 $2^{\text {Dat-CKO }}$ mice express reduced low frequency band (delta and infra-theta, 1-7 Hz) activity during their most active periods compared to CTR2, suggesting a less 'sleepy' type of wakefulness, as the slow frequency range across the delta and inter-delta/theta bands are associated with sleepiness and reduced vigilance in rodents as in humans (Franken et al. 1991a; Cajochen et al. 2002; Sharott et al. 2005; Tinkhauser et al. 2017), and $O x R 1+R 2^{\text {Dat-CKO }}$ mice exhibit the opposite. 
Regarding ECoG Theta $(7-11 \mathrm{~Hz})$, as discussed above, periods of high activity are associated in all genotypes with surge in power (Fig. 2d)). Relative to controls however OxR2Dat-CKO mice showed a much more pronounced theta increase in baseline dark phase, during SD and in recovery dark phase, while OXR1+R2 Dat-CKO mice exhibited a significant theta decrease during SD (Fig. 2d Left), which interestingly is accompanied by an increase in waking beta frequencies (15-30 Hz), compared to controls (Fig. 2d Middle). Finally, paralleling the increase in theta activity, the waking ECoG of OxR2 ${ }^{\text {Dat-CKO }}$ mice, but not of OxR1 $1^{\text {Dat-CKO }}$ or OxR1+R2 Dat-CKO mice, displayed a pronounced increase in fast-gamma frequencies $(52.5-80 \mathrm{~Hz})$ in all active waking periods (Fig. 2d Right).

In sum, loss of OxR2 in DA cells caused major differences in the waking ECoG relative to controls, with a decrease in slow frequencies (1-7 Hz, comprising delta, 1-4 Hz, and inter-delta/theta,4-7 Hz) in baseline dark phase, and an increase in both theta and fast-gamma power in spontaneous or enforced wakefulness. Loss of both receptors in DA cells led in contrast caused opposite changes with higher infra-theta and lower theta power density, thus a slowing of the EEG relative to controls, suggesting that OxR1 and OxR2 perform different functions in DA neural circuits.

\section{Beta band enhancement during enforced wakefulness of OXR fully-ablated mice}

A salient result of our ECOG analysis of mice defective in OxR signaling in DA neurons was that wakefulness of OxR1+2Dat-CKO mice, with a general deficiency in OX modulation of DA activity, presented an abnormal beta band increase specifically during enforced wakefulness, which typically is associated with considerable amount of locomotor activity, as the mice try to escape the human experimenter performing the 'gentle handling' SD procedure (see Methods). Beta activity is normally repressed during movements, and an increase in beta band frequencies is characteristic of animals and humans experiencing a loss of DA cell activity such as Parkinson disease patients, whose EEG displays a characteristic 'anti-movement' beta-band (Sharott et al. 2005; Tinkhauser et al. 2017).

\section{Loss of OxR1 or 2 in DA neurons stabilizes REM sleep.}

To understand the impact of OX input on the DA system upon vigilance state architecture, analyses of state fragmentation and state amounts were performed on the 3-day BL1-BL2-SD recordings. Sleep/wake rhythmicity in baseline conditions was normal in all genotypes, but OxR1 $1^{\text {Dat-CKO }}$ mice showed higher waking time in recovery night period following SD than did CTRS (Suppl Fig. 5, 2-way ANOVA, W: genotype: $\mathrm{F}=5.230 ; p=0.023$; SWS: $\mathrm{F}=6.234 ; p=0.013$ ), and OxR1+R2 $2^{\text {Dat-CKO }}$ mice also showed more $\mathrm{W}$ than CTRs in the dark phase (W: genotype: $\mathrm{F}=8.481, p=0.004$; SWS: genotype: $\mathrm{F}=8.482, p<0.001$ ) (Bonferroni posthoc test, $p<0.05)$.

The most affected state was REMS. Mean TDW bout duration increased in both baseline dark and light phase (BL dark, CKO2: $12.8 \pm 0.7$ s vs CTR2: $8.7 \pm 0.9$ s; BL light, CKO2: $9.2 \pm 0.4$ s vs CTR2: $7.6 \pm 0.4$ s). Strikingly, mean TDW bout duration more than doubled during SD in OxR2CKO relative to CTRs (CKO2: $18.6 \pm 1.7 \mathrm{~s}$ vs CTR2: $9.6 \pm 1 \mathrm{~s}, \mathrm{p}<0.05$, unpaired t-test, Fig.3 c Bottom). TDW bout number, however, did not differ (Fig. 3c Top). In OxR 2Dat-CKO mice, a smaller fraction of REMS was spent 
in 32s bouts than in controls in baseline, and a larger percentage was spent in long bouts lasting 64s or 128s (Fig. 5e). Of the 3 lines, lengthening of REMS bout duration was the most pronounced in OxR2 Dat-CKO mice, leading to an overall increase in time spent in light phase REMS and REMS of the 2nd half of the dark phase (Suppl. Fig. 5 Top; 2-way ANOVA, genotype effect: $\mathrm{F}=16.516, p<0.001$, Bonferroni post-hoc test, $P<0.05)$. Hence loss of OX modulation of the DA system leads to both TDW and REMS state consolidation, suggesting that OX input on the DA system tends to destabilize these 2 states.

\section{Loss of OxR2 in DA neurons leads to an enhancement of theta oscillations during REMS.}

The REMS spectra of OxR2 Dat mice revealed a higher power density across 6.0-8.25 Hz (Bonferroni post-hoc test, between genotypes: $p<0.05$; Fig. 5a). Interestingly, in contrast to OxR2 ${ }^{\text {Dat-CKO }}$ mice, OxR1; OxR2 ${ }^{\text {Dat-CKO }}$ mice had lower power density in 5.5-8.75 Hz during REMS (Bonferroni post-hoc test, between genotype: $p<0.05$ ).

\section{Disruption of OxR2 in DA cells causes delayed and incomplete REMS recovery/rebound following sleep}

\section{deprivation.}

Although total REMS time and average bout duration were longer in OxR2 DatCKO mice than in controls, the mice exhibit delayed and incomplete REMS recovery after SD (Fig. 5f). REMS recovery occurred at a slower rate in OxR2 ${ }^{\text {Dat-CKO }}$ compared to littermate controls (negative slopes indicate loss, and positive ones gain in REMS amount compared to baseline REMS

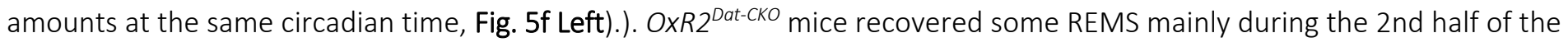
night, but never recovered as well as CTR, even by the end of the dark period (final deficit=23.84 \pm 4.01 min in OxR2 Dat-CKO vs. 9.02 $\pm 2.57 \mathrm{~min}$ in their controls; independent t-test, $p=0.007$ ), although they had accumulated the same amount of REMS deficit during SD as controls (34.90 $\pm 1.59 \mathrm{~min}$ vs. $30.78 \pm 1.90 \mathrm{~min}$ ). Thus at the end of the recovery night, cKO have a PS deficit 2.5-fold higher the duration of CTR. Hourly loss and gain in REMS as shown in Fig. 5 are influenced by the amount and distribution of REMS in each genotype in baseline recording (significant changes can be found if one genotype has significantly more/less REMS at the same time of the day in baseline). Therefore, REMS accumulation specifically during recovery was also analyzed. This analysis shows that the rhythm of REMS recovery is significantly impaired in $O x R 2^{\text {Dat-CKO }}$ mice only (Fig. 5 Right). OxR1+R2 Dat-CKO mice also displayed delayed REMS recovery compared to controls, but the rate of recovery (slope of the gain after SD) was the same as controls, and they recovered similar amounts as controls by the end of the dark period.

Thus even though loss of OxR1 or 2 in DAergic neurons stabilizes REM sleep, OxR2 ${ }^{\text {Dat-CKO }}$ mice show reduced REMS recovery after sleep deprivation. These data suggest that OXR2 signaling in DA neurons may be implicated in REMS state homeostasis. It may also be that OxR2Dat-CKO mice 'need' a lesser REMS rebound time due to differences in REMS quality associated with its enhanced theta activity. 


\section{Waking ECoG response to a novel environment}

Genetic and pharmacological alterations in monoaminergic pathways affect wakefulness quality and maintenance particularly in challenging environments (Hunsley and Palmiter 2003); (Qu et al. 2010). To address how disrupting of dopaminergic OX signaling affects the response to novel environments, we ran animals through a nestbuilding/nest removal and cage transfer experiment (Fig. 4a) as we previously described (Li et al. 2018). Mice were provided nest material (a 'Nestlet', see Methods) at dark onset (ZT12) and their ECoG activity was analyzed during the following $12 \mathrm{~h}$ nocturnal period, as they initially explore the material, and eventually build a nest in which they sleep. Time $\mathrm{x}$ frequency $\mathrm{x}$ power heatmap representations reveal a surge in Theta and Fast-gamma frequencies relative to baseline values in all genotypes, most apparent in the first half of the night (Fig. 4b, Left panels). CKO minus CTR differential heatmaps (CKO-CTR) (Fig. 4b, Right panels) however suggest that this Theta/Fast-gamma surge is more pronounced and lasts longer in CKO relative to CTR, for both the OxR1Dat and OxR2Dat lines. In strike contrast, Theta and Fast-gamma power appear lower in OxR12DatCKO mice than in controls (blue color-encoded datapoints) (Fig. 4b, Right panels). These mice additionally appear to show an increase in delta and infra-theta activities. Thus the EcoG of mice lacking both OxR1 and OxR2 from DA neurons (OxR12DatCKO) shows signs of a lesser electrocortical arousal than control mice, while the loss of OxR2 alone on the opposite leads to an overactive electrocortical profile.

2.5 days later the same mice were exposed to a cage change experiment. Three hours after light-onset (ZT3), when mice mostly sleep, they were removed from their nest and transferred to a fresh cage (foreign environment, Fig. 4a-b). Their waking ECoG was then analyzed for 4 hours or until their next sleep-onset, which usually is approximately 2.2.5 h later. While again Theta and Fast-Gamma frequencies sharply rise above baseline after cage transfer (Fig. 4b, Left panels), OxR2DatCKO mice show the strongest difference with their respective controls (Fig. 4c, Right panels). Spectral analysis of the waking state expressed from the time of nest removal/cage transfer to sleep onset ('foreign environment-induced W') shows differences of opposite polarity in the different lines (Fig. 4a), These differences affect both the Delta and Theta ranges. After cage transfer, OxR2Dat-CKO mice exhibited a higher Theta peak activity (across 7.75-9.75 Hz) relative to controls, while OxR1DatCKO tended to show the opposite, and OxR1+2 Dat-CKO mice exhibited a significant decrease in 8.5-10 Hz Theta peak activity relative to their littermate controls. (Fig. 4a, compare Middle and Bottom spectra). The heatmap representations reflect the same effects (Fig. 4b Right). Additionally they suggest that double mutant OxR1+2 ${ }^{\text {Dat-CKO }}$ mice have a markedly diminished response to the environmental enrichment provided by the nest material. We could hypothesize that this reflect the critical role of the OX-to-DA circuit in behavioral motivation in response to stimuli.

Thus in two contexts of exposure to novelty, either with a stress-associated (cage transfer), or an enriched (nestbuilding) environment, wakefulness spectral quality of mice with defective OX-DA connectivity show changes of opposite polarity depending on whether OxR2 or OxR1 are lost. 


\section{Theta-gamma coupling}

Because theta and fast-gamma activities have been linked to cognition, the increased in those 2 types of oscillations in OxR2Dat-CKO mice prompted us to analyze their relationships. Phase-amplitude cross-frequency coupling (CFC) is thought to have an important role in neuronal computation and communication between brain regions, and the strength of coupling between theta phase and gamma amplitude during wakefulness correlates with learning and task performance (Tort et al. 2008), we determined the mean modulation index (M.I.) of theta and fast-gamma waves during baseline TDW in dark phase. While the M.I of OxR1Dat-CKO (CKO1) mice did not differ from the one of CTR1, CKO2 mice showed a higher degree of thetafast-gamma coupling ( $p=0.0464$ for B1D for CKO2 vs CTR2, Fig $6 c$ Middle). When we next assayed theta-gamma coupling expressed during whole wakefulness in baseline dark phase, we found also that theta and fast-gamma oscillations are better coupled in OxR2Dat-CKO mice than controls (Fig 6c Left).

Because the REMS ECOG is also dominated by theta and fast-gamma frequencies we next measured MI during baseline light phase REMS. The REMS theta rhythm of OxR2Dat-CKO mice showed again a higher coupling index with fast-gamma waves compared to CTR2 ( $p=0.0351$ for B1L CKO2 vs CTR2, Fig 6c Right). OxR1 dopaminergic inactivation (OxR1 ${ }^{\text {Dat-CKO }}$ mice, Fig 6c)), and the Dat-ires-Cre allele by itself (Dat ${ }^{+/ i r e-C r e}$ mice, Suppl. Fig. 6), did not significantly affect theta-gamma coupling.

\section{Discussion}

We here establish for the first time a clear, genetically-defined link between direct orexin-to-DA neuronal connectivity and the power of theta oscillations during both wake and REM sleep. Mice chronically lacking very specific dopaminergic circuit components, the orexinergic input via OXR1, or OXR2, or both, markedly differ in vigilance state spectral characteristics, responses to environmental changes, and homeostatic responses to sleep deprivation. Disruption of OxR2 input to the DA system generates a powerful increase in theta oscillatory activity in spontaneous or induced wakefulness with a pronounced increase in time spent in the TDW sub-state of wakefulness. TDW bouts last longer, and the spectral quality of TDW itself shows increased theta power relative to controls. Intriguingly, the enhanced theta power of OxR2 Dat-CKO mice wakefulness is not coupled to increased locomotor activity. Increased theta power was also seen during REMS, and REMS episodes were of longer duration. This mutant therefore exhibits a general reinforcement of the power and stability of the theta rhythm. These effects were not seen in mice with a chronic disruption of OxR1, or both receptors, in DA cells. In some measures of vigilance state-dependent oscillatory activities, the latter mice even tended to show opposite alterations. By showing that functional and behavioral outputs differ between mutants, our results point to different functions of OxR1 and R2 signaling. How could deleting OxR2 from dopaminergic pathways affect so profoundly theta network activity? Ample evidence exists for a powerful modulation of theta by both OX and DA as we next describe. 


\section{The VTA-theta link}

The upregulation of theta frequencies in wake and REMS of OXR2 Dat-CKO mice is in line with reports that the VTA is part of the broad network governing theta rhythm generation (Dahan et al. 2007) (Orzel-Gryglewska et al. 2014) (Orzel-Gryglewska et al. 2015). Theta waves are recorded with highest amplitude in the hippocampus, which appears to have an intrinsic theta rhythm generator (Amilhon et al. 2015). However, several brain structures can generate theta oscillations, including the medial septum and vertical limb of the diagonal band of Broca, the pontine nucleus incertus, and enthorinal cortex. Moreover, a number of neocortical areas, including the medial PFC (mPFC) and posterior cingulate cortex, appear to contain theta pacemakers (Talk et al. 2004; Korotkova et al. 2017) and hippocampal theta has been shown to be able to entrain mPFC theta(Paz et al. 2008).

Furthermore, the major VTA ${ }^{\mathrm{DA}}$ cell group has been suggested to be located upstream in a circuit that regulates brain theta networks by converging onto the hippocampus (Orzel-Gryglewska et al. 2015). Anatomically, DA fibers originating from the VTA activate the hippocampus via the forebrain septum. Silencing or lesioning the VTA disrupts, while local injection of dopaminergic agents induces, hippocampal theta activity. Local field potential (LFP) recordings in the VTA show strong theta activity both during REMS and active waking (Dahan et al. 2007; Orzel-Gryglewska et al. 2015). Thus, the theta rhythm is thought to arise from a combination of multiple intrinsic theta oscillators and their interaction with hippocampal networks (Wang 2010). At the cellular level, the theta rhythm is generally attributed to the activity of pyramidal (cells, whose subthreshold and bursting activity occur at frequencies that tend to cluster around theta (Wang 2010). The findings of Orzel therefore support the existence of VTA-septo-hippocampal pathways that could position the dopaminergic system in theta

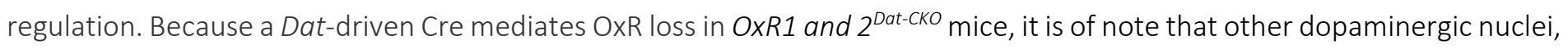
such as hypothalamic or dorsal raphe DA groups, may also be involved in the theta network modulation observed in these mice.

\section{The DA-theta link}

A general link between DA and the theta oscillations is amply documented (e.g., (Vetrivelan et al. 2010);(de Lecea and Huerta 2014). Acute treatment with DA agonists (Nakamura et al. 2000) (Nakagawa et al. 2000) (Yamamoto 1997) and NMDAglutamatergic VTA activation (Matulewicz et al. 2014) induce hippocampal theta rhythms. Sustained optogenetic activation of VTA ${ }^{\text {DA }}$ cells leads to an active waking state with prominent theta frequencies that can be sustained as long as for $6 \mathrm{~h}$ upon continued optogenetic stimulation (Eban-Rothschild et al. 2016). It is striking that the baseline wakefulness spectral profile of OxR2Dat-CKO mice resembles the one of WT mice undergoing VTA ${ }^{\mathrm{DA}}$ optogenetic activation, and it could suggest that OxR2 loss causes a net activating effect on DA cells. Acute manipulation of VTA ${ }^{\mathrm{DA}}$ networks however cannot be directly compared to the baseline waking state of $O X R 2^{\text {Dat CKO }}$ mice, which also show a marked increase in waking theta but are chronically deficient in dopaminergic OXR2 signaling since late embryogenesis. Moreover, the kinetics of the stimulatory action profoundly affects the physiological outcome. For instance, the permanent hyperdopaminergia observed in DAT-KO mice, with a 5-fold increase in extracellular DA levels (Gainetdinov and Caron 2003) (Wisor et al. 2001), decreases 
hippocampal theta activity (Dzirasa et al. 2006) (Dzirasa et al. 2009). Moreover DA-depleted rats show an amplification of oscillations across theta frequencies during execution of a cognitive tasks(Lemaire et al. 2012).

DA effects are inherently complex due to the plasticity of DA cell firing properties, as well as the anatomical heterogeneity of DA cell populations, their targets, and DA receptors' distributions (Lammel et al. 2014) (Baimel et al. 2017). VTA ${ }^{\text {DA }}$ cells can undergo differential modes of activation depending on behavioral contexts. Stimuli can induce VTA ${ }^{\text {DA }}$ phasic firing, or alter the degree of regularity/irregularity of their tonic firing, all of which having distinct effects (Chandler et al. 2014). Importantly, DA actions on targets such as the PFC and the NAc present an "inverted U-shaped" dose response relation, i.e. too little or too much DA impairs network functions and working memory while performing tasks (Chandler et al. 2014). D2/3 agonists are known to show a dose-dependency in sleep/wake effects, enhancing sleep at low dosage but enhancing wakefulness at higher doses (Monti et al. 1988) E(Monti et al. 1989). In narcoleptic dogs, low doses of D2/3 agonists aggravate cataplexy while high doses are stimulating (Reid et al. 1996). Therefore the net effects of DA dysregulations are difficult to predict.

\section{OxR1 vs R2 signaling in DA cells and theta activity}

OXR2-inactivated DA mice exhibit a wakefulness characterized by constitutive electrocortical hyperarousal, with increased waking theta and fast-gamma activity in baseline dark phase and during enforced wakefulness, as well as enhanced theta REMS state, and elevated theta-gamma coupling in both states.

Theta/Fast-Gamma wave upregulation exists in baseline and is further enhanced when mice are exposed to novel environments, either negative such as a sudden transfer to a foreign arena, or positive such as environment enrichment with added nesting material. This was not observed in mice lacking OxR1, or both receptors, in DA cells.

How can the specific loss of OXR2 in DA cells cause such a profound increase in theta network activity? Since OXR2 binds both OXA and OXB, but OXR1 binds only OXA with high affinity (Sakurai et al. 1998), OxR2Dat-CKO mice are expected to be relatively deficient in OXB signaling. Very little is known on differential activity, stability and function of the 2 orexin peptides in the brain and DA system. Moreover, because genetic variations are well known to contribute non-additive effects to the phenotype of complex traits, we cannot infer that OXR2 responsiveness of the DA system necessarily causes a negative impact on theta wave networks.

Nevertheless, the simplest explanation of our results would be that a DA system that responds to OXs exclusively via OXR1 as in our Ox2RDat CKO mice positively contributes to theta networks during wakefulness and REMS, and OXR2 activation would impart a general brake to these networks. This could be consistent with previous observations showing that OX actions at the cell level can also be inhibitory (Muroya et al. 2004) (Belle et al. 2014) (Leonard and Kukkonen 2014).

The reverse would be true for the coupled action of OxR1 and OxR2, as mice lacking both OX receptor signaling in DA cells display a decrease of theta power in wakefulness and REMS. Thus the dopaminergic tone may be increased in OxR2 Dat-CKO mice, but decreased in double CKO mice, in line with the suggestion that DA acts as a facilitator of theta activity (Vetrivelan et al. 2010; de Lecea and Huerta 2014). 
Evidence for differential responses of the two OX receptors in DA cells was reported at the electrophysiological level (Baimel and Borgland 2012), but their significance is poorly understood. The understanding of OX effects on VTA ${ }^{\text {DA }}$ neurons at a cellular level appears to be complex. In addition to OX ability to regulate firing rate and induce burst firing though activation of receptors on the somatodendritic compartment, OXR2 could act preynaptically at the level of both dopaminergic and glutamatergic axons. Furthermore in addition to effects within the VTA itself, OX signaling in our OxR2Dat cKO mutants may be deficient at the level of DA targets such as in the NAc and mPFC. In these targets OxR2 may also be located on DA axonal terminals to regulate DA release, and their absence in OxR2DatCKO mice may lead to alterations in DA release.

DA neurons display 2 major modes of firing, a low-frequency tonic mode, and a high-frequency bursting mode, which are induced by distinct contexts and underlie distinct behaviors (Hyland et al. 2002). DA cell firing mode is modulated by AMPAR and NMDAR currents. NMDAR activation can evoke a burst of high-frequency firing, while the AMPAR current cannot. Coactivation of AMPARs and NMDARs most efficiently induces high-frequency firing (Zakharov et al. 2016). Because OXR2 signaling is known to mediate postsynaptic NMDAR potentiation in DA VTA cells (Borgland et al. 2006), loss of OXR2 in DA cells may unbalance the overall effect of OX towards AMPARs, which may facilitate lower $(<10 \mathrm{~Hz})$ compared to higher $(>20 \mathrm{~Hz})$ frequencies, and thus may enhance theta oscillations.

DA cells express either one receptor singly, or both, or none (Korotkova et al. 2003). Our OxR1 and OxR2 Gfp-reporters indicated that about $80 \%$ of DAT-expressing DA neurons express OxR1 and even more express OxR2. While OXR2 binds both OXA and B with high affinity, OXR1 binds with high affinity only OXA. Thus in Ox2RDatCKO mice DA cells only express OxR1 which will bind OXA but only poorly OXB. DA cells of OX2RDatCKO mice however can theoretically respond to both OXA and OXB. Inactivation of OXR1 in DA neurons appeared to impact sleep and wakefulness and ECoG spectra less than OxR2 loss did, consistent with the fact that, although intracranial OX-1 administration promotes a high arousal state, blockade of OXR1 alone does not elicit sleep (Deng et al., 2007; (Lawrence 2010) R(Rasmussen et al. 2007). Moreover, OxR1-KO mice do not present obvious behavioral state abnormalities (Mieda et al. 2011). OX peptides may be able to regulate DA neuron activity through OxR2 and OxR2 signaling may be sufficient for the normal contribution of DA system to the sleep-wake cycle. Evidence in rodents suggests that OxB levels are generally higher than those of OxA (Mondal et al. 1999), which could further explain the especially sensitive response to OXR2 deletion.

\section{Orexin and Theta and Fast-Gamma oscillations}

We previously found severe disruption in theta oscillatory activity in OXko/ko (Vassalli et al. 2013; Vassalli and Franken 2017)and OxR1 ${ }^{\text {Dhh-CKO }}$ mice that lack OxR1 in noradrenergic cells (Li et al. 2018) affecting predominantly the rodents' "active wakefulness" substate, the fraction of wakefulness associated with goal-oriented, exploratory and motivated behaviors. $O x^{k o / k o}$ show a profoundly reduced time spent in TDW during baseline spontaneous waking with marked decreased TDW episode duration, which however were normalized when wakefulness was enforced (Vassalli et al. 2017). OxR1 ${ }^{\text {Dhh-CKO }}$ mice displayed reduced ability to enhance fast-gamma frequencies in waking upon transfer of the mouse to a novel environment, while beta and slow-gamma activities were abnormally high as compared to controls after nest material addition, a potent, 
positively-valued stimulus (Li et al. 2018).

This is in striking contrast OXR2 $2^{\text {Dat-CKO }}$ mice which exhibit a marked increase in the TDW sub-state throughout spontaneous and enforced wakefulness with an increase in bout duration, and a significant number of TDW bouts lasting as long as 17 min. Surprisingly, TDW overexpression in these mice was not coupled to altered locomotor activity. Moreover, increased theta in wakefulness of $O \times R 2^{\text {Dat-CKO }}$ mice was associated with a decrease in infra-theta activity and elevated fast-gamma (52.5$80 \mathrm{~Hz}$ ) at times of elevated behavioral activity.

Enhanced theta in dissociation with locomotor activity in CKO2 mice is in direct opposition with the phenotype of DAT-KO mice, which feature permanent hyperdopaminergia (Wisor et al. 2001). The latter mice feature locomotor hyperactivity, but show lower baseline hippocampal theta activity than do WT (Dzirasa et al. 2006). This suggests that the increase in TDW of OxR2DatCKOs may not be caused by a hyperdopaminergic tone. The observation of enhanced theta in dissociation with locomotor activity in $\mathrm{CKO} 2$ mice is interesting and questions its functional implications. The mutation may activate thetagenerating networks independently from circuits commonly studied in behavioral paradigms of theta-associated explorative locomotion.

\section{Orexins and REMS}

The other state dominated by theta activity in rodents, REM sleep was also affected in OxR2DatCKO mice. The dramatic increase in time spent in TDW was coupled to an increase in REMS amount and episode duration in OxR2 $2^{\text {Dat-CKO }}$ mice in baseline recording. However, after SD, the dynamics of REMS recovery were considerably slower.

Analysis of REMS spectral profiles, revealed opposing effects of single OxR2 DA cell-specific inactivation and double receptor inactivation on theta power density. REMS of OxR2 $2^{\text {Dat-CKO }}$ mice showed an increase in theta power density, while REMS of OXR1 Dat-CKO; OXR2 Dat-CKO mice showed a decrease. Intriguingly, these changes parallel the changes observed in baseline wakefulness, as well as in TDW. Thus theta power regulation as mediated by OXR neurotransmission in DA cells seems to operate both during theta-dominated-wakefulness and REMS, 2 states characterized by theta rhythm, in mice.

An interesting finding after SD is alterations in the dynamics of REMS recovery. While in baseline, OxR2Dat-CKO mice show enhanced REMS, after $6 \mathrm{~h}$ of enforced wakefulness they exhibit a slower rebound in REMS amount. This suggests that OxR2 and DA neurons are involved in REMS state homeostasis. OxR2Dat-CKO mice may need a shorter REMS rebound time due to differences in REMS quality associated with its enhanced theta activity (Franken et al. 1991b).

How DA regulates REMS is also controversial. While early studies concluded that DA is the only monoamine not involved in sleep because DA neuronal firing does not correlate with vigilance states. Later studies showed cFos expression in DA neurons following a REMS rebound, and microdialysis revealed increased extracellular DA in NAc and prefrontal cortex during REMS (Lena et al., 2005; (Maloney et al. 2002), suggesting specific activation of DA neurons during REMS. In vivo unit recordings of VTA-DA neurons in head restrained rats revealed a prominent bursting activity during REMS, similar to waking activity when rats consumed a palatable food (Dahan et al. 2007).

The parallel regulation of theta power during TDW and REMS of OxR2DatCKO mice is intriguing. OX neurons are known to 
be maximally active during active waking. On the other hand while OX neurons are reported to be mostly inactive during REMS, they were shown to display burst firing during phasic REMS and could therefore regulate DA activity at these moments. TDW could be seen as phasic arousal events during waking, and thus TDW and phasic REMS could reflect a common underlying process (Sakai 2012). It will be interesting to determine if amounts of phasic REMS are altered in OxR2Dat mice.

\section{The OxR2DatCKO mouse, narcolepsy and ADHD}

Another state characterized by a Theta-dominated EEG is cataplexy, the pathognomonic symptom of OX insufficiency. Cataplexy is modulated by D2/D3 and sleep attacks by D1 receptors in mice (Burgess et al. 2010). Direct perfusion of D2/D3 agonists in the VTA of narcoleptic dogs increase cataplexy, while D2/D3 blockers improve it (Reid et al. 1996) (Honda et al. 1999). Because D2/D3 act as inhibitory autoreceptors on DA neurons, these findings suggest DA insufficiency may be implicated in narcolepsy and in particular cataplexy.

The fact that we find signs of electrocortical hyperarousal in mice disrupted in an (presumably excitatory) input on dopaminergic pathways is reminiscent of the neurodevelopmental disorder attention deficiency/hyperactivity disorder $(A D H D)$. Genetic and pharmacological evidence strongly suggest the involvement of DA pathways in ADHD in both humans and mouse models, leading to the "the dopamine hypothesis of ADHD" (Swanson et al. 2007) suggesting that dopaminergic hypofunction, or imbalance underlie ADHD.

The clinical manifestations of narcolepsy and ADHD overlap (Oosterloo et al. 2006; Bioulac et al. 2020), Bioulac 2020). Both pathologies respond well to DA drugs. In particular, methylphenidate and amphetamine, which increase DA and cause hyperarousal in humans, can normalize arousal in ADHD patients. Therefore, inattentiveness/hyperactivity in ADHD may be characterized by DA hypofunction (Swanson et al. 2007). In relation with our findings, enhanced theta rhythms are documented in children with ADHD (Barry et al. 2003) as well as in ADHD mouse models (Won et al. 2011). Moreover, increased theta/beta power ratio with increase in theta $(4-7 \mathrm{~Hz})$ and decrease in beta $(13-30 \mathrm{~Hz})$ activity across fronto-central regions was approved by the US Food and Drug Administration (FDA) as an aid in the diagnosis of ADHD in young patients. The ADHD-like traits in our OXR2 DatCKO mice suggest these may be relevant to study some of the disfunctions seen in ADHD. In this light, the blood-brain-barrier (BBB)-permeable OXR2 agonists being developed for narcolepsy and other hypersomnolences may provide a novel therapeutic approach for ADHD.

Another salient pathophysiological implication of our ECoG analysis is that mice with double OxR1+R2 cKO in DA cells exhibit an abnormal beta band increase in the waking ECoG, which appears specifically during the enforced wakefulness associated with SD. SD is typically accompanied by intense locomotor activity, as the mice escape the experimenter performing the 'gentle handling' procedure. Beta activity is normally repressed during movements. An increase in ECoG beta band activity is characteristic of animals and humans experiencing a loss of DA cell activity and is observed in Parkinson's disease patients ((Brown 2007) and DA-depleted rats performing cognitive (and thus motor) tasks (Lemaire et al. 2012). The beta band is a marker referred to as the 'anti-movement beta band' in PD, which responds to L-dopa and deep brain stimulation therapy, 
showing normalization in relation with clinical improvement. This result appears particularly relevant in the context of recent data suggesting that OXA and OXB have protective effects in PD and PD animal models (Liu et al. 2020) (Bian et al. 2021). Finally, the hippocampal theta rhythm has been proposed as a therapeutic target owing to its vital role in neuroplasticity, learning and memory. Changes in ECoG/LFP theta-gamma oscillatory power and other disruptions of oscillatory rhythms are related to emotional and neuropsychological alterations in disorders of arousal, anxiety and depression. Besides being useful for diagnostic purposes, theta and gamma oscillations may reveal important aspects of the underlying mechanisms of these disorders, explaining why stimulants (dopamine, serotonin) and other therapeutic means induce changes in EEG oscillations in conjunction with their clinical benefits. Thus wave attributes are biomarkers and novel therapeutic targets in several brain pathologies. Importantly, post-mortem quantitative studies evidenced five times heavier orexinergic input to TH-IR neurons in the VTA of humans, as compared with rat. Hence, OX signaling in the VTA may play as critical roles in reward processing and drug abuse in humans, as it does in rodents (Hrabovszky et al. 2013). Understanding the role of OX-to-DA connectivity during development and in the stable circuit may suggest therapeutic strategies aimed at modulating the motivation and arousal linked to attentional control and decision-making. Insight into neuropsychiatric disorders linked to OX and DA systems will benefit from understanding how they interact and process stress and rewarding signals, to shape network activity, brain states, and eventually action strategies and behaviors. 


\section{Methods}

Gene Targeting of OXR2 (HcrtRZ) and generation of conditional knockout allele. The OxR1flox line was generated as we previously described (Li2018). For OxR2, two contiguous Ncol fragments (8.1 kb and 2.1 kb) containing Hcrtr2 exon 1 and intron 1 were subcloned from PAC clone RP23-392M3 of a C57BL/6J mouse genomic library (BACPAC Resources Center, Oakland, CA, USA) and used to construct the targeting vector. The $5^{\prime}$ loxP was inserted 70 bp downstream of the transcription start site (TSS) (Chen and Randeva, 2003) and 37 bp upstream of the ATG initiation codon in the $5^{\prime}$ untranslated region (UTR) in Exon 1 (Chen and Randeva, 2004), The 3'loxP site was inserted approximately $1 \mathrm{~kb}$ within Intron 1, together with a promoter-less GFP coding sequence followed by a rabbit polyadenylation signal. The allele is designed such that Crerecombinase-mediated loxP site-recombination results in expression of GFP instead of the OXR2 receptor under the control of the OxR2/Hcrtr2 gene promoter. The targeting vector was linearized and electroporated in IC1, a C57BL/6NTac embryonic stem (ES) cell line (ingenious targeting laboratory, Ronkonkoma, NY, USA). Single colonies were screened by Southern blot analysis using probes external to the targeting vector in both 5' and 3', and a Gfp internal probe. Two ES cell clones having undergone correct recombination events were identified and injected into BALB/CAnNHEW blastocysts. The FRT-flanked neo cassette was removed in the germline by mating the resulting chimeras to mice harboring an Actin promoter-Flp recombinase transgene (Tg(ACTFLPe)9205Dym) on a mixed C57BL/6J and C57BL/6NTac background. The neo-excised conditional KO allele, Hcrtr2tm1.1Ava (MGI: 563740XX), is referred hereafter as OxR2flox (http://www.informatics.jax.org/allele/MGl:5637400). Experimental mice were generated by intercrossing Hcrtr1 $1^{\text {flox/flox }}$ animals with one of the two parents heterozygous for a Dat-ires-Cre allele (Slc6a3<tm1.1(cre)Bkmn> Bäckman et al., 2006). Each of these crosses generate two offspring groups: OxR1,2 flox/flox; Dat+/ire-Cre mice (CKO mice), and Hcrtr1flox/flox littermates (CTR mice). Each mutant line' assessment is based upon pair-wise comparative analyses between littermate mice belonging to 2 genotype groups: CKO and CTR (for OxR1 and OxR2 lines), Cre and WT (for the Dat-ires-Cre line). Mice were therefore in a mixed C57BL/6NTac x C57BL/6J background.

Generation of OxR2-delta-Gfp-reporter (Hcrtr2tm1.2Ava) mice. OxR2flox/flox mice were mated to Tg(Ella-cre)C5379Lmgd transgenic mice, which express Cre at embryonic preimplantation stages. Offspring that stably transmitted the recombined (Hcrtr2tm1.2Ava) allele were selected for further breeding, and Tg(Ella-cre) was segregated out. Genomic DNA extracted from two animals was sequenced to confirm accurate CRE/loxP recombination at Hcrtr2. Resulting mice carry the recombined KO/GFP-reporter (Hcrtr2tm1.2Ava MGI: 563740XX, or Hcrtr2KO-Gfp) allele in all cells (http://www.informatics.jax.org/allele/MGI:563740XX). Because the GFP coding sequence in this allele does not, unlike the HCRTR2 coding sequence that it replaces, carry a N-terminal signal peptide, it generates cytoplasmic GFP, which distributes through soma and neurites. Thus GFP expression reflects Hcrtr2 promoter expression, but does not inform about HCRTR2 protein intracellular distribution. 
Mice surgery, EEG recording and analyses were done a as previously described Vassalli et al 2013 and Li et 2018. Briefly, after EEG/EMG electrode implantation surgery, the mice were allowed approximatively 1 week for recovery, and 1 week for cable habituation. Signal was acquired using EMBLA ${ }^{\mathrm{TM}}$ hardware and analyzed using Somnologica-3 ${ }^{\mathrm{TM}}$ (Medcare) software. Analogous EEG and EMG signals were digitized at 2,000 Hz and stored at $200 \mathrm{~Hz}$. The EEG was subjected to discrete Fourier transformation (DFT) yielding power spectra (range: $0.25-90 \mathrm{~Hz}$, resolution: $0.25 \mathrm{~Hz}$, window function: hamming) for consecutive 4-s epochs. For each vigilance state, the spectra of all artifact-free 4-s epochs in the 48h baseline recording period (representing in total $~ 70 \%$ of the total recording time) were averaged to generate a mean ECoG spectrum first for each animal. Animals showing epileptic-like seizure or pre-epileptic-like spikes in their 3-day recordings were excluded from analysis (an altogether frequency of approximately 10\%). we observed a higher susceptibility to epileptic-like events in C57BL/6NTac mice compared to C57BL/6J). To analyze how specific spectral components of the waking ECOG evolved across time we divided the the ECOG spectrum into 5 frequency ranges: delta (1-4 Hz), inter-delta/thet (4-7 Hz), theta (7-11 Hz), beta $(15-30 \mathrm{~Hz})$ and fast-gamma $(52.5-80 \mathrm{~Hz})$, and plotted the respective power density values across time. For each of these frequency bands, power density values are expressed as percentage of the mean power density value in that band in the last $6 \mathrm{~h}$ of the two baseline light periods, except stated otherwise.

Animals. All ECoG data are derived from 10 to 13-week-old males (weight 27-31 g). Mice were individually housed with food and water ad libitum under an LD12:12 cycle (lights-on, i.e., Zeitgeber Time ZT0, at 08:00 AM). Locomotor activity was monitored in parallel by infrared movement counts and analyzed across the 3-day recording period, i.e. in a familiar environment (i.e. the home cage), in the SD paradigm or after the SD period. This analysis shows clear circadian regulation of activity in all genotypes, with low activity in light period, and increased locomotion in dark. All animal procedures followed Swiss federal laws and were approved by the State of Vaud Veterinary Office. At all times, care was taken to minimize animal discomfort and avoid pain.

Theta-gamma cross-frequency coupling. We used the modulation index (MI) to measure theta-gamma coupling (Tort, Kramer et al. 2008). Using finite impulse response filters with an order equal to three cycles of the low cutoff frequency, we first bandpass-filtered ECoG signals into theta $(7-11 \mathrm{~Hz})$ and fast-gamma $(52.5-80 \mathrm{~Hz})$ in both forward and reverse directions to eliminate phase distortion. We then estimated instantaneous phase of theta and the envelope of fast-gamma using the Hilbert transform. Theta phase was discretized into 18 equal bins $\left(N=18\right.$, each $\left.20^{\circ}\right)$ and the average value of fast-gamma envelope within each bin was calculated. The resulting phase-amplitude histogram $(P)$ was compared with a uniform distribution $(U)$ using the Kullback-Leibler distance, $D_{K L}(P, U)=\sum_{j=1}^{N} P(j) * \log [P(j) / U(j)]$, and normalized by $\log (N)$ to obtain the modulation index, $M I=D_{K L} / \log (N)$. For each animal, we first filtered continuous $12 \mathrm{~h}$ recordings (dark phase for wakefulness and TDW, light phase for REM sleep) into the theta and fast-gamma bands and estimated the Hilbert transform, and then concatenated episodes of each state to calculate the MI. To explore possible coupling patterns between different 
pairs of low and high frequency bands, we used the comodulogram analysis (Tort et al. 2008). We considered 16 frequency bands for phase (1-18 Hz, 1-Hz increments, 2-Hz bandwidth), and 14 frequency bands for amplitude $(15-90 \mathrm{~Hz}, 5-\mathrm{Hz}$ increments, $10-\mathrm{Hz}$ bandwidth). MI values were then calculated for all these pairs to obtain the comodulogram graph.

Behavioral timeline. Cohorts of CKO and CTR mice previously instrumented for ECoG/EMG recording were sequentially exposed to four behavioral contexts: (i) baseline, (ii) sleep deprivation (SD), (iii) nestbuilding, (iv) transfer to fresh cage (Fig. 4a). Following SD, mice were left undisturbed for 2 days. At dark onset (ZT12) of day 6, a square of highly packed shreddable cotton (NestletTM, Ancare, Bellmore, NY, Ref. Nr. 14010) was introduced in the cage. Mice were then left undisturbed through the night until light onset and assessment of nest morphology. All nests were found to score at least 3 according to Gaskill et al.' nestbuilding scale. Following nest assessment, mice were left undisturbed for another 2 days. On ZT3 of day 9, mice were transferred from their home cage where the nest had been built to a fresh cage. Latency to SWS-onset was defined as the time until the first SWS episode lasting $\geq 2 \mathrm{~min}$.

TMN brain slices. A total of 16 young adult C57BL6/J mice (Charles River, USA), 13 OxR2 flox/flox mice, and 17 OxR2 del/del mice of both sexes ( 7 males and 9 females, 6+7, and 9+8, respectively), ranging from P21 to P49, were kept in pathogen-free conditions, with free access to food and water, and a $12 \mathrm{~h}$ light-dark cycle. The described procedures followed the Italian law (2014/26, implementing the 2010/63/UE) and were approved by the local Ethical Committee and the Italian Ministry of Health. After a deep anaesthesia with 5\% isoflurane, mice were decapitated and the brains were rapidly extracted and placed in ice-cold solution, containing (mM): $87 \mathrm{NaCl}, 21 \mathrm{NaHCO}_{3}, 1.25 \mathrm{NaH}_{2} \mathrm{PO}_{4}, 7 \mathrm{MgCl}_{2}, 0.5 \mathrm{CaCl}_{2}, 2.5 \mathrm{KCl}, 25 \mathrm{D}$-glucose, 75 sucrose, 0.8 ascorbic acid, and aerated with $95 \% \mathrm{O}_{2}$ and $5 \% \mathrm{CO}_{2}(\mathrm{pH}$ 7.4). Coronal slices (300 $\mu \mathrm{m}$ thick) from the TMN were cut between $-2.18 \mathrm{~mm}$ and $-2.92 \mathrm{~mm}$ from bregma (Franklin and Paxinos), with a VT1000S vibratome (Leica Microsystems) and maintained at $30^{\circ} \mathrm{C}$ in the above solution for at least $1 \mathrm{~h}$ before being transferred to the recording chamber.

Drugs and solutions. Orexin B (OXB), [Ala11,D-Leu15]-Orexin B (OXB-Ala,Leu), and (2S)-1- (3,4-dihydro-6,7-dimethoxy2(1H)-isoquinolinyl)-3,3-dimethyl-2-[(4-pyridinylmethyl)amino]-1-butanone hydrochloride (TCS-OX2-29) were purchased from Tocris Bioscience, Bristol, UK. They were dissolved in distilled water-based stock solutions, aliquoted and stored at $20^{\circ} \mathrm{C}$, then unfrozen upon usage.

Patch-clamp whole-cell recordings. Cells were examined with an Eclipse E600FN microscope (Nikon), as reported (Aracri et al., 2017). Stimulation and recording were carried out with a Multiclamp 700A (Molecular Devices), at $32-34^{\circ} \mathrm{C}$. Micropipettes (2-4 M $\Omega$ ) were pulled from borosilicate capillaries (Science Products GmbH) with a P-97 Flaming/Brown Micropipette Puller (Sutter Instruments). The cell capacitance and series resistance were always compensated (up to 75\%). 
Series resistance was generally below $10 \mathrm{M} \Omega$. Neurons were both voltage- and current-clamped in whole-cell configuration and the input resistance was usually between 30 and $70 \mathrm{M} \Omega$. Slices were perfused at $1.8-2 \mathrm{~mL} / \mathrm{min}$ with artificial cerebrospinal fluid (ACSF) containing (mM): $129 \mathrm{NaCl}, 21 \mathrm{NaHCO}_{3}, 1.6 \mathrm{CaCl}_{2}, 3 \mathrm{KCl}, 1.25 \mathrm{NaH}_{2} \mathrm{PO}_{4}, 1.8 \mathrm{MgSO}$, $10 \mathrm{D}$-glucose, aerated with $95 \% \mathrm{O}_{2}$ and $5 \% \mathrm{CO}_{2}$ (pH 7.4). Pipettes contained (mM): $140 \mathrm{~K}$-gluconate, $5 \mathrm{KCl}, 1 \mathrm{MgCl}_{2}, 0.1 \mathrm{BAPTA}, 2 \mathrm{Mg}$ ATP, $0.3 \mathrm{Na}-\mathrm{GTP}, 10$ HEPES ( $\mathrm{pH}$ 7.25). In some experiments, $0.15 \%$ biocytin was added for post-recording staining and morphological reconstruction.

Traces were low-pass Bessel filtered at $2 \mathrm{kHz}$ and digitized at $10 \mathrm{kHz}$, with pClamp9/Digidata 1322A (Molecular Devices). The resting membrane potential $\left(V_{\text {rest }}\right)$ was measured in open circuit mode, soon after obtaining the whole-cell configuration. No correction was applied for liquid junction potentials. Drugs were perfused in the bath and their effects on cell firing were measured for 2 min after reaching the maximal effect, which in the case of OxR2 agonists usually occurred within 30 s after the drug was removed. Only one neuron was sampled in each slice, to avoid uncontrolled long-term effects of neuromodulators (e.g. on receptor desensitization).

Analysis of patch-clamp data. Passive membrane properties (cell capacity, $\tau$ membrane charging, $\tau$ membrane discharging, $\tau$ sag, $V$ rest), action potential (AP) features (AP amplitude, AHP, AP half-width, AP rise slope, AP decay slope, AP threshold, AP triggering slope, $1^{\text {st }} / 4^{\text {th }}$ spike interval) and firing responses to agonists were analysed off-line by using Clampfit 9.2 (Molecular Devices), and OriginPro 2019 (OriginLab Corporation, Northampton, MA, USA). All the AP features were analysed during the first step of current injection able to trigger multiple AREMS; parameters were measured on the first AP of the induced train, but the $1^{\text {st }} / 4^{\text {th }}$ spike interval, which was evaluated on the first depolarizing step inducing at least four AREMS. Spike width was calculated at half-amplitude, spike amplitude was computed as the difference between the AP threshold and the peak. Adaptation was measured as the ratio between the fourth and the first spike interval. Spike intervals were measured between consecutive peaks. After hyperpolarization (AHP) was measured as the difference between the AP threshold and the most negative $\mathrm{Vm}$ reached on repolarization.

Finally, the triggering depolarization slope was the difference between the most negative $\mathrm{Vm}$ reached on repolarization and the following AP threshold, divided by the relative time. The time constants of membrane charging and discharging were estimated by mono-exponential fit to the passive response to -100 pA injection, whereas the time constant of the $I_{h}$-related sag was analogously fitted to the reduction in steady-state current upon -50 pA injection, from the negative peak to the end of the $0.5 \mathrm{~s}$ current pulse. The effect of treatments was usually measured for $2 \mathrm{~min}$ after reaching the maximal effect, which - in the case of OxR2 agonists - usually did not occur during the drug administration, but at least 30 seconds after the administration end.

Statistics. For electrophysiology: The results from multiple experiments are given as mean values \pm SEM. The number of experiments $(\mathrm{N})$ refers to the number of tested neurons (in different brain slices). Data normality and variance homogeneity 
were respectively verified with the Shapiro-Wilk and the F test, as well as by Q-Q plot inspection. Statistical comparison between genotypes was carried out with one-way ANOVA test and Tukey Test for multiple mean comparison, at the indicated level of significance $(p)$.

For ECoG analysis: Animals of all genotypes were randomly distributed for sleep recording sessions. Investigators involved in performing SD and scoring of sleep recordings were blinded as to the animals' genotype. Results are expressed as mean \pm SEM or mean \pm SD. Statistical analyses were performed using GraphPad prism. and statistical significance of comparisons was determined by t-test, one- or two-way ANOVA and exact P, F, t and df values are reported in figure legends. Significant ANOVA analyses were followed by Bonferroni or Tukey multiple comparison post hoc tests. All statistical analyses were reviewed by our institutional statistician.

Immunofluorescence and confocal microcopy__Coronal sections (20 um thick) through the midbrain (bregma from -2.92 mm to $-3.88 \mathrm{~mm}$ ) were collected, representing approximately 48 sections per mouse, of which 6 sections (approx. 1 out of 8 ) $(-2.92,-3.08,-3.16,-3.40,-3.52 \mathrm{~mm}$ from Bregma) were used for cell counts. In table below, the average number of TH neurons per mouse is indicated.

According to different bregma levels, midbrain was sub-divided into VTA, PBP, PN and SNc.

16-wk old mice were deeply anesthetized with sodium pentobarbital (100 mg/kg, i.p.), and transcardially perfused with $4 \%$ paraformaldehyde ( $\mathrm{pH}$ 7.4). Brains were quickly removed, post-fixed in the same fixative for $2 \mathrm{~h}$ at $4{ }^{\circ} \mathrm{C}$, and immersed successively in $15 \%(1 \mathrm{~h})$ and $30 \%$ sucrose $(\mathrm{o} / \mathrm{h})$ at $4{ }^{\circ} \mathrm{C}$, frozen and stored at $-80^{\circ} \mathrm{C}$ until use. Coronal sections $(20-\mu \mathrm{m})$ were collected on SuperFrost-Plus glass slides, blocked in 2\% BSA, 5\% normal donkey serum, 0.3\% TritonX-100 in TBS (pH 7.5) for 30 min at r.t., and antibodies were applied in 1\% BSA, 0.2\% TritonX-100 in TBS, and incubated o/n at $4{ }^{\circ} \mathrm{C}$. When double staining involved the HCRTR1 antibody, an additional 'antigen-retrieval' step in Sodium Citrate buffer (pH 6.0) buffer at 550 C for 7 min was applied before blocking and primary antibody incubation. Antibodies were anti-tyrosine hydroxylase (TH) from mouse (Incstar, Cat\#22941; 1:5000), anti-green fluorescent protein (GFP) from chicken (Aves Labs, Cat\#1020; 1:500), anti-CRE from rabbit (Novagen, Cat\#69050-3; 1:500), and anti-HCRTR1 from rabbit (Origene Cat\#TA328918; 1:100-1:500). Donkey IgG secondary antibodies coupled to Alexa-594, or -488 fluorophores were used at a 1:500 dilution and incubated for $1 \mathrm{~h}$ at r.t. Images were acquired on an inverted Zeiss LSM710 confocal laser-scanning microscope (405, 488, and 561 nm lasers) using a 40x oil objective (EC plan-Neofluar 40x/1.30 Oil DIC M 27). Identical minimal image processing parameters were used for CKO and CTR mice.

\section{References}

Adamantidis AR, Zhang F, Aravanis AM, Deisseroth K, de Lecea L. 2007. Neural substrates of awakening probed with optogenetic control of hypocretin neurons. Nature 450: 420-424.

Amilhon B, Huh CYL, Manseau F, Ducharme G, Nichol H, Adamantidis A, Williams S. 2015. Parvalbumin Interneurons of Hippocampus Tune Population Activity at Theta Frequency. Neuron 86: 1277-1289. 
Baimel C, Borgland SL. 2012. Hypocretin modulation of drug-induced synaptic plasticity. Orexin/Hypocretin System 198: 123-131.

Baimel C, Lau BK, Qiao M, Borgland SL. 2017. Projection-Target-Defined Effects of Orexin and Dynorphin on VTA Dopamine Neurons. Cell reports 18: 1346-1355.

Balcita-Pedicino JJ, Sesack SR. 2007. Orexin axons in the rat ventral tegmental area synapse infrequently onto dopamine and gamma-aminobutyric acid neurons. The Journal of comparative neurology 503: 668-684.

Barry RJ, Clarke AR, Johnstone SJ. 2003. A review of electrophysiology in attention-deficit/hyperactivity disorder: I. Qualitative and quantitative electroencephalography. Clinical neurophysiology : official journal of the International Federation of Clinical Neurophysiology 114: 171-183.

Belle MD, Hughes AT, Bechtold DA, Cunningham P, Pierucci M, Burdakov D, Piggins HD. 2014. Acute suppressive and longterm phase modulation actions of orexin on the mammalian circadian clock. The Journal of neuroscience : the official journal of the Society for Neuroscience 34: 3607-3621.

Bian K, Liu C, Wang Y, Xue Y, Chen L. 2021. Orexin-B exerts excitatory effects on nigral dopaminergic neurons and alleviates motor disorders in MPTP parkinsonian mice. Neuroscience letters 765: 136291.

Bioulac S, Taillard J, Philip P, Sagaspe P. 2020. Excessive Daytime Sleepiness Measurements in Children With Attention Deficit Hyperactivity Disorder. Frontiers in psychiatry 11: 3.

Blomeley C, Garau C, Burdakov D. 2017. Accumbal D2 cells orchestrate innate risk-avoidance according to orexin signals. Nature neuroscience.

Borgland SL, Storm E, Bonci A. 2008. Orexin B/hypocretin 2 increases glutamatergic transmission to ventral tegmental area neurons. The European journal of neuroscience 28: 1545-1556.

Borgland SL, Taha SA, Sarti F, Fields HL, Bonci A. 2006. Orexin A in the VTA is critical for the induction of synaptic plasticity and behavioral sensitization to cocaine. Neuron 49: 589-601.

Brown P. 2007. Abnormal oscillatory synchronisation in the motor system leads to impaired movement. Current opinion in neurobiology 17: 656-664.

Burgess CR, Tse G, Gillis L, Peever JH. 2010. Dopaminergic regulation of sleep and cataplexy in a murine model of narcolepsy. Sleep 33: 1295-1304.

Cajochen C, Wyatt JK, Czeisler CA, Dijk DJ. 2002. Separation of circadian and wake duration-dependent modulation of EEG activation during wakefulness. Neuroscience 114: 1047-1060.

Calipari ES, Espana RA. 2012. Hypocretin/orexin regulation of dopamine signaling: implications for reward and reinforcement mechanisms. Frontiers in behavioral neuroscience 6: 54.

Chandler DJ, Gao WJ, Waterhouse BD. 2014. Heterogeneous organization of the locus coeruleus projections to prefrontal and motor cortices. Proceedings of the National Academy of Sciences of the United States of America 111: 68166821.

Dahan L, Astier B, Vautrelle N, Urbain N, Kocsis B, Chouvet G. 2007. Prominent burst firing of dopaminergic neurons in the ventral tegmental area during paradoxical sleep. Neuropsychopharmacology : official publication of the American College of Neuropsychopharmacology 32: 1232-1241.

de Lecea L, Huerta R. 2014. Hypocretin (orexin) regulation of sleep-to-wake transitions. Frontiers in pharmacology 5: 16.

Dzirasa K, Ribeiro S, Costa R, Santos LM, Lin SC, Grosmark A, Sotnikova TD, Gainetdinov RR, Caron MG, Nicolelis MA. 2006. Dopaminergic control of sleep-wake states. The Journal of neuroscience : the official journal of the Society for Neuroscience 26: 10577-10589.

Dzirasa K, Santos LM, Ribeiro S, Stapleton J, Gainetdinov RR, Caron MG, Nicolelis MA. 2009. Persistent hyperdopaminergia decreases the peak frequency of hippocampal theta oscillations during quiet waking and REM sleep. PloS one 4: e5238.

Eban-Rothschild A, Appelbaum L, de Lecea L. 2018. Neuronal Mechanisms for Sleep/Wake Regulation and Modulatory Drive. Neuropsychopharmacology : official publication of the American College of Neuropsychopharmacology 43: 937-952.

Eban-Rothschild A, Rothschild G, Giardino WJ, Jones JR, de Lecea L. 2016. VTA dopaminergic neurons regulate ethologically relevant sleep-wake behaviors. Nature neuroscience 19: 1356-1366. 
Eriksson KS, Sergeeva O, Brown RE, Haas HL. 2001. Orexin/hypocretin excites the histaminergic neurons of the tuberomammillary nucleus. The Journal of neuroscience : the official journal of the Society for Neuroscience 21: 9273-9279.

Fadel J, Deutch AY. 2002. Anatomical substrates of orexin-dopamine interactions: lateral hypothalamic projections to the ventral tegmental area. Neuroscience 111: 379-387.

Franken P, Dijk DJ, Tobler I, Borbely AA. 1991a. Sleep deprivation in rats: effects on EEG power spectra, vigilance states, and cortical temperature. The American journal of physiology 261: R198-208.

Franken P, Tobler I, Borbely AA. 1991b. Sleep homeostasis in the rat: simulation of the time course of EEG slow-wave activity. Neuroscience letters 130: 141-144.

Franklin KBJ, Paxinos G. Paxinos and Franklin's The mouse brain in stereotaxic coordinates.

Gainetdinov RR, Caron MG. 2003. Monoamine transporters: from genes to behavior. Annu Rev Pharmacol Toxicol 43: 261-284.

Giardino WJ, Eban-Rothschild A, Christoffel DJ, Li SB, Malenka RC, de Lecea L. 2018. Parallel circuits from the bed nuclei of stria terminalis to the lateral hypothalamus drive opposing emotional states. Nature neuroscience 21: 1084-1095.

Gomperts SN, Kloosterman F, Wilson MA. 2015. VTA neurons coordinate with the hippocampal reactivation of spatial experience. elife 4.

Gonzalez JA, lordanidou P, Strom M, Adamantidis A, Burdakov D. 2016. Awake dynamics and brain-wide direct inputs of hypothalamic MCH and orexin networks. Nature communications 7: 11395.

Harris GC, Aston-Jones G. 2006. Arousal and reward: a dichotomy in orexin function. Trends in neurosciences 29: $571-577$.

Honda K, Riehl J, Mignot E, Nishino S. 1999. Dopamine D3 agonists into the substantia nigra aggravate cataplexy but do not modify sleep [corrected]. Neuroreport 10: 3111-3118.

Hrabovszky E, Molnar CS, Borsay BA, Gergely P, Herczeg L, Liposits Z. 2013. Orexinergic input to dopaminergic neurons of the human ventral tegmental area. PloS one 8: e83029.

Hunsley MS, Palmiter RD. 2003. Norepinephrine-deficient mice exhibit normal sleep-wake states but have shorter sleep latency after mild stress and low doses of amphetamine. Sleep 26: 521-526.

Hyland BI, Reynolds JN, Hay J, Perk CG, Miller R. 2002. Firing modes of midbrain dopamine cells in the freely moving rat. Neuroscience 114: 475-492.

Ikeno T, Yan L. 2018. A comparison of the orexin receptor distribution in the brain between diurnal Nile grass rats (Arvicanthis niloticus) and nocturnal mice (Mus musculus). Brain research 1690: 89-95.

Korotkova T, Ponomarenko A, Monaghan CK, Poulter SL, Cacucci F, Wills T, Hasselmo ME, Lever C. 2017. Reconciling the different faces of hippocampal theta: the role of theta oscillations in cognitive, emotional and innate behaviors. Neuroscience and biobehavioral reviews.

Korotkova TM, Sergeeva OA, Eriksson KS, Haas HL, Brown RE. 2003. Excitation of ventral tegmental area dopaminergic and nondopaminergic neurons by orexins/hypocretins. The Journal of neuroscience : the official journal of the Society for Neuroscience 23: 7-11.

Kukkonen JP, Leonard CS. 2014. Orexin/hypocretin receptor signalling cascades. British journal of pharmacology 171: 314331.

Lammel S, Lim BK, Malenka RC. 2014. Reward and aversion in a heterogeneous midbrain dopamine system. Neuropharmacology 76 Pt B: 351-359.

Lawrence AJ. 2010. Regulation of alcohol-seeking by orexin (hypocretin) neurons. Brain research 1314: 124-129.

Lee MG, Hassani OK, Jones BE. 2005. Discharge of identified orexin/hypocretin neurons across the sleep-waking cycle. The Journal of neuroscience : the official journal of the Society for Neuroscience 25: 6716-6720.

Lemaire N, Hernandez LF, Hu D, Kubota Y, Howe MW, Graybiel AM. 2012. Effects of dopamine depletion on LFP oscillations in striatum are task- and learning-dependent and selectively reversed by L-DOPA. Proceedings of the National Academy of Sciences of the United States of America 109: 18126-18131.

Leonard CS, Kukkonen JP. 2014. Orexin/hypocretin receptor signalling: a functional perspective. British journal of pharmacology 171: 294-313.

Li S, Franken P, Vassalli A. 2018. Bidirectional and context-dependent changes in theta and gamma oscillatory brain activity in noradrenergic cell-specific Hypocretin/Orexin receptor 1-KO mice. Scientific reports 8: 15474. 
Liblau RS, Vassalli A, Seifinejad A, Tafti M. 2015. Hypocretin (orexin) biology and the pathophysiology of narcolepsy with cataplexy. The Lancet Neurology 14: 318-328.

Liu C, Xue Y, Liu MF, Wang Y, Chen L. 2020. Orexin and Parkinson's disease: A protective neuropeptide with therapeutic potential. Neurochem Int 138: 104754.

Luo YJ, Li YD, Wang L, Yang SR, Yuan XS, Wang J, Cherasse Y, Lazarus M, Chen JF, Qu WM et al. 2018. Nucleus accumbens controls wakefulness by a subpopulation of neurons expressing dopamine D1 receptors. Nature communications 9: 1576.

Maloney KJ, Mainville L, Jones BE. 2002. c-Fos expression in dopaminergic and GABAergic neurons of the ventral mesencephalic tegmentum after paradoxical sleep deprivation and recovery. The European journal of neuroscience 15: 774-778.

Marcus JN, Aschkenasi CJ, Lee CE, Chemelli RM, Saper CB, Yanagisawa M, Elmquist JK. 2001. Differential expression of orexin receptors 1 and 2 in the rat brain. The Journal of comparative neurology 435: 6-25.

Matulewicz P, Orzel-Gryglewska J, Kusmierczak M, Jurkowlaniec E. 2014. NMDA-glutamatergic activation of the ventral tegmental area induces hippocampal theta rhythm in anesthetized rats. Brain research bulletin 107: 43-53.

Michael NJ, Zigman JM, Williams KW, Elmquist JK. 2020. Electrophysiological Properties of Genetically Identified Histaminergic Neurons. Neuroscience 444: 183-195.

Mieda M, Hasegawa E, Kisanuki YY, Sinton CM, Yanagisawa M, Sakurai T. 2011. Differential Roles of Orexin Receptor-1 and-2 in the Regulation of Non-REM and REM Sleep. Journal of Neuroscience 31: 6518-6526.

Mondal MS, Nakazato M, Date Y, Murakami N, Hanada R, Sakata T, Matsukura S. 1999. Characterization of orexin-A and orexin-B in the microdissected rat brain nuclei and their contents in two obese rat models. Neuroscience letters 273: 45-48.

Monti JM, Hawkins M, Jantos H, Dangelo L, Fernandez M. 1988. Biphasic Effects of Dopamine D-2 Receptor Agonists on Sleep and Wakefulness in the Rat. Psychopharmacology 95: 395-400.

Monti JM, Jantos H, Fernandez M. 1989. Effects of the selective dopamine D-2 receptor agonist, quinpirole on sleep and wakefulness in the rat. European journal of pharmacology 169: 61-66.

Mukai K, Kim J, Nakajima K, Oomura Y, Wayner MJ, Sasaki K. 2009. Electrophysiological effects of orexin/hypocretin on nucleus accumbens shell neurons in rats: an in vitro study. Peptides 30: 1487-1496.

Muroya S, Funahashi H, Yamanaka A, Kohno D, Uramura K, Nambu T, Shibahara M, Kuramochi M, Takigawa M, Yanagisawa $\mathrm{M}$ et al. 2004. Orexins (hypocretins) directly interact with neuropeptide $\mathrm{Y}, \mathrm{POMC}$ and glucoseresponsive neurons to regulate $\mathrm{Ca} 2+$ signaling in a reciprocal manner to leptin: orexigenic neuronal pathways in the mediobasal hypothalamus. The European journal of neuroscience 19: 1524-1534.

Muschamp JW, Dominguez JM, Sato SM, Shen RY, Hull EM. 2007. A role for hypocretin (orexin) in male sexual behavior. The Journal of neuroscience : the official journal of the Society for Neuroscience 27: 2837-2845.

Nakagawa T, Ukai K, Ohyama T, Gomita Y, Okamura H. 2000. Effect of dopaminergic drugs on the reserpine-induced lowering of hippocampal theta wave frequency in rats. Nihon Shinkei Seishin Yakurigaku Zasshi 20: 71-76.

Nakamura T, Uramura K, Nambu T, Yada T, Goto K, Yanagisawa M, Sakurai T. 2000. Orexin-induced hyperlocomotion and stereotypy are mediated by the dopaminergic system. Brain research 873: 181-187.

Oishi Y, Suzuki Y, Takahashi K, Yonezawa T, Kanda T, Takata Y, Cherasse Y, Lazarus M. 2017. Activation of ventral tegmental area dopamine neurons produces wakefulness through dopamine D2-like receptors in mice. Brain structure \& function 222: 2907-2915.

Oosterloo M, Lammers GJ, Overeem S, de Noord I, Kooij JJS. 2006. Possible confusion between primary hypersomnia and adult attention-deficit/hyperactivity disorder. Psychiat Res 143: 293-297.

Orzel-Gryglewska J, Matulewicz P, Jurkowlaniec E. 2014. Theta activity in local field potential of the ventral tegmental area in sleeping and waking rats. Behavioural brain research 265: 84-92.

-. 2015. Brainstem system of hippocampal theta induction: The role of the ventral tegmental area. Synapse 69: 553-575.

Patyal R, Woo EY, Borgland SL. 2012. Local hypocretin-1 modulates terminal dopamine concentration in the nucleus accumbens shell. Frontiers in behavioral neuroscience 6.

Paz R, Bauer EP, Pare D. 2008. Theta synchronizes the activity of medial prefrontal neurons during learning. Learning \& memory 15: 524-531. 
Peleg-Raibstein D, Burdakov D. 2021. Do orexin/hypocretin neurons signal stress or reward? Peptides 145: 170629.

Qu WM, Xu XH, Yan MM, Wang YQ, Urade Y, Huang ZL. 2010. Essential role of dopamine D2 receptor in the maintenance of wakefulness, but not in homeostatic regulation of sleep, in mice. The Journal of neuroscience : the official journal of the Society for Neuroscience 30: 4382-4389.

Rasmussen K, Hsu MA, Yang Y. 2007. The orexin-1 receptor antagonist SB-334867 blocks the effects of antipsychotics on the activity of $A 9$ and $A 10$ dopamine neurons: implications for antipsychotic therapy. Neuropsychopharmacology : official publication of the American College of Neuropsychopharmacology 32: 786-792.

Reid MS, Tafti M, Nishino S, Sampathkumaran R, Siegel JM, Mignot E. 1996. Local administration of dopaminergic drugs into the ventral tegmental area modulates cataplexy in the narcoleptic canine. Brain research 733: 83-100.

Sakai K. 2012. Discharge Properties of Presumed Cholinergic and Noncholinergic Laterodorsal Tegmental Neurons Related to Cortical Activation in Non-Anesthetized Mice. Neuroscience 224: 172-190.

Sakurai T, Amemiya A, Ishii M, Matsuzaki I, Chemelli RM, Tanaka H, Williams SC, Richarson JA, Kozlowski GP, Wilson S et al. 1998. Orexins and orexin receptors: a family of hypothalamic neuropeptides and $G$ protein-coupled receptors that regulate feeding behavior. Cell 92: 1 page following 696.

Schone C, Apergis-Schoute J, Sakurai T, Adamantidis A, Burdakov D. 2014. Coreleased orexin and glutamate evoke nonredundant spike outputs and computations in histamine neurons. Cell reports 7: 697-704.

Sharott A, Magill PJ, Harnack D, Kupsch A, Meissner W, Brown P. 2005. Dopamine depletion increases the power and coherence of beta-oscillations in the cerebral cortex and subthalamic nucleus of the awake rat. The European journal of neuroscience 21: 1413-1422.

Swanson JM, Kinsbourne M, Nigg J, Lanphear B, Stefanatos GA, Volkow N, Taylor E, Casey BJ, Castellanos FX, Wadhwa PD. 2007. Etiologic subtypes of attention-deficit/hyperactivity disorder: Brain imaging, molecular genetic and environmental factors and the dopamine hypothesis. Neuropsychol Rev 17: 39-59.

Talk A, Kang E, Gabriel M. 2004. Independent generation of theta rhythm in the hippocampus and posterior cingulate cortex. Brain research 1015: 15-24.

Thompson JL, Borgland SL. 2011. A role for hypocretin/orexin in motivation. Behavioural brain research 217: 446-453.

Tinkhauser G, Pogosyan A, Tan H, Herz DM, Kuhn AA, Brown P. 2017. Beta burst dynamics in Parkinson's disease OFF and ON dopaminergic medication. Brain : a journal of neurology 140: 2968-2981.

Tort AB, Kramer MA, Thorn C, Gibson DJ, Kubota Y, Graybiel AM, Kopell NJ. 2008. Dynamic cross-frequency couplings of local field potential oscillations in rat striatum and hippocampus during performance of a T-maze task.

Proceedings of the National Academy of Sciences of the United States of America 105: 20517-20522.

Vassalli A, Dellepiane JM, Emmenegger Y, Jimenez S, Vandi S, Plazzi G, Franken P, Tafti M. 2013. Electroencephalogram paroxysmal theta characterizes cataplexy in mice and children. Brain : a journal of neurology 136: 1592-1608.

Vassalli A, Franken P. 2017. Hypocretin (orexin) is critical in sustaining theta/gamma-rich waking behaviors that drive sleep need. Proceedings of the National Academy of Sciences of the United States of America 114: E5464-E5473.

Vassalli A, Li S, Franken P, Tafti M. 2017. Hypocretin (Orexin) signaling in distinct neuronal groups differentially regulates oscillatory components of wakefulness and slow-wave-sleep. Sleep medicine 40: e337.

Vassalli A, Li S, Tafti M. 2015. Did hypocretin receptor 2 autoantibodies cause narcolepsy with hypocretin deficiency in Pandemrix-vaccinated children? Comment on "Antibodies to influenza nucleoprotein cross-react with human hypocretin receptor 2". Science translational medicine 7: 314le312.

Vetrivelan R, Qiu MH, Chang C, Lu J. 2010. Role of Basal Ganglia in sleep-wake regulation: neural circuitry and clinical significance. Frontiers in neuroanatomy 4: 145.

Vittoz NM, Berridge CW. 2006. Hypocretin/orexin selectively increases dopamine efflux within the prefrontal cortex: involvement of the ventral tegmental area. Neuropsychopharmacology : official publication of the American College of Neuropsychopharmacology 31: 384-395.

Wang XJ. 2010. Neurophysiological and computational principles of cortical rhythms in cognition. Physiological reviews 90: 1195-1268.

Wisor JP, Nishino S, Sora I, Uhl GH, Mignot E, Edgar DM. 2001. Dopaminergic role in stimulant-induced wakefulness. Journal of Neuroscience 21: 1787-1794. 
Won H, Mah W, Kim E, Kim JW, Hahm EK, Kim MH, Cho S, Kim J, Jang H, Cho SC et al. 2011. GIT1 is associated with ADHD in humans and ADHD-like behaviors in mice. Nature medicine 17: 566-+.

Yamamoto J. 1997. Cortical and hippocampal EEG power spectra in animal models of schizophrenia produced with methamphetamine, cocaine, and phencyclidine. Psychopharmacology 131: 379-387.

Yamanaka A, Tsujino N, Funahashi H, Honda K, Guan JL, Wang QP, Tominaga M, Goto K, Shioda S, Sakurai T. 2002. Orexins activate histaminergic neurons via the orexin 2 receptor. Biochemical and biophysical research communications 290: 1237-1245.

Zakharov D, Lapish C, Gutkin B, Kuznetsov A. 2016. Synergy of AMPA and NMDA Receptor Currents in Dopaminergic Neurons: A Modeling Study. Frontiers in computational neuroscience 10: 48.

\section{Acknowledgements}

We thank Paul Franken for code used in the early stages of this study and for his expert advice on sleep/wake phenotyping and EEG analysis. We thank Anne-Catherine Thomas for her essential help in animal genotyping. This work was supported by the Swiss National Science Foundation (grants 31003A_144282 and 182613 to A.V.).

\section{Author Contribution}

M.B. performed analysis. S.L. recorded the EEG of the mice and did EEG and sleep/wake analysis, G.C. did patch clamp recordings, A.B. supervised G.C., A.V. did OxR1 (Hcrtr1) and OxR2 (Hcrtr2) gene targeting, created the flox and delta mouse lines and wrote the paper. A.V., M.T. and M.B. conceived and supervised the project.

\section{Competing interests}

The authors declare no competing interests.

\section{Supplementary Information}

\section{Patch clamp recordings of TMN histaminergic neurons in Ox $2 \mathrm{R}^{\text {flox/flox }}$ and OxR2 ${ }^{\text {del/del }}$ mice}

Identification of putative histaminergic neurons in the hypothalamic TMN. (A) Putative histaminergic neurons were characterized by testing the firing response to consecutive depolarizing current steps, lasting $500 \mathrm{~ms}$. The responses to the $-100 \mathrm{pA}$ and the $100 \mathrm{pA}$ steps for a representative neuron show the classical hyperpolarization-triggered sag, attributed to $I_{h}$, and the low-frequency late firing. $(B)$ Relation between injected current and firing frequency for putative histaminergic neurons (25, 16, 20 cells for Ctrl, OxR2flox/flox and OxR2del/del, respectively). Data points are average firing frequencies calculated from an ensemble of similar neurons and plotted as a function of injected current. 
Electrophysiological features of putative histaminergic neurons. Passive membrane properties, including $\tau$ membrane charging, $\tau$ membrane discharging and $\tau_{\text {sag, }}$ and AP features were coherent across genotypes and with those reported by Haas and Reiner (1988). In particular the slow depolarization induced by the step current injection identified the cells as histaminergic neurons. Some action potential (AP) features were however different between C57BL/6J and OxR2- $\triangle$ cells: AP amplitude was reduced and more variable in OxR2- $\Delta$ ( $p$-value $=0.01097)$, AP half-width was increased and more variable $(p=0.01294)$, AP rise slope was reduced $(p=0.01026)$ and AP decay slope decreased ( $(p=0.0431)$. These small changes lead to slightly slower AP dynamics and suggest a partly reduced maturation of histaminergic cells in OxR2- $\Delta$ mice, with a possible role of OxR2 in the developmental specification of the histaminergic neuronal phenotype, since AP amplitude is known to increase and AP duration decrease during stages of neuronal development and differentiation in many cell types (e.g., Cajal-Retzius cortical layer I neurons (Zhou et al, 1996), CA1 pyramidal neurons (Spigelman et al, 1992, Sanchez et al, 2020).. Thus TMN ${ }^{\text {HA }}$ neurons having lost OXR2 developmentally may exhibit a slightly diminished excitability, warranting further investigation to decipher the role of OxR2 in neuronal maturation.

\section{Sleep/wake behavior of C57BL/6J and C57BL/6NTac mice}

Because mice were in a mixed C57BL/6NTac x C57BL/6J background, we analyzed mice from each pure strain individually (C57BL/6NTac, $n=8)$ and C57BL/6J mice (n=11). We found the two strains to significantly differ in sleep/wake-related variables. C57BL/6NTac mice spent less time awake $(P=0.02)$, and more time both in SWS $(P=0.048)$ and REMS $(P=0.03$, unpaired two-tailed Student's $t$ tests) than C57BL/6J mice. The distributions of behavioral states (wake:SWS:REMS) were as follows: C57BL/6NTac mice ( $n=8)$ : 50.57 $\pm 1.24 \%$ W; 43.74 $\pm 1.14 \%$ SWS; 5.69 0.27\% REMS, and C57BL/6J mice ( $n=11)$ : 54.86 $\pm 1.14 \%$ W; 40.25 $\pm 1.12 \%$ SWS; $4.89 \pm 0.21 \%$ REMS. (Wake: $t_{17}=2.520, P=0.02$; SWS: ${ }_{17}=-2.129, P=0.048 ;$ REMS: ${ }_{17}$ $=-2.332, P=0.03$, unpaired two-tailed Student's $t$ tests).

\section{Sleep/wake behavior of DAT ${ }^{+/ i r e s-c r e}$ and $D A T^{+/+}$mice}

Knock-in mice expressing Cre recombinase from the Dat locus (Dat ${ }^{+/ i r e s-C r e}$ ) (Backman et al., 2006) are widely used. Eventhough animals heterozygous for the mutation (Dat ${ }^{+/ i r e s-C r e}$ mice) were shown by Western blot to display a non-significant slight (17\%) reduction in DAT expression levels., and expression of various DA -dependent genes were shown to be unchanged, we addressed the potential effect of the KI by recording Dat ${ }^{+/ \text {ires-Cre }}$ and $\mathrm{Dat}^{+/+}$littermates. We found that Dat $^{+/ \text {ires- }}$ cre mice slightly differed from WT in ECoG spectral profiles in baseline and delta power recovery response to SD.

$D A T^{+/ i r e s-C r e}$ mice display an enhanced number of brief awakenings, compared to $D A T^{+/+}$mice $(p=0.021$; unpaired two tails student's t-test). [Note this phenotype is not seen in OxR2Dat-CKO mice]

ECOG spectral profiles of each state in baseline are shown in Fig.3. Significant genotype differences in W and SWS spectra were seen, as well an interaction of genotype and frequency in all 3 states (genotype effect: W: $F=42,765, p<0.001$; SWS: 
$F=5,489, p=0.019$; interaction of genotype and frequency $W: F=1.448, p<0.001 ;$ SWS: $F=2.734, P<0.001 ; R E M S: F=1.191$, $p=0.048$ ).

Waking spectral distribution of Dat ${ }^{+/ C r e}$ mice shows reduced power in the 2.25 to $7.5 \mathrm{~Hz}$ frequency range.

REMS of Dat ${ }^{+/ C r e}$ mice showed reduced activity in the $7.25 \mathrm{~Hz}$ to $8.5 \mathrm{~Hz}$ range

$\mathrm{DAT}^{+/ C r e}$ had higher SWS delta in both baseline and recovery SWS. Enhanced delta power in $\mathrm{DAT}^{+/ C r e}$ might represent a response to sleep need due to the higher number of short awakenings during sleep, ie more fragmented sleep,

Locomotor activity of $\mathrm{Dat}^{+/+}$and $\mathrm{Dat}^{+/ \text {Cre }}$ mice was quantified by IR beam counting and found not to significantly differ, either in baseline or during the SD experiment (2-way ANOVA for factors genotype and time, neither by factor genotype, nor interaction), indicating that unlike homozygous DatKO mice, the Dat-ires-Cre mice are not hyperactive.

\section{References for Supplementary Information}

Aracri, P., Meneghini, S., Coatti, A., Amadeo, A., \& Becchetti, A. $\alpha 4 \beta 2 *$ nicotinic receptors stimulate GABA release onto fast-spiking cells in layer $\vee$ of mouse prefrontal (Fr2) cortex. Neuroscience 340, 48-61 (2017).

Eriksson, K. S., Sergeeva, O., Brown, R. E., \& Haas, H. L. Orexin/hypocretin excites the histaminergic neurons of the tuberomammillary nucleus. J. Neurosci. 21, 9273-9279 (2001).

Franklin, K.B.J., \& Paxinos, G. The mouse brain in stereotaxic coordinates. 3rd ed. San Diego (CA): Academic Press. p. 256 (2008).

Haas, H. L., \& Reiner, P. B. Membrane properties of histaminergic tuberomammillary neurones of the rat hypothalamus in vitro. J. Physiol. 399, 633-646 (1988).

Ikeno, T., \& Yan, L. A comparison of the orexin receptor distribution in the brain between diurnal Nile grass rats (Arvicantis niloticus) and nocturnal mice (Mus musculus). Brain Res. 1690, 89-95 (2018).

Marcus, J.N. et al. Differential expression of orexin receptors 1 and 2 in the rat brain. J. Comp. Neurol. 435, 6-25 (2001).

Michael, N. J., Zigman, J. M., Williams, K. W., \& Elmquist, J. K. Electrophysiological properties of genetically identified histaminergic neurons. Neuroscience 444, 183-195 (2020).

Peyron, C. et al. Neurons containing hypocretin (orexin) project to multiple neuronal systems. J. Neurosci. 18, 9996-10015 (1998).

REINERT, H. L. H. A. P. B. MEMBRANE PROPERTIES OF HISTAMINERGIC TUBEROMAMMILLARY NEURONES OF THE RAT HYPOTHALAMUS IN VITRO. (1988).

Sánchez-Aguilera, A., Monedero, G., Colino, A. \& Vicente-Torres, M. Á. Development of action potential waveform in hippocampal CA1 pyramidal neurons. Neuroscience 442, 151-167 (2020).

Spigelman, I., Zhang, L. \& Carlen, P. L. Patch-clamp study of postnatal development of CA1 neurons in rat hippocampal slices: Membrane excitability and K+ currents. J. Neurophysiol. 68, 55-69 (1992).

Yamanaka, A. et al. Orexins activate histaminergic neurons via the orexin 2 receptor. Biochem. Biophys. Res. Commun. 290, 1237-1245 (2002).

Zhou, F. M. \& Hablitz, J. J. Postnatal development of membrane properties of layer I neurons in rat neocortex. J. Neurosci. 16, 1131-1139 (1996) 


\section{Figure Legends}

Figure 1. Conditional inactivation of the Orexin/Hypocretin Receptor 2 (OxR2/HcrtR2) gene in Dopamine (DA) neurons.

(a) Schematic representation of the gene targeting strategy. HcrtR2 is located on chromosome 9 and has 8 exons. The $5^{\prime}$ loxP site was inserted in the 5'untranslated region (downstream of TSS and upstream of initiation codon) in Exon 1. The 3'loxP was inserted in Intron 1. The Cre recombinase excises genomic DNA comprising the coding sequences for 74 aa, thus deleting the coding capacity for OXR2 signal peptide, N-terminal extracellular domain, and almost entire first transmembrane region (TM1), in Dat-ires-Cre-expressing dopaminergic neurons (see Supplementary Fig. 2 for Dat-ires-Cre penetrance in dopamine neurons). Cre-mediated recombination results in the replacement of the OxR2/Hcrtr2 open reading frame with the one of a promoterless Gfp, preceded by a Kozak sequence, and followed by a polyadenylation signal (pA). As a result, GFP is expressed under the endogenous HcrtR2 gene promoter within cells having undergone Cre recombination, and inactivated HcrtR2.

(b) Evidence of tissue-specific genomic recombination. Genomic DNA isolated from various tissues of OxR2 ${ }^{\text {Dat-CKO }}$ and OxR2 ${ }^{\text {Dat- }}$

${ }^{C T R}$ mice was subject to PCR. Unrecombined HcrtR2 floxed allele diagnostic band (Flox, 2,145 bp) was observed in cortex, TMN, VTA and ear from CTR2 and CKO 2mice, while the knockout (KO) diagnostic band (KO; 792 bp) was only observed in the VTA of CKO2 mice. The $792 \mathrm{bp}$ band was fully sequenced, confirming exact genomic recombination at the nucleotide level $(n=2)$.

(c-d) GFP immunostaining demonstrates the penetrance and specificity of Hcrtr2 Cre/loxP recombination in midbrain DA cells. Distribution of neurons having undergone Dat-ires-Cre-mediated HcrtR2 (Left) gene disruption, and replacement of OxR2 open reading frame with the one of GFP, in the ventral midbrain. Representative photomicrographs depict TH colocalization with GFP in OxR2 ${ }^{\text {Dat-CKO }}$ (Left) but not OxR2 $2^{\text {Dat-CTR }}$ (Right) mice. $87.2 \pm 1.5 \%$ of TH positive neurons expressing Dat co-express GFP in OxR2 ${ }^{\text {Dat-CKO }}$ mice $(n=2)$. PBP, parabrachial pigmented nucleus of the VTA; PN, paranigral nucleus of the VTA; SNc, substantia nigra pars compacta; VTA, ventral tegmented area. Coronal $20 \mu \mathrm{m}$ brain sections at approximately Bregma value $-3.08 \mathrm{~mm}$. Scale bar: $100 \mu \mathrm{m}$ for low magnification; $20 \mu \mathrm{m}$ for high magnification.

(e) Electrophysiological demonstration that HcrtR2 Cre/lox recombination inactivate OxR2s. (Top) Spontaneous voltage oscillations recorded from putative histaminergic neurons in the hypothalamic TMN of C57BL6/J, OxR2 flox/flox , or OxR2 $2^{\Delta / \Delta}$ mice. Cells were held at $-50 \mathrm{mV}$ in current-clamp. Voltage traces represent 5 minutes continuous recording, before, during (red line), and after OXB-AL $200 \mathrm{nM}$ application. OXB-AL triggered a long train of approximately $2 \mathrm{~Hz}$ APs in neurons from both $C 57 B L 6 / J$ and $O X R 2^{f l o x / f l o x}$ mice but failed to do so in cells from $O \times R 2^{\Delta / \Delta}$ mice. (Bottom) Percentage of neurons responding to

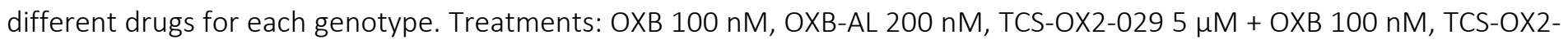
$02910 \mu \mathrm{M}+$ OXB $100 \mathrm{nM}$, TCS-OX2-029 $10 \mu \mathrm{M}+$ OXB-AL $200 \mathrm{nM}$. Total number of neurons, respectively: C57BL6/J 19, 17,

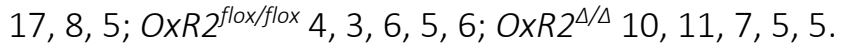

\section{Figure 2. Loss of Orexin-to-Dopamine neuron connectivity via OxR1 or OxR2 differentially affects wakefulness ECoG spectral profile.}

(a) Average ECoG spectral profiles of wakefulness in baseline for OxR1Dat, OxR2Dat and OxR12Dat CKO and respective CTR littermate mice (CKO1 and CTR1, CKO2 and CTR2, CKO12 and CTR12), analyzed from $0.75 \mathrm{~Hz}$ to $80 \mathrm{~Hz}$. CKO mice are indicated by black curves; CTR littermates are indicated by grey curves. Power density values (\%) are expressed as percentage of an average total ECoG power density reference value calculated across all states and frequencies and corrected for stateamount (according to Franken et al., 1998, see Methods). Note the non-linear ordinate Y-axes. Inset panels magnify spectra across $0.75-15 \mathrm{~Hz}$ with a linear Y-axis. OxR2 Dat-CKO mice show decreased delta but increase theta $(6.5-10 \mathrm{~Hz})$ activity compared to $O x R 2^{\text {Dat-CTR }}$ mice. Red lines indicate significant differences between genotypes (two-way ANOVA with Bonferroni multiple comparison test, $p<0.05)$. 
(b) Heatmap time $X$ frequency $x$ power representations of ECoG signals during wakefulness across 3 days of continuous recordings, consisting of $48 \mathrm{~h}$ baseline, a $6 \mathrm{~h}$ sleep deprivation (SD) initiated at ZTO of the $3^{\text {rd }}$ day, and $18 \mathrm{~h}$ of recovery period. Depicted are data for OxR1Dat, OxR2Dat and OxR12Dat CKO mice (CKO1, CKO2, and CKO12, respectively). The left heatmaps correspond to wakefulness of CKO mice, where color coded is the average ECoG power in each frequency bin $(0.25 \mathrm{~Hz}$ resolution) during a segment of wakefulness, normalized to the average power in the same frequency bin during the waking state of the last $4 \mathrm{~h}$ of the baseline light phase (ZT8-12). A power density value of $100 \%$ (no spectral differences relative to baseline) is color-coded in blue and warmer colors represent progressively relative higher power density values). The right heatmaps represent the differential dynamics of the waking ECoG of CKO and CTR mice (CKO-CTR). Shown are time $X$ frequency representations of CKO mice values after subtraction from heatmaps of their respective control littermate group. A power density difference of 0 (no change between CKO and CTR is color-coded in green (see color scales adjacent to heatmaps).

(c) Total Theta, Beta, Theta/Beta ratio and Fast-gamma ECoG power expressed during wakefulness of Baseline light (L), Baseline dark (D) phase, during SD and Recovery D phase in mouse groups as indicated.

(c) Timecourse of Theta, Beta and Fast-gamma ECoG power density during wakefulness of mice inactivated in OxR1, OxR2, or both in dopaminergic neurons. ECoG power values are shown during Baseline (2 averaged baseline days), SD, and 18h Recovery, expressed relative to their average value across the last $6 \mathrm{~h}$ of the baseline light phase.

Stars above the curves indicate significant differences between genotypes (two-way ANOVA, followed by Bonferroni multicomparison test, $p<0.05$; Theta $(7-11 \mathrm{~Hz})$ : OxR2Dat, baseline: genotype: $\mathrm{F}=33.896, p<0.001$; genotype $\mathrm{X}$ time interaction: $\mathrm{F}=$ 2.159, $p=0.005$; SD: genotype: $F=84.493, p<0.001$; genotype $X$ time interaction: $F=1.896, p=0.008 ;$ OxR12Dat SD: genotype: $\mathrm{F}=10.676, p<0.001) ;$ Beta $(15-30 \mathrm{~Hz}):$ OxR12Dat SD: genotype: $\mathrm{F}=23.300, p<0.001$; Fast-gamma $(52.5-80 \mathrm{~Hz}):$ OxR2Dat, baseline: genotype: $\mathrm{F}=31.172, p<0.001$; genotype $\mathrm{X}$ time interaction: $\mathrm{F}=1.693, p=0.043$; SD: genotype: $\mathrm{F}=73.561, p<0.001$; genotype $X$ time interaction: $F=2.085, p=0.003$; OxR12Dat, baseline: genotype: $F=6.551, p=0.011$; SD: genotype: $F=5.922$,

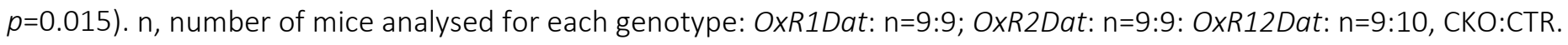

Figure 3. Disruption of OxR2 in DA neurons causes a prominent increase in ECoG theta and time spent in an active waking state, or theta-dominated wakefulness (TDW), uncoupled from locomotion.

(a) Histograms depict the total amount of theta-dominated wakefulness (TDW) during the $12 \mathrm{~h}$ baseline dark phase, 6-h SD, and $12 \mathrm{~h}$ recovery dark phase, for OxR1Dat, OxR2Dat and OxR12Dat CKO mice and their respective control littermates. Values are normalized to values of the respective control group. Stars indicate significant differences between genotypes, assessed by independent two-tailed student's $t$-test, $p<0.05$.

(b) Timecourses of time spent in total wakefulness (W) and TDW, TDW/W ratio, and locomotor activity in OxR2 ${ }^{\text {Dat-CKO }}$ and $O \times R 2^{\text {Dat-CTR }}$ mice. Wakefulness of $O \times R 2^{\text {Dat-CKO }}(\mathrm{CKO} 2)$ mice is profoundly enriched in an 'active' or theta-rich substate of wakefulness which is uncoupled to locomotor activity. This difference in wakefulness of $O \times R 2^{\text {Dat-CKO }}$ relative to $O \times R 2^{\text {Dat-CTR }}$ mice is seen both in spontaneous and enforced waking during SD. W and TDW values are hourly means $(\mathrm{min} / \mathrm{h}) \pm \mathrm{SEM}$. Mice were monitored by infrared and locomotor activity was quantified as counts $/ \mathrm{h} \pm \mathrm{SEM}$. Stars above the curves indicate significant differences between the 2 genotypes (two-way ANOVA, $W$ in baseline: genotype: $F=52.804, p<0.001$, genotype $X$ time interaction: $F=2.445, p<0.001$, during SD: $F=97.222, p<0.001$, followed by Bonferroni multi-comparison test, $p<0.05$; TDW/W ratio in baseline: genotype: $F=127.572 p<0.001$, during SD: $F=133.609, p<0.001$, genotype $X$ time interaction: $F=$ 133.609, $p=0.03$, followed by Bonferroni multi-comparison test, $p<0.05)$.

(c) Mean number (Top) and duration (Bottom) of TDW episodes during baseline dark (D) phase, SD, and the recovery dark phase for OxR2DatCKO (CKO2) and OxR2DatCTR (CTR2) mice. 
(d) OxR2 $2^{\text {Dat-CKO }}$ mice exhibit longer TDW episodes than OxR2 ${ }^{\text {Dat-CTR }}$ mice. Number of waking and TDW bouts of the indicated duration (4s to 1024s) during $48 \mathrm{~h}$ baseline recording. Percent of time in total waking (Top) or TDW (Bottom) that was spent in bouts of the indicated duration is shown. CKO2 and CTR2 mice did not differ in the distribution of total-waking bouts. Bouts spent in TDW state were however differently distributed in CKO2 and CTR2 mice, both for bout number and relative contribution. CKO2 mice spent less \% of TDW time in, and showed a lesser number of, TDW bouts of $\leq 64 \mathrm{~s}$, while they spent more relative TDW time in, and expressed a higher number of, TDW bouts lasting 17 min (1024s).

(2-way ANOVA for genotype and numbers of TDW bouts of each duration showed a genotype effect $(F=13.880, p<0.001)$ and a significant genotype $X$ bout duration interaction $(F=4.646, p<0.001)$. 2-way ANOVA for genotype and relative time spent in TDW bouts of various durations showed only a genotype effect ( $F=16.925, p<0.001)$.) Stars indicate significant genotype differences (independent two-tailed student's $t$-test, $p<0.05$ ).

(e) TDW spectral profiles during baseline for OxR1Dat, OxR2Dat and OxR12Dat CKO and their respective controls are shown from 0.75 to $80 \mathrm{~Hz}$. The inset panels show magnification of TDW spectral profiles across 0.75 to $15 \mathrm{~Hz}$. Significant differences are marked in red (two-way ANOVA, followed by Bonferroni test, $\mathrm{p}<0.05$ ).

(f) Wakefulness oscillatory dynamics within specific frequency bands: Delta (1-4 Hz), Inter-Delta/Theta (4-7 Hz), Theta (7-11 $\mathrm{Hz}$ ) and Fast-gamma (52.5-80 Hz). ECoG power values are shown during wakefulness of (averaged) 2 baseline days, 6-h SD and $18 \mathrm{~h}$ of recovery, relative to their average value during wakefulness of the last $6 \mathrm{~h}$ of baseline light phase. Stars indicate significant genotype differences (two-way ANOVA, followed by post-hoc Bonferroni test, Delta (1-4 Hz): baseline: genotype: $\mathrm{F}=39.615, p<0.001$; Inter-Delta/Theta $(4-7 \mathrm{~Hz})$ : baseline: genotype: $\mathrm{F}=20.667, p<0.001$; SD: genotype: $\mathrm{F}=17.107, p<0.001$; Theta $(7-11 \mathrm{~Hz}$ ) power in baseline wake: genotype: $\mathrm{F}=33.896, p<0.001$; interaction: $\mathrm{F}=2.159, p=0.005$; SD: genotype: $\mathrm{F}=84.493, p<0.001$; interaction: $\mathrm{F}=1.896, p=0.008$; Fast-gamma $(52.5-80 \mathrm{~Hz})$ power in baseline wake: genotype: $\mathrm{F}=31.172$, $p<0.001$; interaction: $\mathrm{F}=1.693, p=0.043$; $\mathrm{SD}$ : genotype: $\mathrm{F}=73.561, p<0.001$; interaction: $\mathrm{F}=2.085, p=0.003$ ).

(g) TDW spectral profiles in enforced wakefulness during the sleep deprivation for OxR1Dat, OxR2Dat and OxR12Dat CKO and their respective controls.

OxR1Dat: $\mathrm{n}=9: 9 ;$ OxR2Dat: $\mathrm{n=9:9:} \mathrm{OxR12Dat:} \mathrm{n=9:10,} \mathrm{CKO:CTR.}$

Figure 4: OX2R loss increases, but loss of OX1R and OX2R in dopaminergic neurons decreases, waking theta power of mice transferred into a novel environment. Theta and Fast-gamma activity are enhanced in wakefulness induced by a foreign or enriched environment. Ox1RDatCKO and CTR, and Ox2RDat CKO and CTR mice were provided a preferred nesting material at dark onset (ZT12) of Day 6 of a 9-day experimental timeline (a). On Day 9, mice were removed from the nest they had built and transferred to a fresh cage at ZT3, i.e., during an otherwise major sleep period.

(a) ECoG spectral profiles of novelty-induced wakefulness as it is expressed from environmental transfer to sleep onset are depicted. Insets show magnification of waking spectra at frequencies $<15 \mathrm{~Hz}$. OxR2Dat-CKO mice exhibit higher theta power relative to controls across the 7.75-9.75 Hz window, while OxR1Dat-CKO tend to show the opposite, and OxR1\&2Dat-CKO mice exhibit significant decreased theta activity across $8.5-10 \mathrm{~Hz}$ relative to controls. Red lines indicate significant differences between genotypes (Two-way ANOVA, followed by Bonferroni test, $P<0.05$ ).

(b-c) Time $X$ frequency heatmap representations of the spectral dynamics of wakefulness expressed from environmental transfer to sleep onset ( $b$, an approximately 2-h time period), or from Nest material addition at dark onset (ZT12) until the next light onset (ZTO) (c, a 12-hour time window) in OxR1Dat, and OxR2Dat CKO and CTR mice. For each mouse line and behavioral context, left heatmaps depict CKO mice wakefulness, with colors encoding the average ECoG power value for each $0.25 \mathrm{~Hz}$ frequency bin and time interval normalized to its average value during waking of the last $4 \mathrm{~h}$ of the baseline 
light phase (ZT8-12). Right heatmaps represent the differential dynamics of the waking ECoG of CKO and CTR mice (CKOCTR). (See Fig. 2 b). OxR1Dat ( $n=7: 9)$. OxR2Dat $(n=8: 7)$. OxR12Dat $(n=7: 8)(n=C K O: C T R)$.

\section{Figure 5. Loss of OxR2 in DA neurons consolidates REM sleep and enhances Theta.}

(a) Baseline REM sleep spectra of OxR1Dat, OxR2Dat and OxR12Dat CKO and respective CTR littermate mice (CKO1 and CTR1, CKO2 and CTR2, CKO12 and CTR12). Power density values (\%) are expressed as percentage of an average total ECoG power density reference value (as used in Figure 2a). OxR2 ${ }^{\text {Dat-CKO }}$ mice show enhanced theta activity compared to OxR2 $2^{\text {Dat-CTR }}$ mice, while REMS of OXR12 ${ }^{\text {Dat-CKO }}$ mice show reduced theta popwer compared to OXR12 ${ }^{\text {Dat-CKO }}$ mice. Red lines indicate significant differences between genotypes (two-way ANOVA with Bonferroni multiple comparison test, $p<0.05$ ). OxR1Dat: $\mathrm{n}=9: 9$; OxR2Dat: n=9:9: OxR12Dat: n=9:10, CKO:CTR. (b) Time-course of REMS in OxR2 ${ }^{\text {Dat-CKO }}$ and OxR2 ${ }^{\text {Dat-CTR }}$ mice. Shown are hourly means $\pm S E M$ in $\mathrm{min} / \mathrm{h}$. Asterisks indicate time points with significant genotype differences (two-way ANOVA, baseline: genotype effect: $\mathrm{F}=15.516, p<0.001$, followed by post-hoc Bonferroni $t$ - test, $p<0.05$ ). OxR2Dat: $\mathrm{n}=9: 9$ (CKO:CTR).

(c) Total time spent in REMS during baseline light and dark phase in $O x R 2^{\text {Dat-CKO }}$ and $O x R 2^{\text {Dat-CTR }}$ mice. Statistical difference was assessed by independent $t$-test, $\mathrm{P}<0.05$.

(d) Average REMS bout number and duration in baseline in $O \times R 2^{\text {Dat-CKO }}$ and $O \times R 2^{\text {Dat-CTR }}$ mice.

(e) Distribution of REMS bout durations in baseline recording of $O x R 2^{\text {Dat-CKO }}$ and $O \times R 2^{\text {Dat-CTR }}$ mice. Time spent in different REMS bout durations are shown over nine consecutive bout lengths (4, 8-12, 16-28, 32-60, 64-124, 128-252, 256-508, 512$1020,>1024$ s). Only the lower bin limit is indicated. The relative contribution of bouts is expressed as a percentage of the total amount of REMS and genotypes. Stars indicate bins with significant differences between genotypes (two-way ANOVA for genotype and duration, $p<0.05$, post-hoc Bonferroni test, $p<0.05)$.

(f) REMS total Theta and Fast-Gamma power in D, L across BL, SD, Recovery

(g) OxR2DatCKO mice show a lesser and slower REMS rebound following sleep deprivation (SD) relative to controls. Timecourse of REMS loss and gain during and after sleep deprivation. Left, SD-Baseline REMS time differences are calculated at 1 - $\mathrm{h}$ intervals $(\mathrm{min} / \mathrm{h}$ ) for the $24 \mathrm{~h}$ recordings comprising $6 \mathrm{~h}$ SD and $18 \mathrm{~h}$ of recovery, expressed as accumulated difference with baseline. Values are mean \pm SEM. Right: gain is calculated at 1-h interval for the $18 \mathrm{~h}$ recovery, starting at the end of SD (ZT6). Stars above the curves indicate significant differences between genotypes (delay, CKO2 vs. CTR2, independent t-test $\mathrm{p}=0.0435$, unpaired student's $t$-test). OxR2Dat: $n=9: 9$ (CKO:CTR).

Figure 6. Destruction of orexin2 signaling in VTA dopaminergic neurons enhances theta-gamma phase-amplitude coupling during wakefulness and REM sleep. (a) Representative dynamics of theta-gamma coupling across vigilance states in OxR1Dat and OxR2Dat mice. Red traces on top show the modulation index (MI) between theta $(7-11 \mathrm{~Hz})$ and fast-gamma (52.5-80 $\mathrm{Hz}$ ) oscillations, calculated using a moving window of 4s. Heatmaps color-code the corresponding phase-amplitude histograms of $4 \mathrm{~s}$ windows. Hypnogram is depicted below. (b) Heatmaps show the comodulogram analysis of phaseamplitude coupling during REM sleep (12h baseline light). CKO1 mice show similar levels of theta-gamma coupling compared to their controls, while CKO2 mice has enhanced coupling. Left panels indicate the phase-amplitude histograms. (c) Pair-wise statistical comparisons between theta-gamma coupling values of KO and CTR mice for wakefulness and TDW during baseline dark phase and REM sleep during baseline light phase. Theta-gamma coupling significantly increased in CKO2 mice compared to their controls during all states. Data derive from $n$ mice in each group as indicated. Two-way ANOVA for OxR1Dat: n=9:9; OxR2Dat: $\mathrm{n}=9: 9$, CKO:CTR. 


\section{Supplementary Figure Legends}

SFig. 1. Conditional inactivation of $O X R 1$ in dopaminergic neurons: $\mathrm{TH}^{+}$cells in the ventral midbrain of $O x R 1^{\text {Dat-CKO }}$ (CKO) mice express GFP in place of OXR1. (a) Schematic representation of homologous recombination between the OxR1 genomic locus and the targeting vector. Two loxP sites (red triangles) were inserted to flank the first coding exon (exon 3) and exon 4, which together encode the $\mathrm{N}$-terminal first 126 aa of OXR1. The neomycin resistance gene used for selection in embryonic stem cells (neo; flanked by two FRT sites shown as orange triangles) was deleted using the FLP recombinase, creating the $O x R 1^{\text {flox }}$ allele. In Dat-ires-Cre-expressing cells, CRE excises the inter-loxP fragment (1.1 kb), creating the OxR ${ }^{+/ K O-G f p}$ allele. In the latter, the translation start site (ATG) of OxR1 is replaced by the ATG of the Gfp cassette. Thus Gfp expression (green rectangle) becomes regulated by the OXR1 promoter. Gfp reading frame is followed by a polyadenylation site (pA) to terminate transcription and prevent downstream expression. Boxes depict exons (dark, protein-coding sequences; white, untranslated regions). TSS, transcription start site. PA, polyA signal. (b-f) Representative confocal images of the ventral tegmental area (VTA, b-d) of mice of the indicated genotypes. DA and NA neurons are identified using a tyrosine hydroxylase antibody ( $\mathrm{TH}+$ ). (b) In the VTA of OxR1 ${ }^{\text {Dat-CKO }}$ mice, DA ( $\mathrm{TH}+$ ) cells are seen to co-express CRE. Dat-driven Cre mediates DAselective loxP site recombination and consequent replacement of $O x R 1$ coding sequences with Gfp, as seen by TH-GFP coimmunoreactivity in cells of $O X R 1^{\text {Dat-CKO }}$ (c, left), but not $O X R 1^{\text {Dat-CTR }}$ (c, right) mice. Consistently VTA-TH+ cells of OXR1 $1^{\text {Dat-CTR }}$ mice express OXR1 immunoreactivity (d, right), while in Dat-CKO1 littermates they do not (d, left). The scale bar represents $100 \mathrm{um}$ in large field images a-d, $50 \mathrm{um}$ in e (TH and GFP), and $20 \mathrm{um}$ in small field images. All images were taken at 40X magnification, except the images of LC (GFP/TH) were taken at 20x. OxR1flox is Hcrtr1tm1.1Ava (MGI:5637400), and OxR1KO-Gfp is Hcrtr1tm1.2Ava (MGI: 5637401) (www.informatics.jax.org/reference/j:226158 50).

SFig. 2. Penetrance and specificity of Cre expression by the Dat-Cre allele in ventral midbrain dopamine neurons of $O x R 2^{\text {Dat-CKO }}$ (CKO) mice. Tyrosine Hydroxylase (TH)-immunoreactivity (red) identifies dopamine neurons. $88.4 \pm 1.1$ of $\mathrm{TH}$ immunoreactive (red) cells in the ventral midbrain of $O x R 2^{\text {Dat-CKO }}$ mice $(n=4)$ express CRE (green) immunoreactivity.

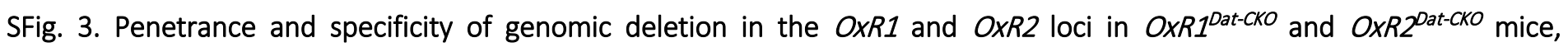
respectively.

SFig. 4. Identification (a-b) and electrophysiological features (c-f) of putative histaminergic neurons in the hypothalamic TMN. (a) Putative histaminergic neurons were characterized by testing the firing response to consecutive depolarizing current steps, lasting $500 \mathrm{~ms}$. The responses to the -100 pA and the 100 pA steps for a representative neuron show the classical hyperpolarization-triggered sag, attributed to $I_{h}$, and the low-frequency late firing. (b) Relation between injected current and firing frequency for putative histaminergic neurons $\left(25,16,20\right.$ cells from C57BL/6J, OxR $2^{\text {flox/flox }}$ and $O x R 2^{\Delta / \Delta}$ mice, respectively). Data points are average firing frequencies calculated from a coherent ensemble of neurons and plotted as a function of injected current. Passive membrane properties are coherent with those reported by Haas and Reiner (1988) (Suppl. Table 1). AP features of C57BL/6J and $O \times 2 R^{\text {floxfflox }}$ neurons are also in line with classical evidence (c-f), but OxR2 ${ }^{\Delta / \Delta}$ cells display a reduced mean and more variable AP amplitude $(c, p$-value $=0.01097)$, an increased mean and more variable AP half-width $(\mathrm{d}, p$-value $=0.01294)$, a reduced AP rise slope $(e, p$-value $=0.01026)$ and an increased AP decay slope $(f, p$-value $=0.0431)$. These small changes lead to slightly slower AP dynamics and suggest a partly reduced excitability of histaminergic cells in $O \times R 2^{\Delta / \Delta}$ mice, that could be related to a possible role of OxR2 in the developmental specification of the histaminergic neuronal phenotype. 
SFig5. Timecourses and total amounts of W, SWS and REMS in OxR1, OxR2 and OxR12Dat CKO and CTR mice. (a) Hourly amounts of each state are given in minutes across the Baseline-SD-Recovery timeline. Values are hourly means \pm SEM in $\mathrm{min} / \mathrm{h}$. Asterisks indicate time points with significant differences (2 way-ANOVA for time and genotype followed by Bonferroni multiple comparison test. (W: OxR1Dat, baseline: genotype: $\mathrm{F}=5.230, p=0.023$; SD: genotype: $\mathrm{F}=6.944, p=0.009$, OxR2Dat, baseline: genotype: $F=52.804, p<0.001$, genotypeXtime interaction: $F=2.445, p<0.001$, during SD: $F=97.222$, $p<0.001$. SWS: OxR1Dat, baseline: genotype: $\mathrm{F}=6.237, p=0.013$; SD-day: genotype: $\mathrm{F}=6.924, p=0.009$; OxR2Dat SD-day: genotype: $\mathrm{F}=5.109, p=0.024 ;$ OxR12Dat, baseline: genotype: $\mathrm{F}=11.812, p<0.001$. REMS : OxR1Dat, SD-day: genotype: $\mathrm{F}=$ 3.982, $p=0.047$; OxR2Dat, baseline: genotype: $\mathrm{F}=15.516, p<0.001)$. Triangles below the curves indicate hours at which values differed from baseline (grey: CTR; black: CKO, paired, two-tailed student's $t$-test, $p<0.05$ ). (b) Histograms depict total amount of W, SWS and REMS in baseline light and dark period, and over $24 \mathrm{~h}$ in the indicated mouse groups. Stars above the bars indicate significant differences between genotypes (independent $t$-test, $p<0.05$ ). OxR1Dat: $\mathrm{n}=9: 9 ;$ OxR2Dat: $\mathrm{n}=9: 9$ : OxR12Dat: $\mathrm{n}=9: 10$, CKO:CTR.

SFig6. State Spectra of $\mathrm{Dat}^{+/ \mathrm{Cre}}$ and $\mathrm{Dat^{+/+ }}$ littermates. ECoG power density spectra of W, SWS, and PS during baseline recording shown from $0.75 \mathrm{~Hz}$ to $15 \mathrm{~Hz}$ in $\mathrm{DAT}^{+/+}$and $\mathrm{DAT}^{+/ / \mathrm{Cre}}$ mice. All ECoG power density values are normalized by the average ECoG power density value of each animal calculated across all states and frequencies, and corrected for state-amount, and finally averaged on all animals. ECoG power density values are derived from discrete Fourier transform of $4 \mathrm{~s}$ time windows. Statistical difference was assessed by two-way ANOVA, $p<0.05$, followed by Tukey's test. When power was analyzed by frequency (W: $2.25 \mathrm{~Hz}-7.5 \mathrm{~Hz}$; SWS: $0.75 \mathrm{~Hz}-3 \mathrm{~Hz}$; REMS: $0.75 \mathrm{~Hz}-2.75 \mathrm{~Hz} ; 7.25 \mathrm{~Hz}-8.5 \mathrm{~Hz}$ ) showed significant differences between the 2 genotypes, $P<0.05$.

SFig7. Locomotor activity in OxR1Dat, OxR2Dat and OxR1\&2Dat CKO and CTR littermates. Mice were monitored by infrared and locomotor activity (counts/h) is plotted across time in baseline (0-24 h), $6 \mathrm{~h}$ sleep deprivation (24-30 h), and recovery (30-48 h). Values are hourly means \pm SEM. The grey areas indicate dark phase. The striped area indicates the $6 \mathrm{~h}$ SD. The

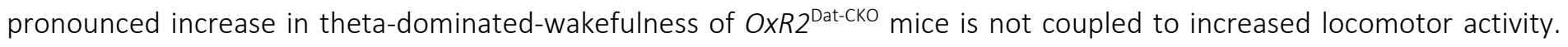
OxR1DatCKO mice showed higher activity during one timepoint in SD, but not during baseline or recovery. OxR12DatCKO showed higher activity during the first half of $B L$ dark phase, but not during SD or in recovery. Stars above the curves indicate significant differences between genotypes (2-way ANOVA, followed by post-hoc Bonferroni test, $p<0.05$; OxR1Dat, SD: genotype: $\mathrm{F}=6.792, p=0.009$; OxR1+2Dat, baseline: genotype: $\mathrm{F}=38.381 p<0.001$; interaction: $\mathrm{F}=2.646 ; p<0.001)$. By the end of the dark phase, the accumulation of locomotor activity reached $852.9 \pm 121$ counts $/ 12 \mathrm{~h}$ in OxR1+R2Dat-CKO vs. 481.2 \pm 52 counts $/ 12 \mathrm{~h}$ in controls ( $p=0.016$ by Mann-Whitney $U$ statistics). In $24 \mathrm{~h}$ of baseline, total locomotor activity reached $970.0 \pm 142$ counts/24 h in OxR1+R2Dat-CKO vs. $603.3 \pm 70$ counts/24 h in controls ( $p=0.04$ by Mann-Whitney U statistics). OxR1Dat: $\mathrm{n}=10: 9 ;$ OxR2Dat: $\mathrm{n}=8: 7:$ OxR1+2Dat: $\mathrm{n}=12: 12$, CKO:CTR. 
Table S1. Electrophysiological features of putative histaminergic neurons in the hypothalamic TMN.

A. Passive Membrane Properties

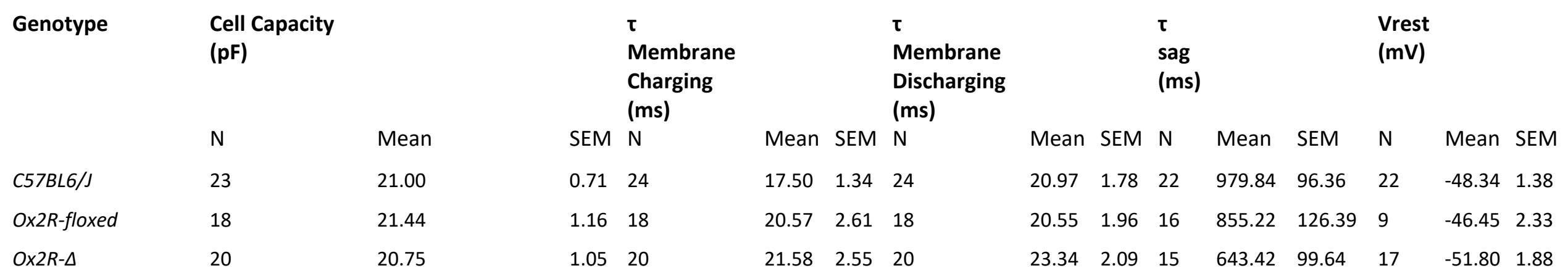

B. Action Potential Features

\begin{tabular}{|c|c|c|c|c|c|c|c|c|c|c|c|c|c|c|c|c|c|c|c|c|c|c|c|c|}
\hline Genotype & $\begin{array}{l}\text { AP } \\
\text { Amplitude } \\
\text { (mV) }\end{array}$ & & & $\begin{array}{l}\text { AHP } \\
(\mathrm{mV})\end{array}$ & & & $\begin{array}{l}\text { AP } \\
\text { half width } \\
\text { (ms) }\end{array}$ & & & $\begin{array}{l}\text { AP } \\
\text { rise slope } \\
(\mathrm{mV} / \mathrm{ms})\end{array}$ & & & $\begin{array}{l}\text { AP } \\
\text { decay } \\
\text { slope } \\
(\mathrm{mV} / \mathrm{ms})\end{array}$ & & & $\begin{array}{l}\text { AP } \\
\text { threshold } \\
\text { (mV) }\end{array}$ & & & $\begin{array}{l}\text { AP } \\
\text { triggering } \\
\text { slope } \\
\text { (mV/ms) }\end{array}$ & & & $\begin{array}{l}\text { 4th/1st } \\
\text { spike } \\
\text { interval }\end{array}$ & & \\
\hline & $\mathrm{N}$ & Mean & SEM & $\mathrm{N}$ & Mean & SEM & $\mathrm{N}$ & Mean & SEM & N & Mean & SEM & $\mathrm{N}$ & Mean & SEM & $\mathrm{N}$ & Mean & SEM & $\mathrm{N}$ & Mean & SEM & $\mathrm{N}$ & Mean & SEM \\
\hline C57BL6/J & 23 & 72.30 & 2.42 & 23 & -11.53 & 0.46 & 23 & 1.90 & 0.05 & 23 & 136.87 & 10.60 & 23 & -37.95 & 1.17 & 23 & -36.46 & 0.80 & 21 & 0.27 & 0.12 & 23 & 1.33 & 0.13 \\
\hline$O \times 2 R$-floxed & 16 & 67.35 & 2.58 & 16 & -10.28 & 0.46 & 16 & 2.10 & 0.12 & 16 & 112.54 & 8.24 & 16 & -34.26 & 1.99 & 16 & -38.89 & 1.28 & 16 & 0.23 & 0.04 & 15 & 1.18 & 0.10 \\
\hline$O \times 2 R-\Delta$ & 20 & 58.65 & 4.28 & 20 & -11.22 & 0.61 & 20 & 2.42 & 0.18 & 20 & 88.35 & 13.45 & 20 & -29.45 & 3.58 & 20 & -31.39 & 3.81 & 19 & 0.14 & 0.04 & 15 & 1.28 & 0.13 \\
\hline
\end{tabular}


Table S2. Comparisons between conditional knockout mice and their respective wild-type controls. W: wakefulness, SWS: slow wave sleep, SD: sleep

\begin{tabular}{|c|c|c|c|}
\hline & 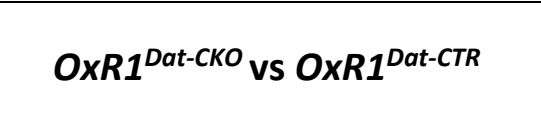 & $O \times R 2^{\text {Dat-CKO }}$ vs $O \times R 2^{\text {Dat-CTR }}$ & $\begin{array}{l}\text { OxR1+R2 } \\
\text { vs } O \times R 1+R 2^{\text {Dat-CTR }}\end{array}$ \\
\hline W light baseline & - & - & - \\
\hline W dark baseline & - & - & Increased \\
\hline SWS light baseline & - & - & - \\
\hline SWS dark baseline & - & - & Decreased \\
\hline REMS light baseline & - & Increased & - \\
\hline REMS dark baseline & - & - & - \\
\hline W light recovery & - & - & - \\
\hline W dark recovery & - & Increased in $1^{\text {st }}$ part & - \\
\hline SWS light recovery & - & - & - \\
\hline SWS dark recovery & - & Decreased in $1^{1 \mathrm{tt}}$ part & - \\
\hline REMS light recovery & - & - & - \\
\hline REMS dark recovery & - & Decreased in $1^{\text {st }}$ part & - \\
\hline REMS state stability & increased & increased & increased \\
\hline W ECoG in baseline & - & $\begin{array}{c}\text { Decreased in } 2.75-5.0 \mathrm{~Hz} \\
\text { Increased in } 6.5-10 \mathrm{~Hz}\end{array}$ & $\begin{array}{l}\text { Decreased in } 2.0-7.25 \mathrm{~Hz} \\
\text { Increased in } 8.5-9.75 \mathrm{~Hz}\end{array}$ \\
\hline SWS ECOG in baseline & - & & - \\
\hline REMS ECoG in BL & - & Increased 6.0-8.25 Hz & Decreased in $5.5-8.75 \mathrm{~Hz}$ \\
\hline W ECoG during SD & Increased in $9-10.5 \mathrm{~Hz}$ & $\begin{array}{l}\text { Decreased in } 2-6 \mathrm{~Hz} \\
\text { Increased in } 7-10.75 \mathrm{~Hz}\end{array}$ & - \\
\hline \multicolumn{4}{|l|}{$\begin{array}{l}\text { W ECoG after placing } \\
\text { nestlet }\end{array}$} \\
\hline W ECoG after CC & - & $\begin{array}{l}\text { Decreased in } 0.75-1.25 \mathrm{~Hz} \\
\text { Increased in } 7.75-9.75 \mathrm{~Hz}\end{array}$ & $\begin{array}{l}\text { Decreased } 1-1.75 \mathrm{~Hz} \text { and } \\
\quad 8.5-10 \mathrm{~Hz}\end{array}$ \\
\hline $\begin{array}{l}\text { SWS delta power } \\
\text { density after SD }\end{array}$ & $\begin{array}{l}\text { Increased in slow-delta and decreased in } \\
\text { fast-delta in } 1^{\text {st }} 30 \mathrm{~min} \text {. }\end{array}$ & $\begin{array}{l}\text { Decreased in slow-delta and increased in } \\
\text { fast-delta in } 1^{\text {st }} 30 \text { min. Increased in the } \\
\text { dark period }\end{array}$ & $\begin{array}{l}\text { Increased in the dark period of baseline } \\
\text { only }\end{array}$ \\
\hline
\end{tabular}

deprivation, CC: cage change. 
bioRxiv preprint doi: https://doi.org/10.1101/2022.01.30.478401; this version posted January 31, 2022. The copyright holder for this preprint (which was not certified by peer review) is the author/funder, who has granted bioRxiv a license to display the preprint in perpetuity. It is made available under aCC-BY-NC-ND 4.0 International license. 
bioRxiv preprint doi: https://doi.org/10.1101/2022.01.30.478401; this version posted January 31, 2022. The copyright holder for this preprint (which was not certified by peer review) is the author/funder, who has granted bioRxiv a license to display the preprint in perpetuity. It is made available under aCC-BY-NC-ND 4.0 International license.

Figure 1.

a
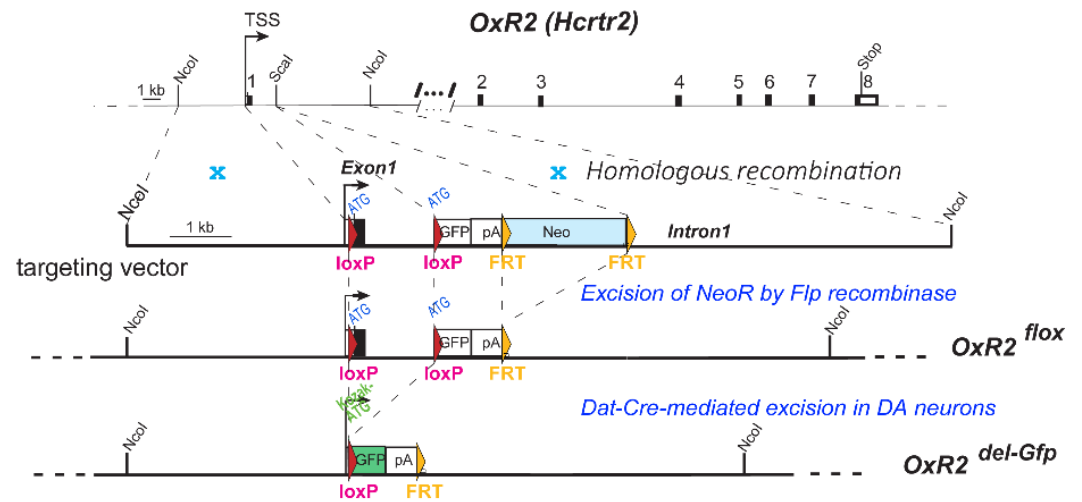

b
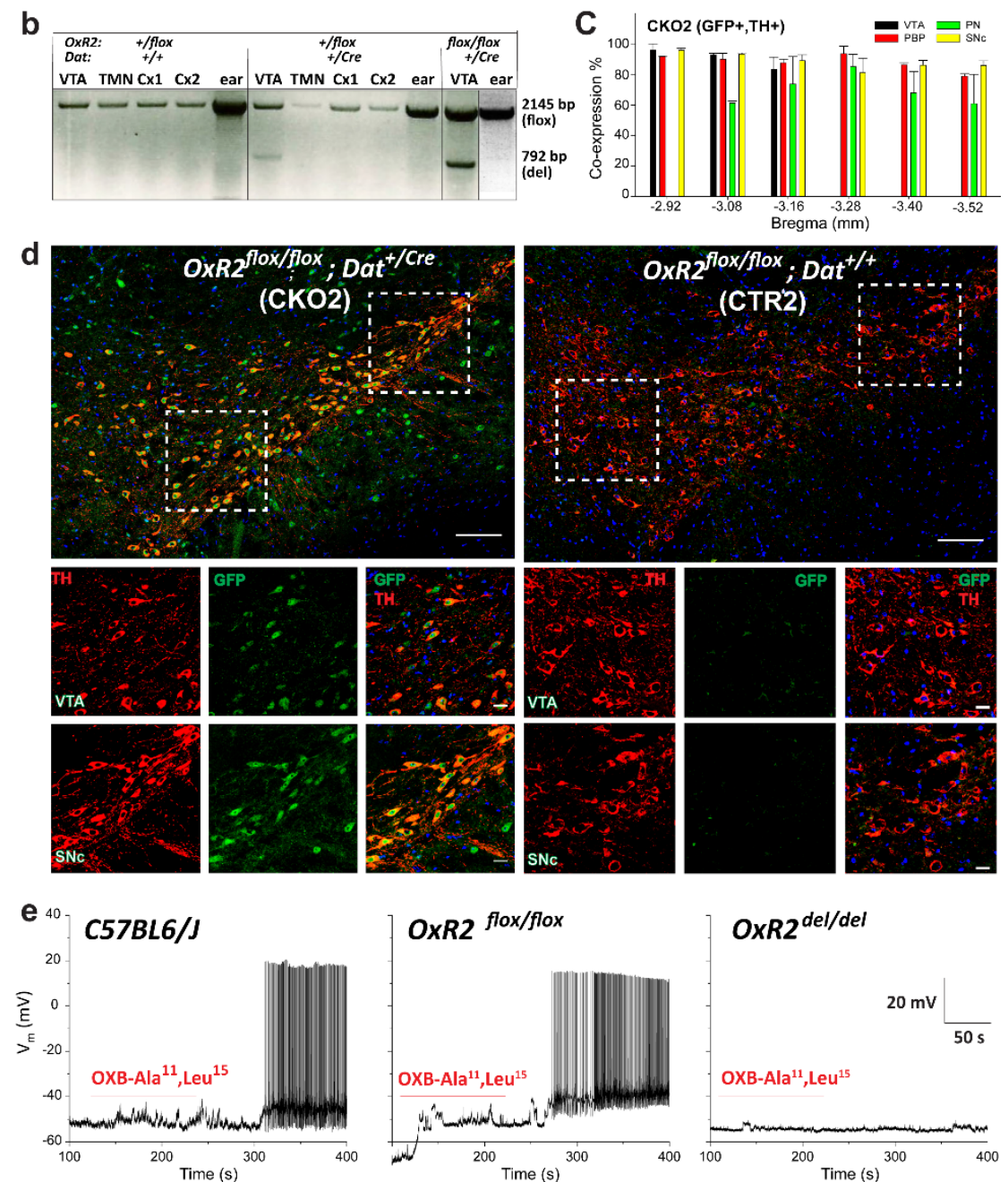

OxR2 flox/flox

OXR2 $2^{d e l / d e l}$
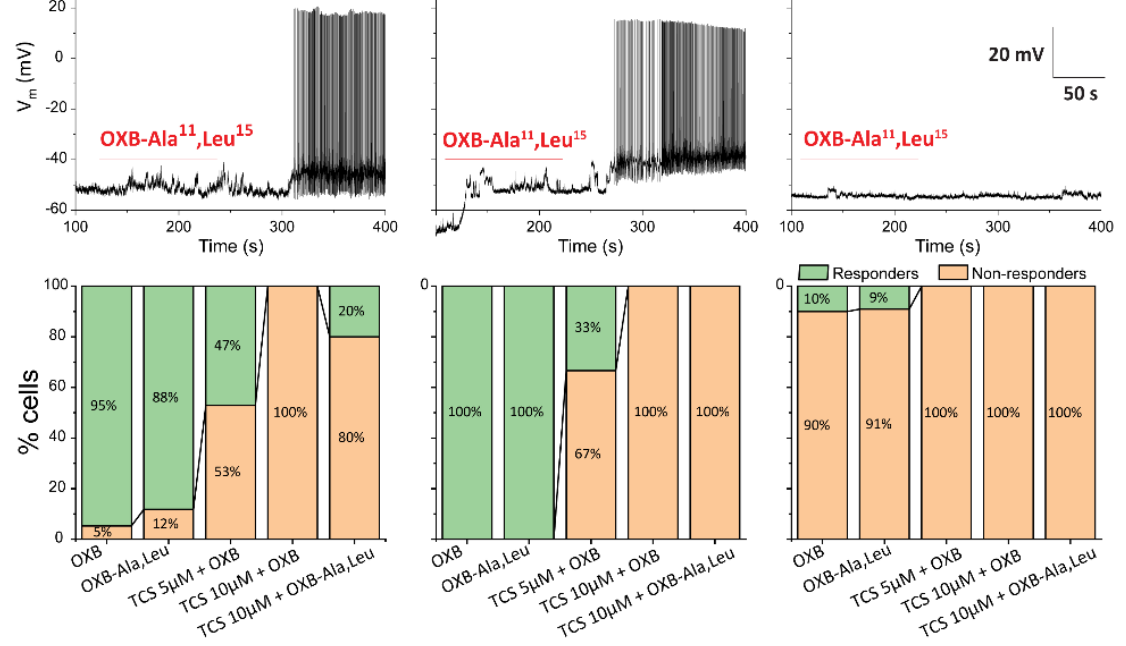
bioRxiv preprint doi: https://doi.org/10.1101/2022.01.30.478401; this version posted January 31, 2022. The copyright holder for this preprint (which was not certified by peer review) is the author/funder, who has granted bioRxiv a license to display the preprint in perpetuity. It is made available under aCC-BY-NC-ND 4.0 International license.

\section{Figure 2.}
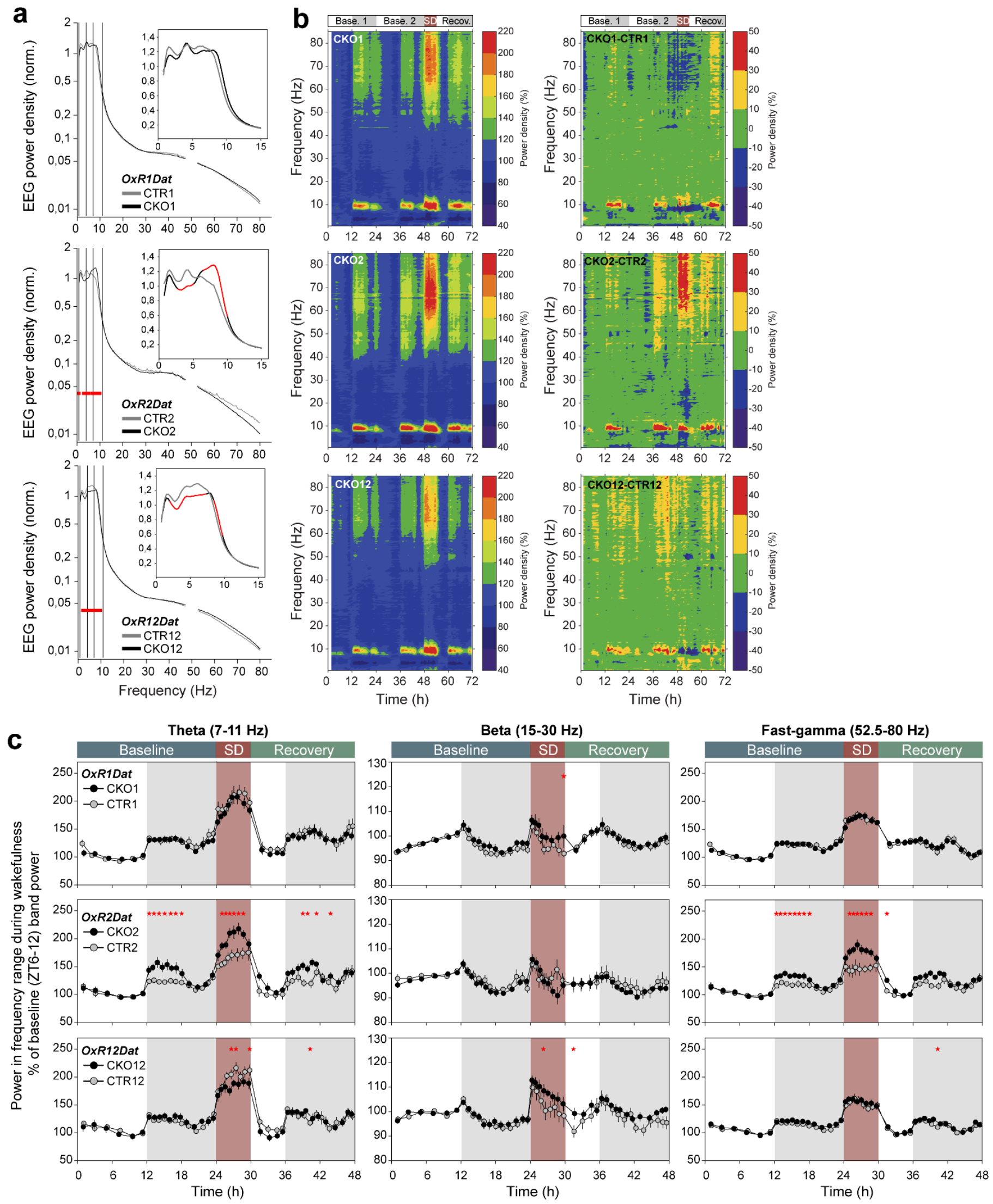
bioRxiv preprint doi: https://doi.org/10.1101/2022.0130.478401; this version posted January 31, 2022. The copyright holder for this preprint (which was not certified by peer review) is the author/funder, who has granted bioRxiv a license to display the preprint in perpetuity. It is made available under aCC-BY-NC-ND 4.0 International license.

Figure 3.
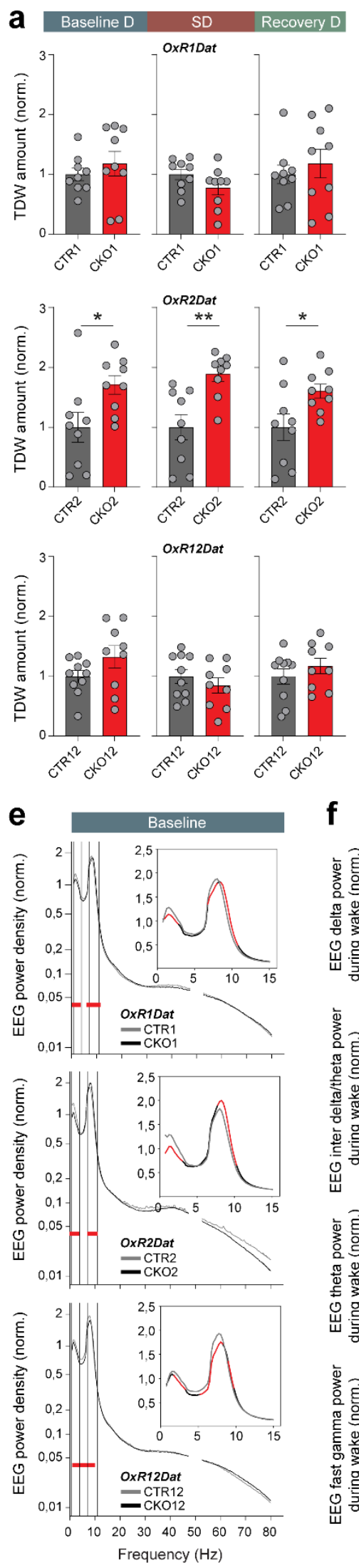

\section{f}

b
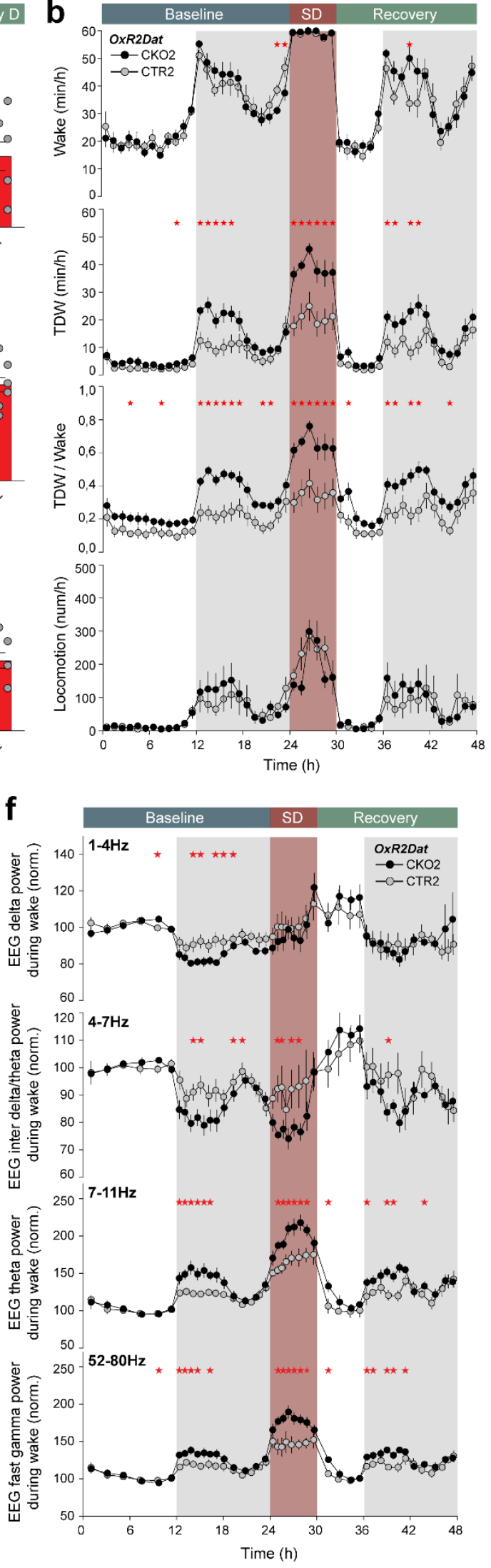

C
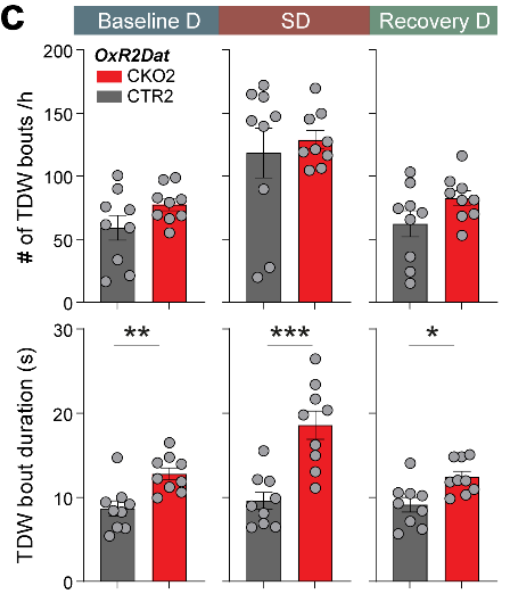

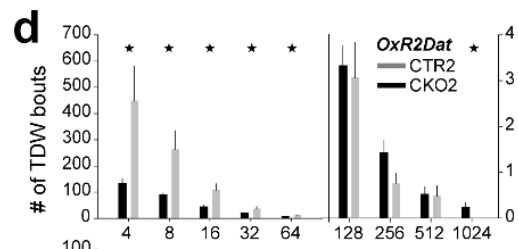
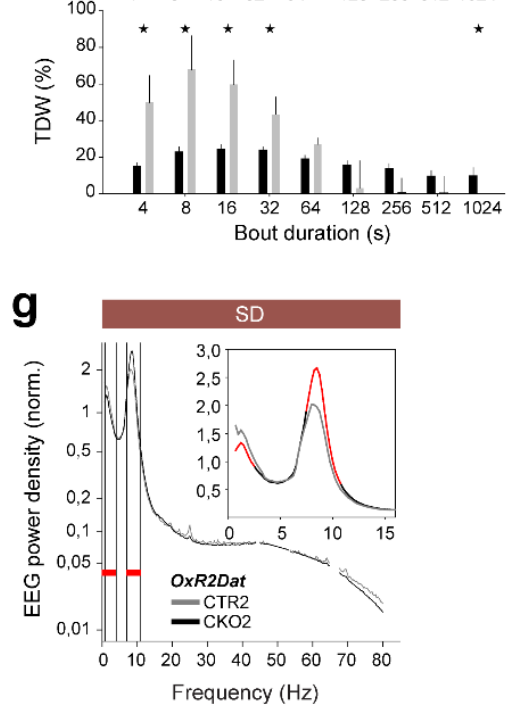
bioRxiv preprint doi: https://doi.org/10.1101/2022.01.30.478401; this version posted January 31,2022 . The copyright holder for this preprint (which was not certified by peer review) is the author/funder, who has granted bioRxiv a license to display the preprint in perpetuity. It is made available under aCC-BY-NC-ND 4.0 International license.

\section{Figure 4.}
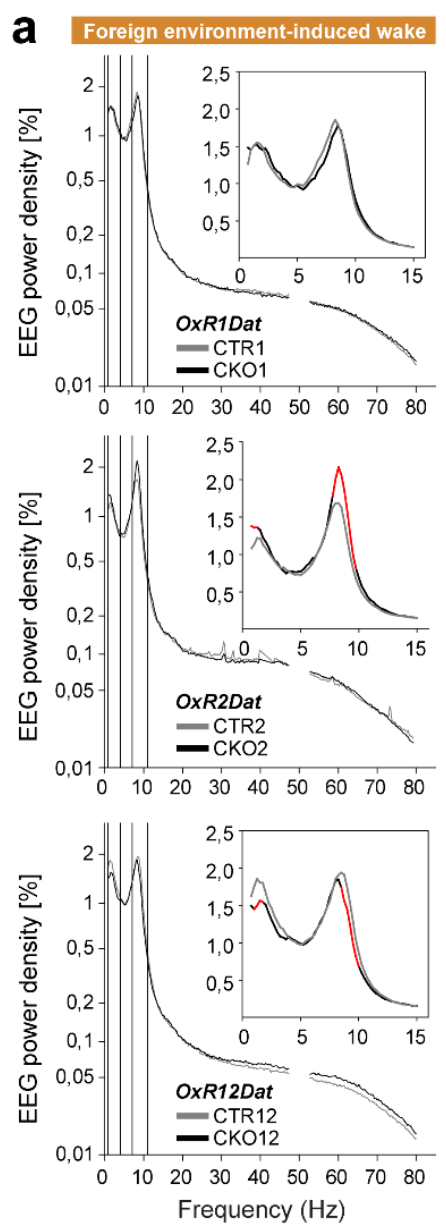
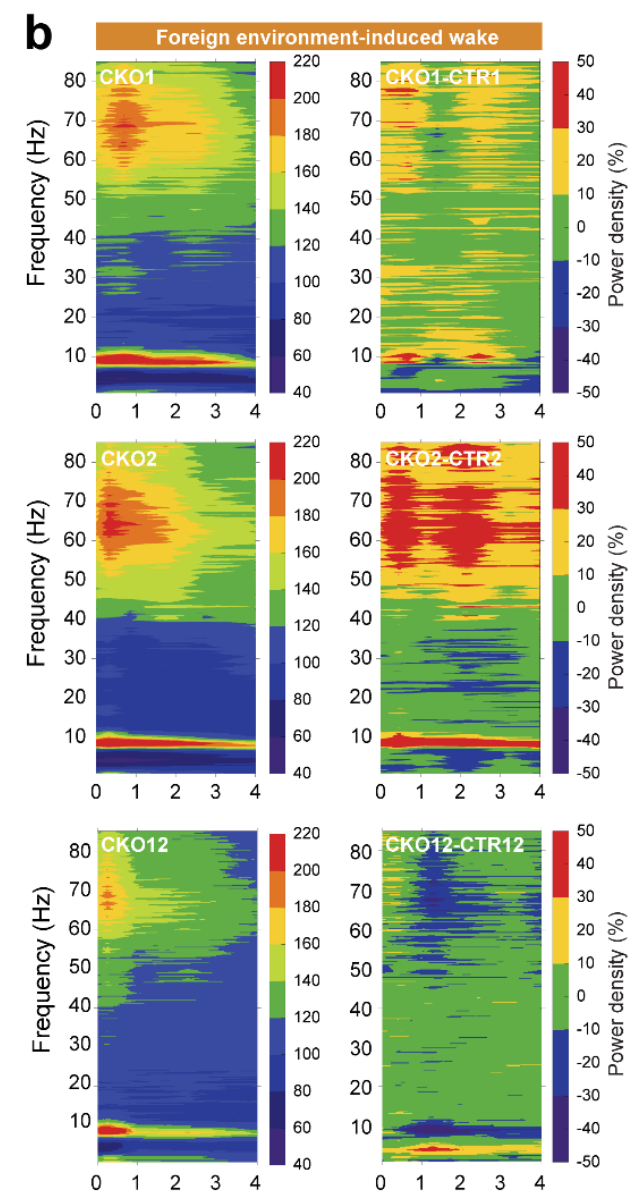

Time (h)

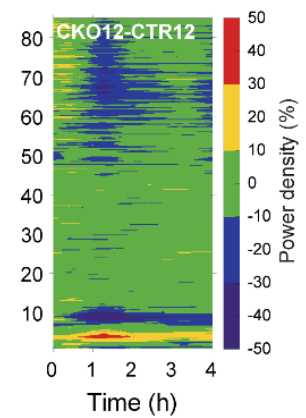

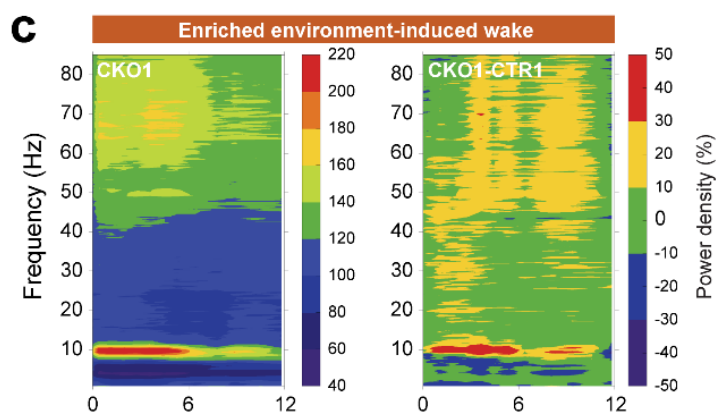
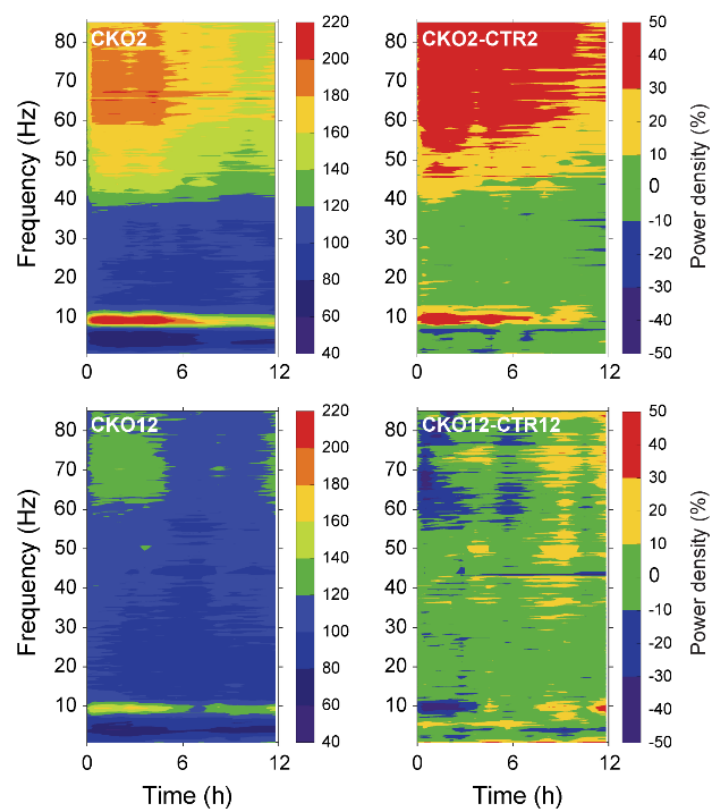
bioRxiv preprint doi: https://doi.org/10.1101/2022.01.30.478401; this version posted January 31, 2022. The copyright holder for this preprint (which was not certified by peer review) is the author/funder, who has granted bioRxiv a license to display the preprint in perpetuity. It is made available under aCC-BY-NC-ND 4.0 International license.

\section{Figure 5.}
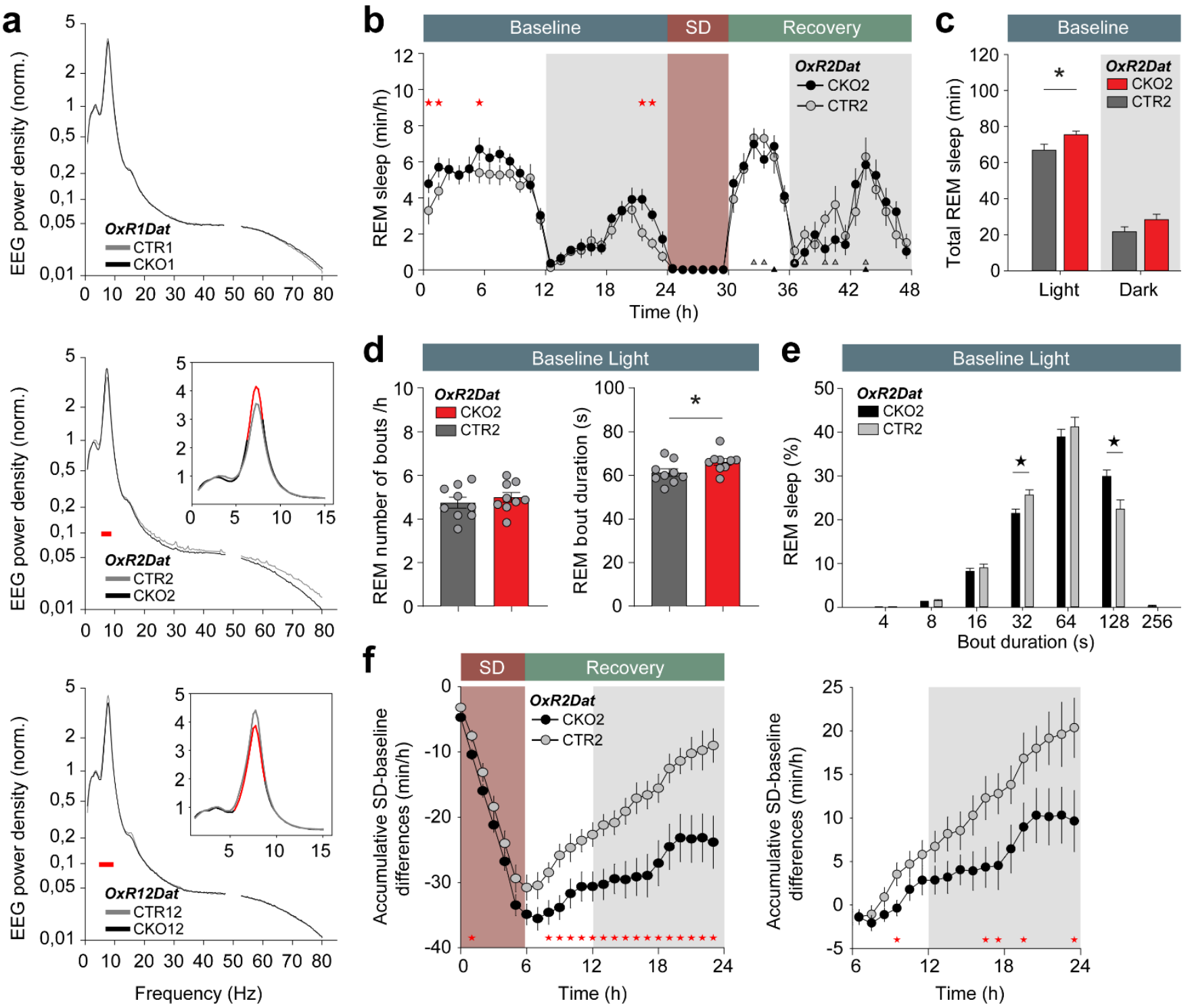
bioRxiv preprint doi: https://doi.org/10.1101/2022.01.30.478401; this version posted January 31,2022 . The copyright holder for this preprint (which was not certified by peer review) is the author/funder, who has granted bioRxiv a license to display the preprint in perpetuity. It is made available under aCC-BY-NC-ND 4.0 International license.

Figure 6.
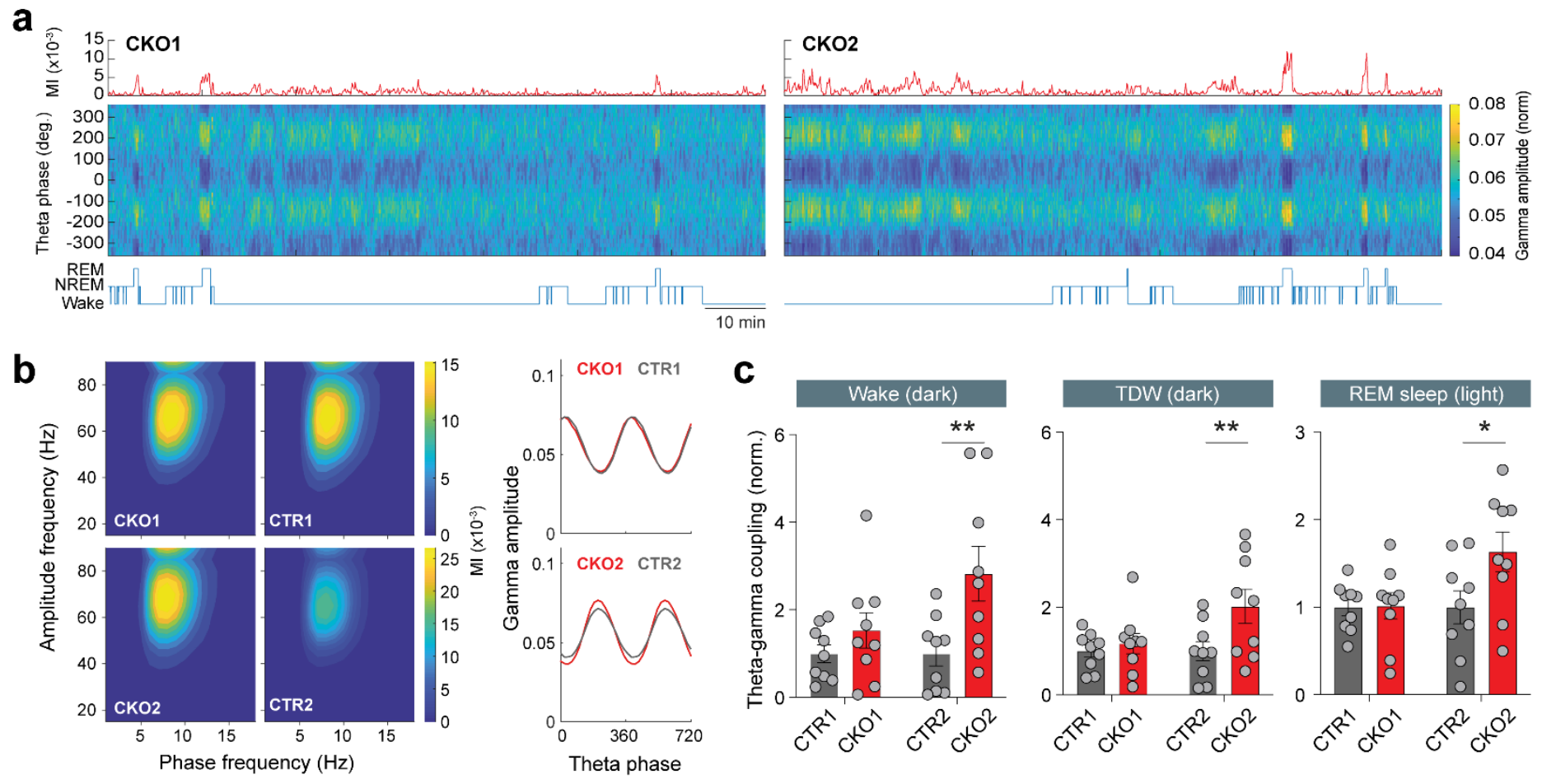


\section{SFigure 1.}
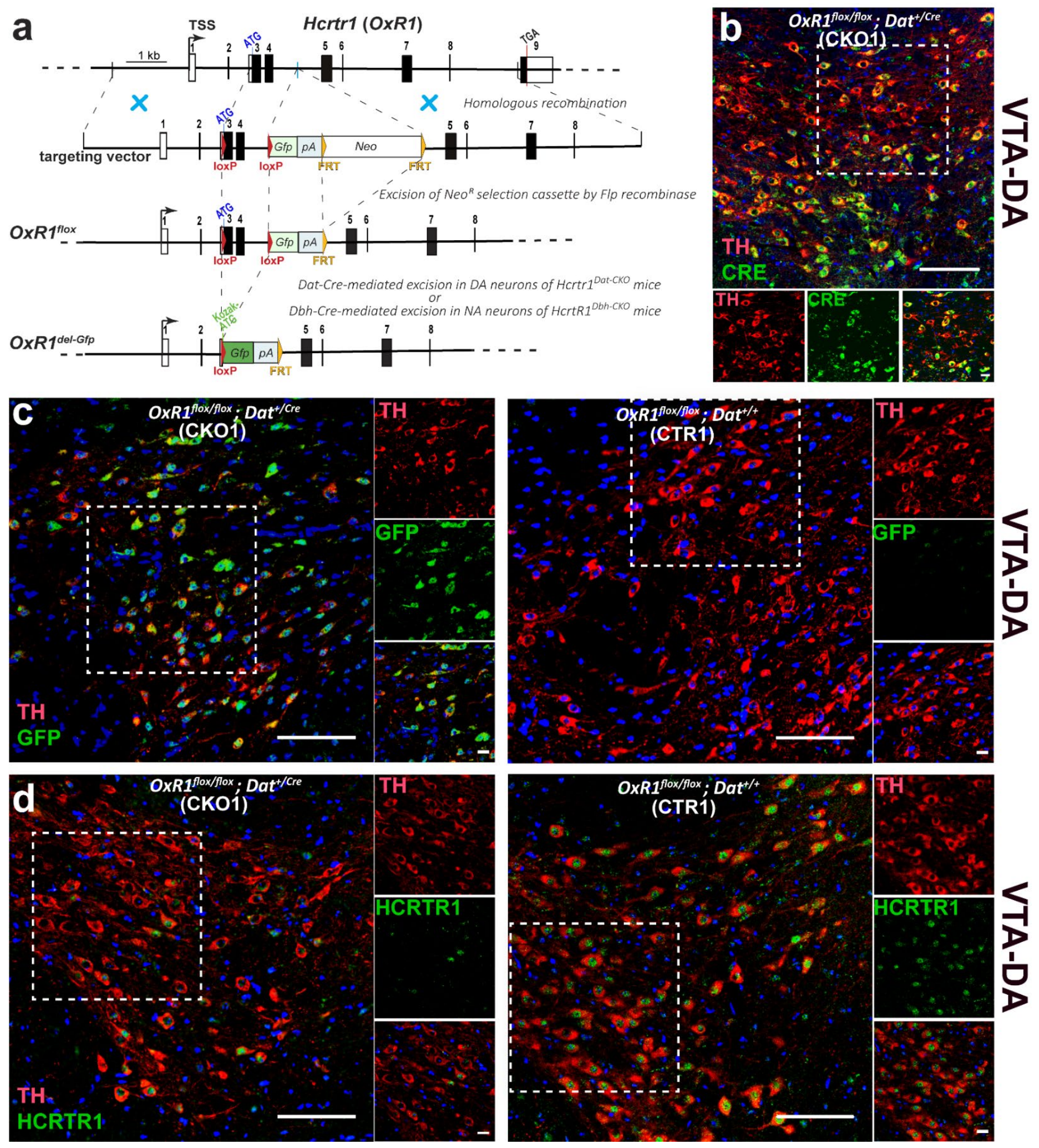


\section{SFigure 2.}
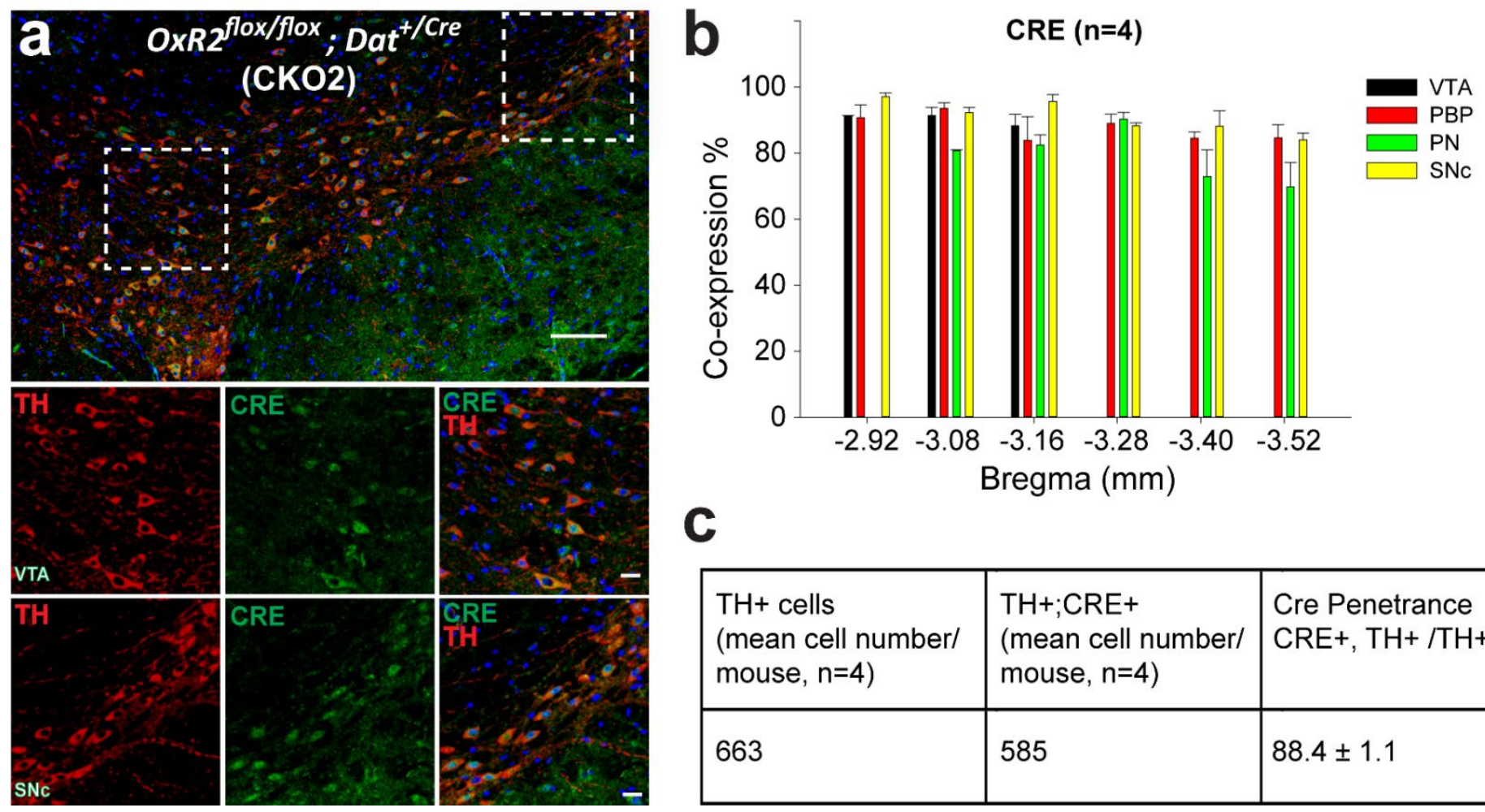

\begin{tabular}{|l|l|l|}
\hline $\begin{array}{l}\text { TH+ cells } \\
\text { (mean cell number/ } \\
\text { mouse, } n=4)\end{array}$ & $\begin{array}{l}\text { TH+;CRE+ } \\
\text { (mean cell number/ } \\
\text { mouse, } n=4)\end{array}$ & $\begin{array}{l}\text { Cre Penetrance } \\
\mathrm{CRE}+, \mathrm{TH}+/ \mathrm{TH}+\end{array}$ \\
\hline 663 & 585 & $88.4 \pm 1.1$ \\
\hline
\end{tabular}


bioRxiv preprint doi: https://doi.org/10.1101/2022.01.30.478401; this version posted January 31, 2022. The copyright holder for this preprint (which was not certified by peer review) is the author/funder, who has granted bioRxiv a license to display the preprint in perpetuity. It is made available under aCC-BY-NC-ND 4.0 International license.

\section{SFigure 3.}

a

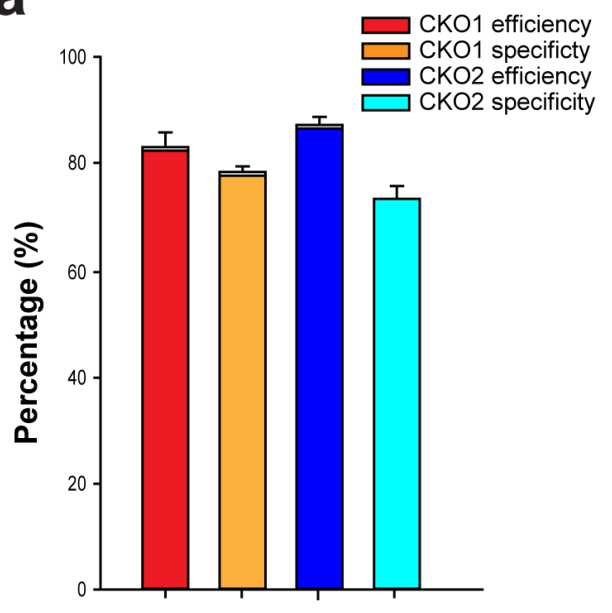

b

\begin{tabular}{|c|c|c|c|c|c|}
\hline & $\begin{array}{l}\text { TH+ cells } \\
\text { (mean cell } \\
\text { number/ } \\
\text { mouse, } n=2 \text { ) }\end{array}$ & $\begin{array}{c}\text { GFP+ } \\
\text { (mean cell } \\
\text { number/ } \\
\text { mouse, } n=2 \text { ) }\end{array}$ & $\begin{array}{c}\text { GFP+TH+ } \\
\text { (mean cell } \\
\text { number/ } \\
\text { mouse, } n=2 \text { ) }\end{array}$ & $\begin{array}{l}\text { Efficiency of Cre/loxP } \\
\text { Recombination in DA } \\
\text { neurons } \\
(\% \text { GFP'TH+ }\end{array}$ & $\begin{array}{c}\text { Specificity of Cre/loxP } \\
\text { Recombination in DA } \\
\text { neurons } \\
(\% \text { GFP'TH } / G F P)^{+}\end{array}$ \\
\hline CKO1 & 658 & 730 & 543 & $83.0 \pm 2.8$ & $74.4 \pm 0.54$ \\
\hline CKO2 & 712 & 848 & 620 & $87.2 \pm 1.5$ & $73.19 \pm 2.42$ \\
\hline
\end{tabular}




\section{SFigure 4.}

a
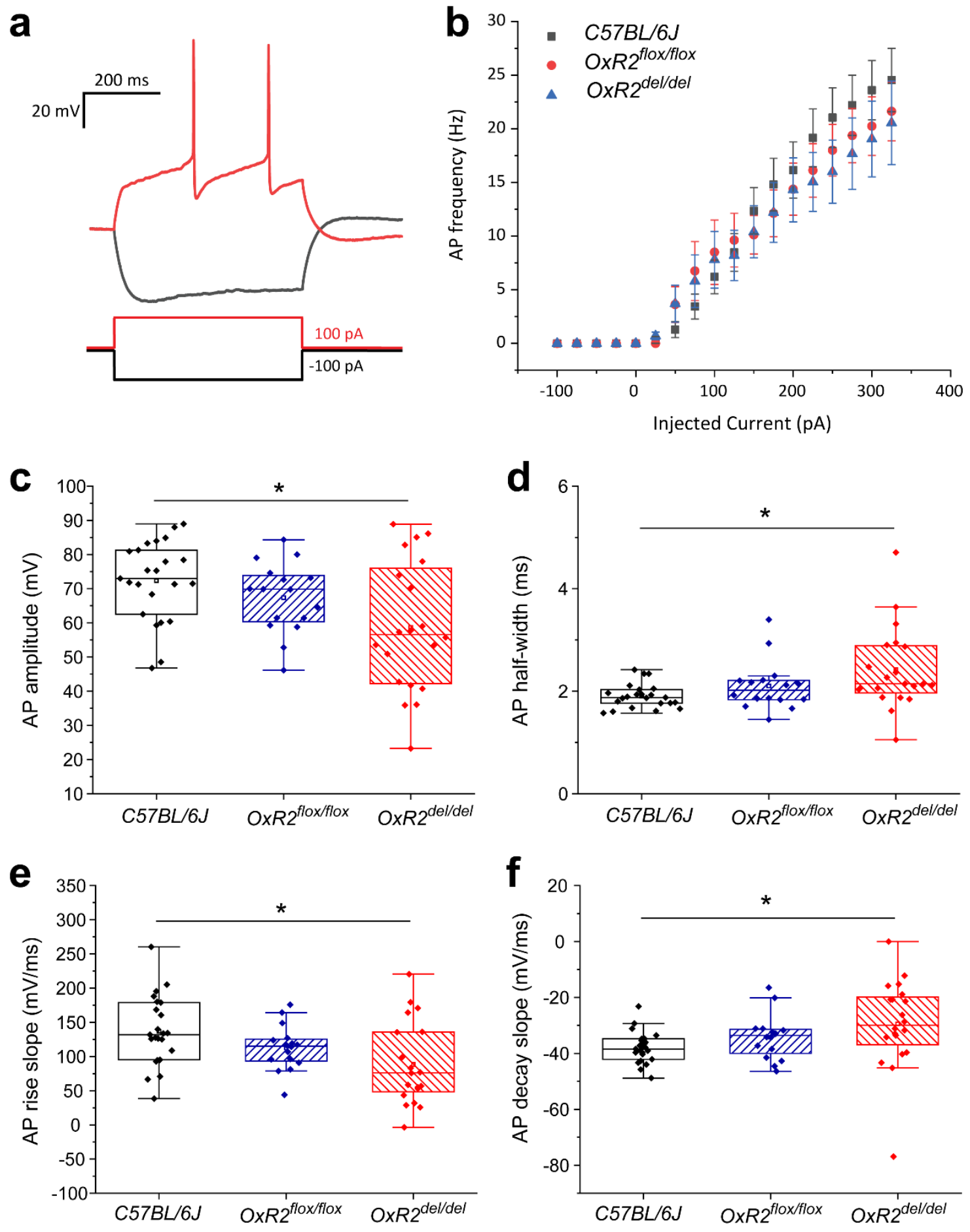
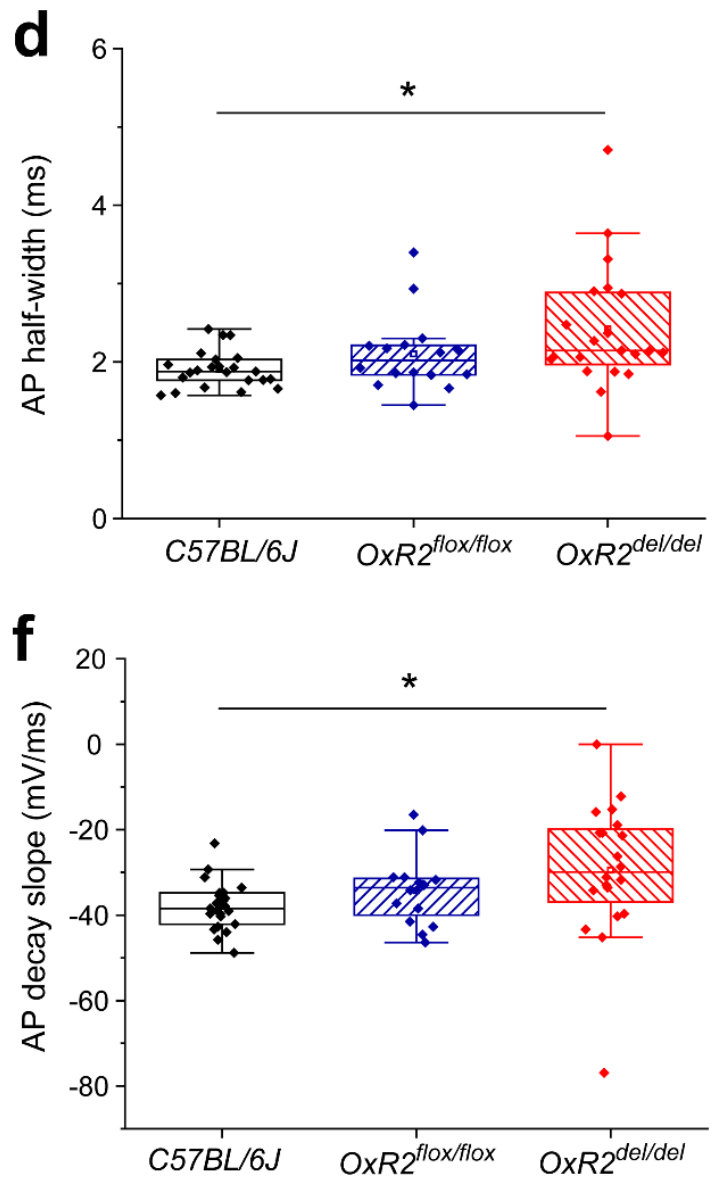
bioRxiv preprint doi: https://doi.org/10.1101/2022.0130.478401; this version posted January 31, 2022. The copyright holder for this preprint (which was not certified by peer review) is the author/funder, who has granted bioRxiv a license to display the preprint in perpetuity. It is made available under aCC-BY-NC-ND 4.0 International license.

\section{SFigure 5.}

a
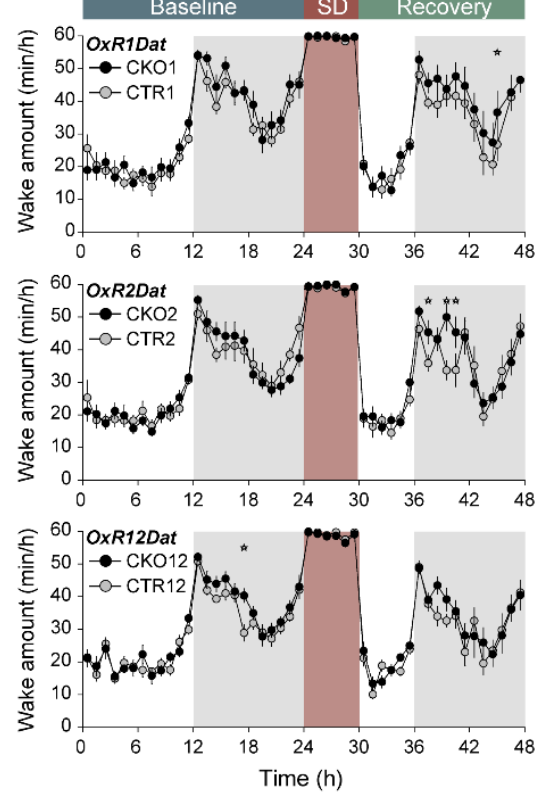

\section{b}
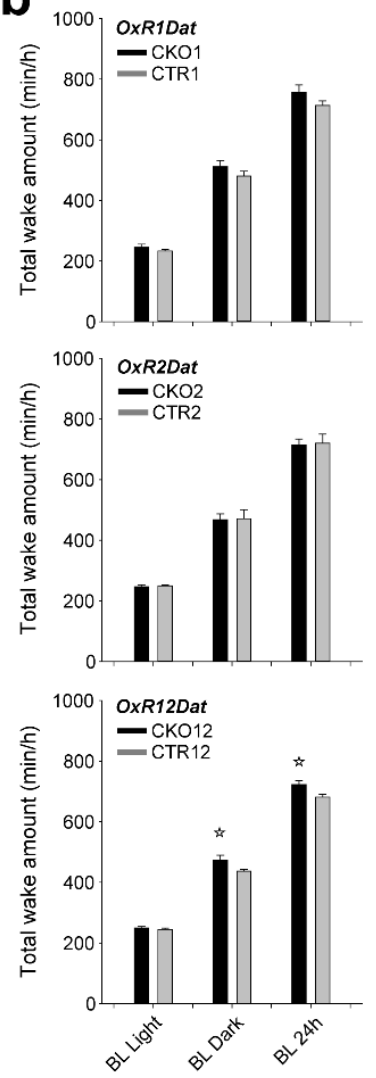
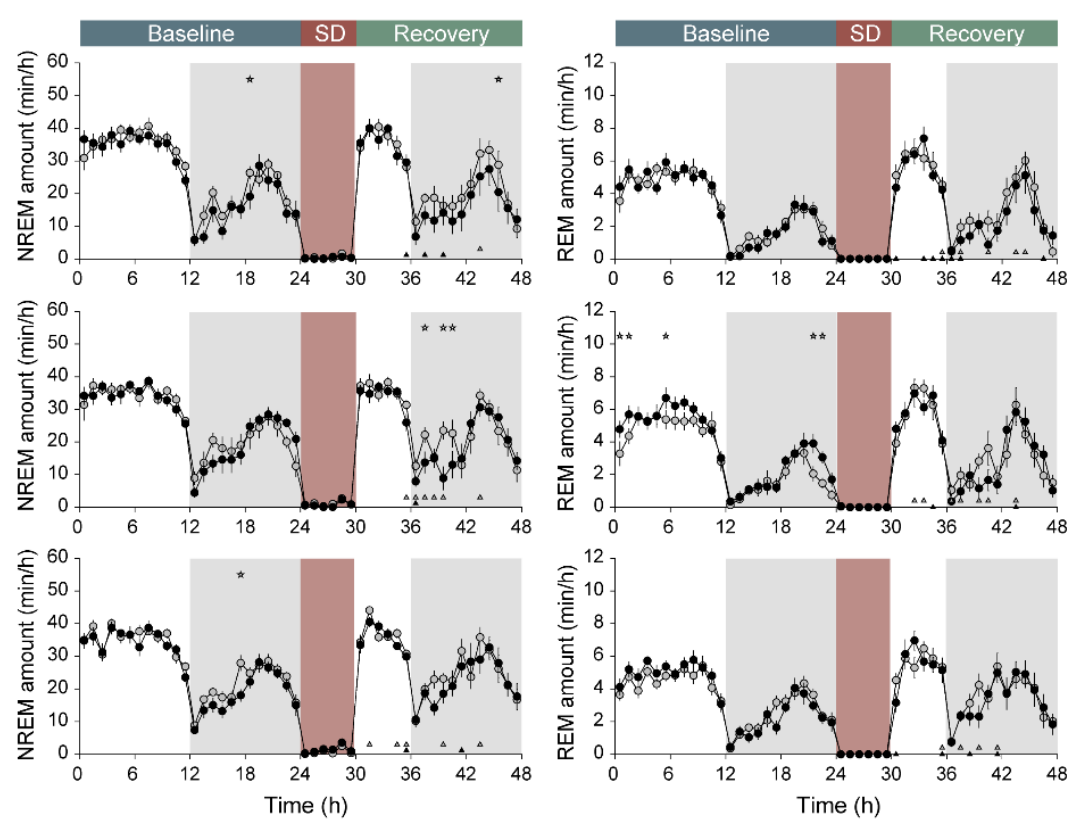
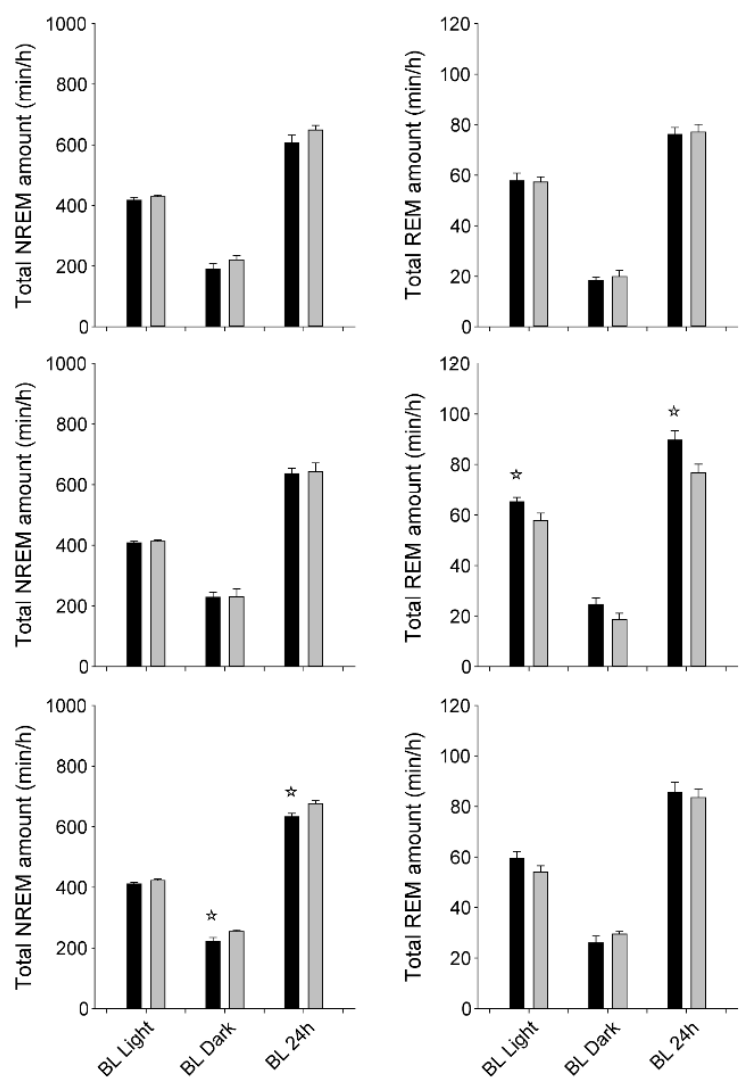
bioRxiv preprint doi: https://doi.org/10.1101/2022.01.30.478401; this version posted January 31,2022 . The copyright holder for this preprint (which was not certified by peer review) is the author/funder, who has granted bioRxiv a license to display the preprint in perpetuity. It is made available under aCC-BY-NC-ND 4.0 International license.

\section{SFigure 6.}

\section{Dat ${ }^{\text {ires-Cre }}$ vs Dat ${ }^{+/+}$}
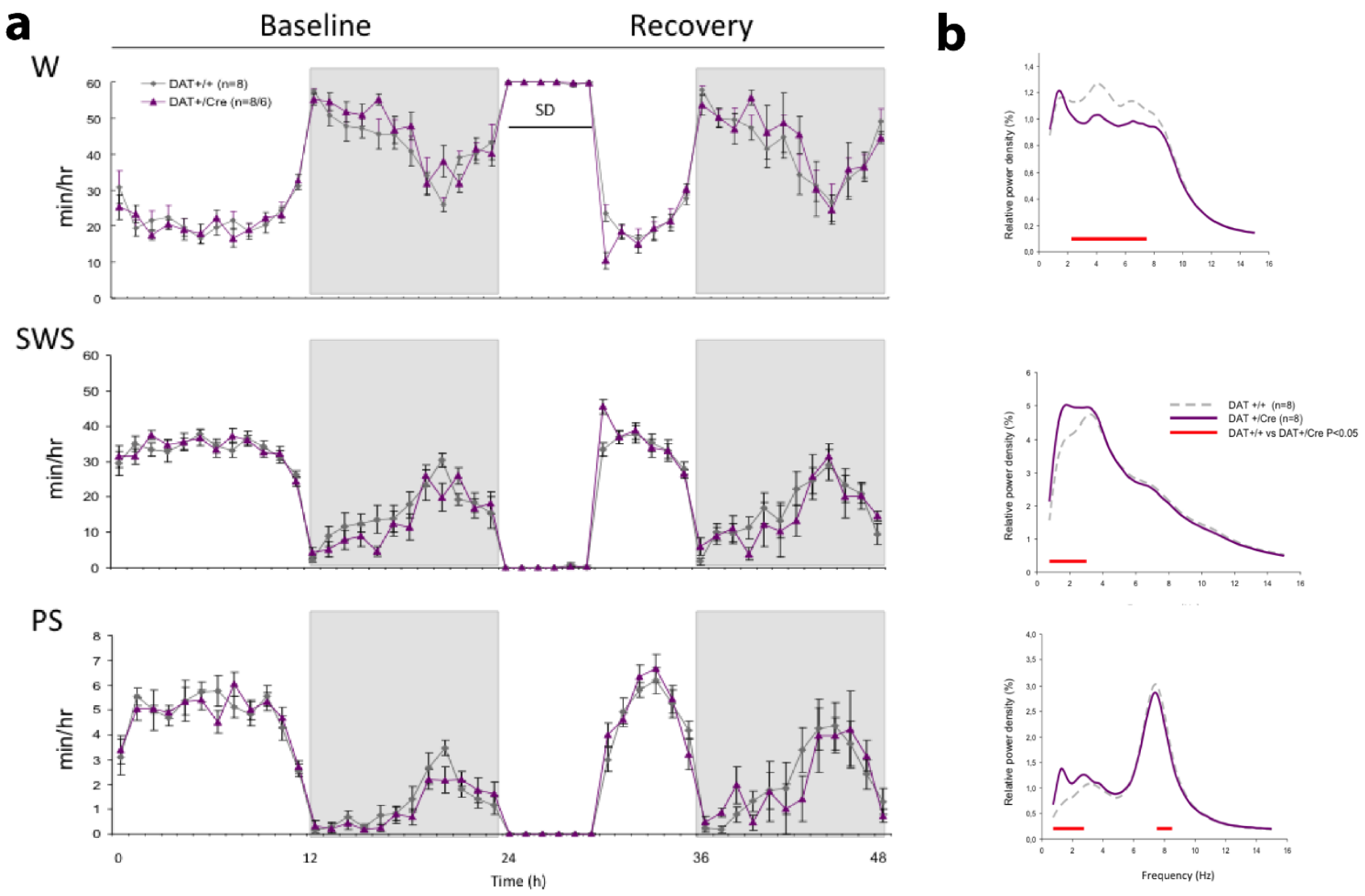

C

W

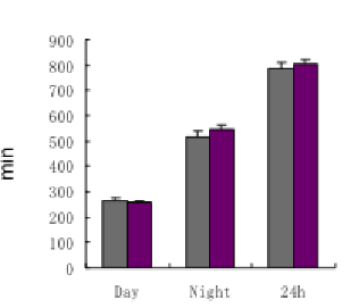

SWS

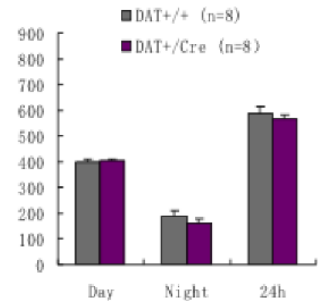

PS

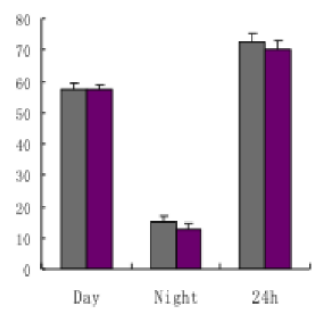


bioRxiv preprint doi: https://doi.org/10.1101/2022 0130.478401 t this version posted January 312022. The copyright holder for this preprint (which was not certified by peer review) is the author/funder, who has granted bioRxiv a license to display the preprint in perpetuity. It is made available under aCC-BY-NC-ND 4.0 International license.

\section{SFigure 7.}
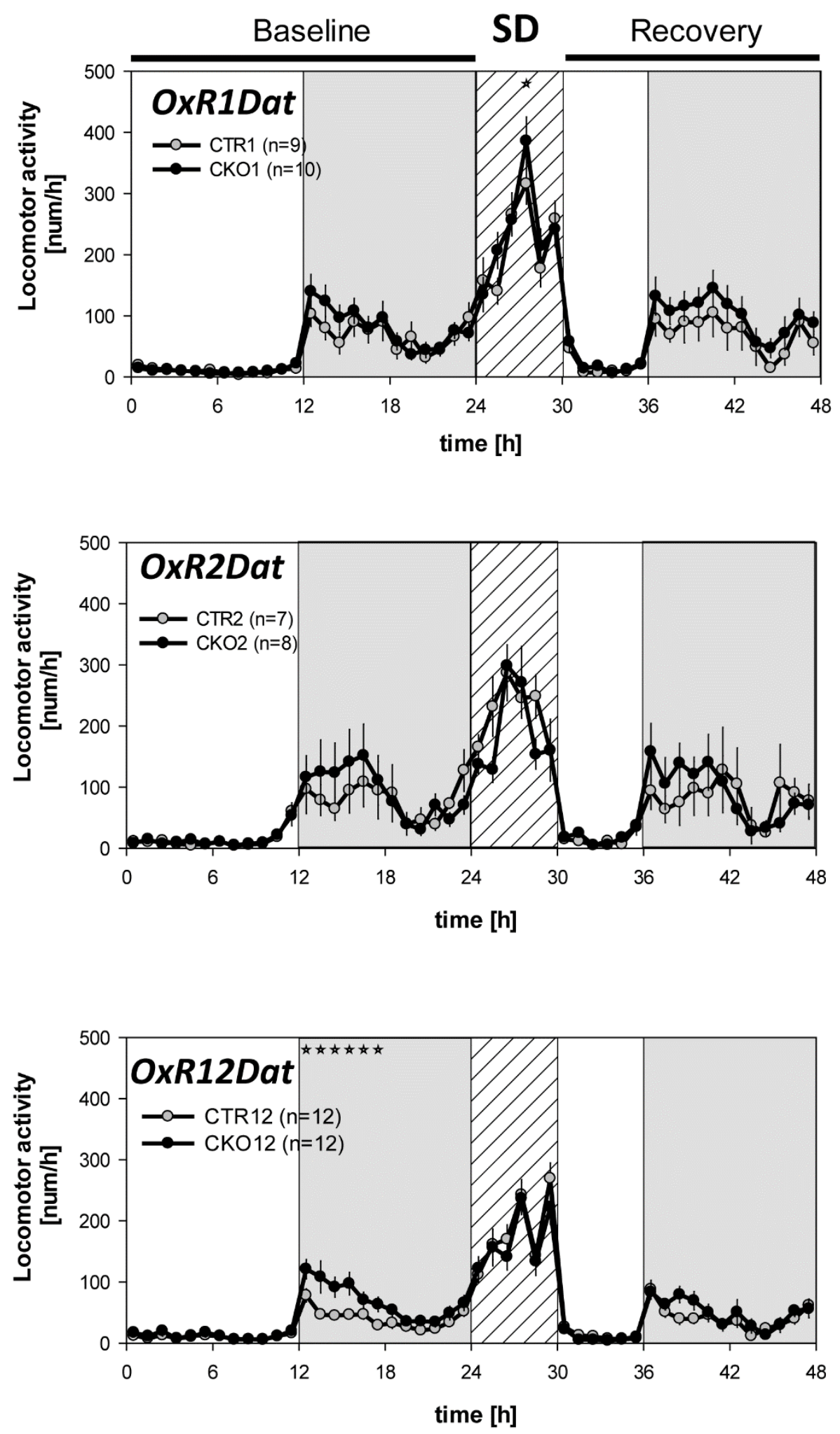